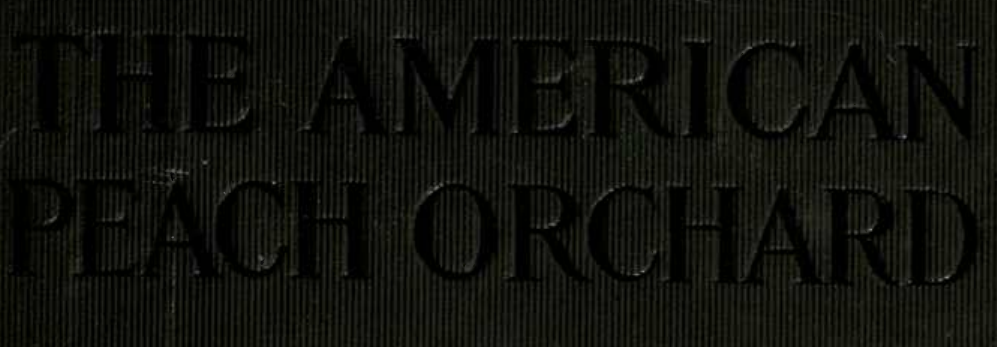




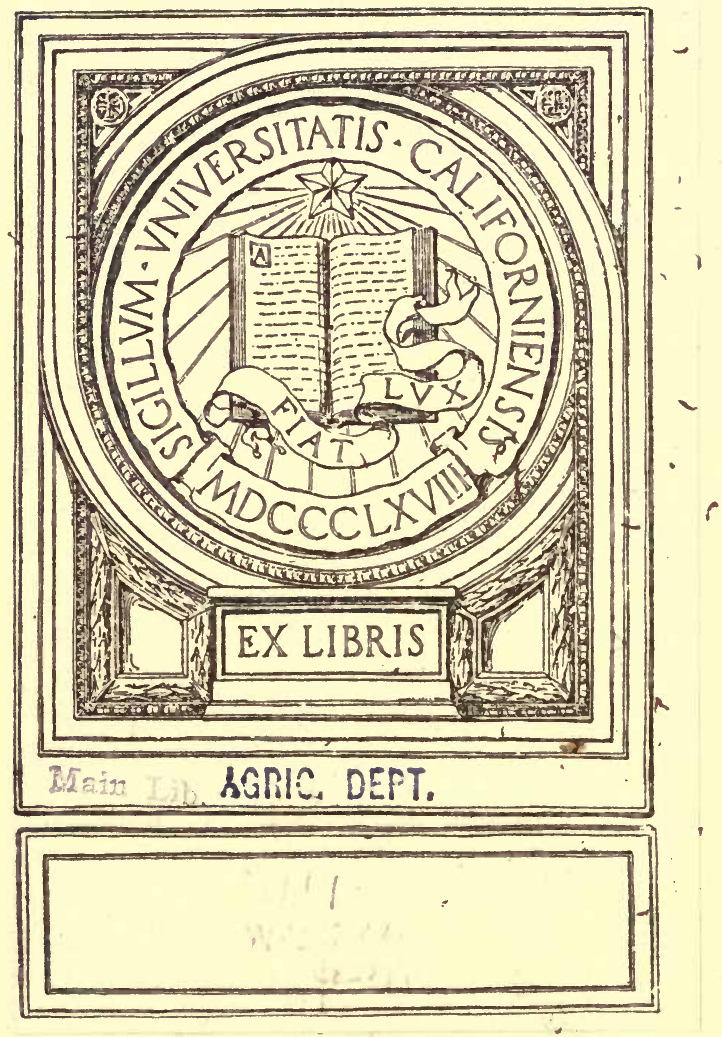





\section{THE AMERICAN PEACH ORCHARD}




\section{Other Books by the Same Author}

LANDSCAPE GARDENING

PLUMS AND PLUM CULTURE

FRUIT HARVESTING, STORING AND MARKETING

SYSTEMATIC POMOLOGY

DWARF FRUIT TREES

THE AMERICAN APPLE ORCHARD

THE LANDSCAPE BEAUTIFUL

BEGINNERS' GUIDE TO FRUIT GROWING 



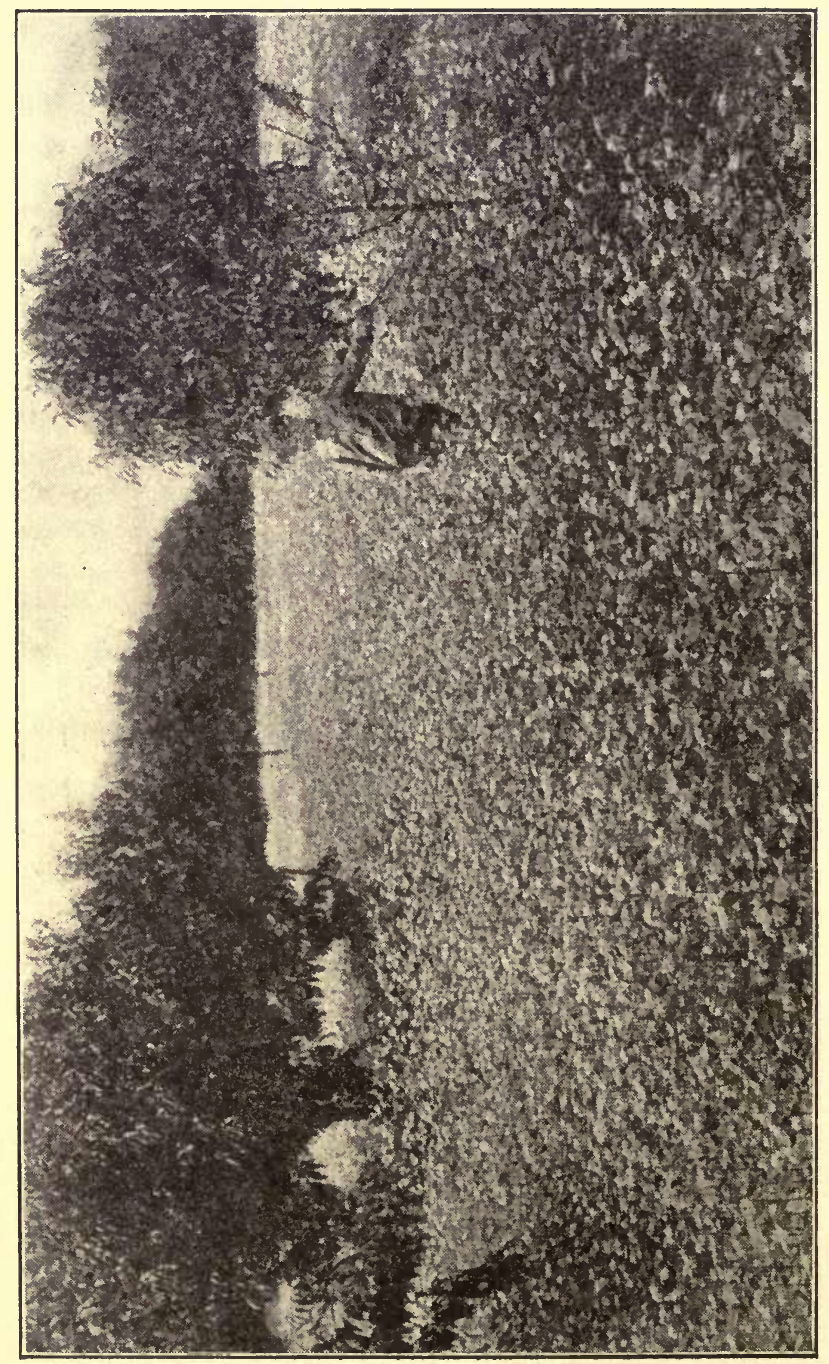


The American

Peach Orchard

A Sketch of the Practice of Peach Growing in North America at the Beginning of the Twentieth Century

\author{
By \\ F. A. WAUGH
}

Fully Illustrated

NEW YORK

ORANGE JUDD COMPANY

LONDON

KEGAN PAUL, TRENCH, TRÜBNER \& CO., Limited 1913 


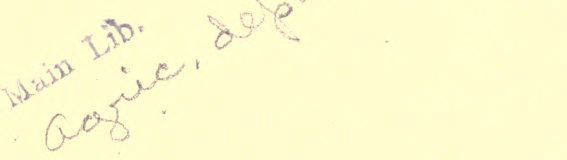

Copyright, 1913, by ORANGE JUDD COMPANY All rights reserved

Entered at Stationers' Hall, London, England.

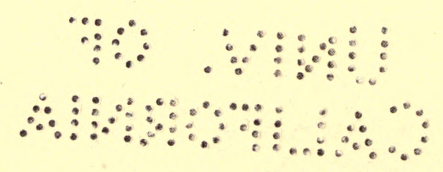

Printed in U. S. A. 


\section{Inscribed to FRED COLEMAN SEARS}

Schoolmate, Friend, Colleague in Teaching and Partner in Peach Growing

\section{2}





\section{PREFACE}

The rapid specialization of all the fruit-growing industries in North America has made the production of peaches an art by itself. To keep pace with such specialization it has been found expedient to discuss the management of the several fruit crops in separate monographs. Peach growing is now a large and important industry and deserves a book of its own.

The demand for such a book has existed for several years, but special difficulties have been experienced in meeting it. The work of preparing such a book was undertaken by the late Charles Wright of Delaware, and by the late Prof. W. G. Johnson of the Orange Judd Company, but both gentlemen died leaving the manuscripts unwritten. The writer has, indeed, experienced many tedious and troublesome delays, but has finally brought the work to completion through the help of many kind friends. In writing this book he has called to his aid a large number of practical peach growers in all parts of the United States and Canada, whose help and advice he wishes most cordially to acknowledge. To interpret properly their wide and varied experience has been the author's prime endeavor.

$$
\text { F. A. WAUGH. }
$$

Massachusetts Agricultural College, 19I3. 



\section{Elberta}

Last summer when we parted, sweet Elberta!

You looked quite fair enough to eat, Elberta!

Yet this for absence may atone,

Since last we met you've fairer grown; Yes, though you have a heart of stone, Elberta, you're a peach!

Your cheeks reflect the sunset glow, Elberta!

Your rounded outlines please me so, Elberta!

Your breath is sweet as summer dew; Your life blood richly flowing through Imparts a matchless charm to you. Elberta, you're a peach!

You've caused me many an aching pain Elberta!

I swore you never would again, Elberta!

Your ripening beauty tempts like wine; Yet though your charms were all divine Touch not your downy cheek to mine; Elberta, you're a peach!

I would not mar your bloom so fresh, Elberta!

Nor bruise the fairness of your flesh, Elberta!

I promised my right worthy mate That I would be most temperate, And gaze on you with thought sedate; Elberta, you're a peach!

I would devour you with my eyes, Elberta!

But gazing never satisfies, Elberta!

Soon in your flesh so rosy bright I'll set my teeth most sharp and white, For when you're peeled you're out of sight ; Elberta, you're a peach! 



\section{TABLE OF CONTENTS}

Chapter

Page

I. Peach-Growing Geography _._-_-_-_-_-_-_ 1

II. Climatology _.-_-_-_-_-_-_-_-_-_-_-_-_-_-_- 12

III. Solls ANd Exposures _-_-_-_-_-_-_-_-_-_-_ 32

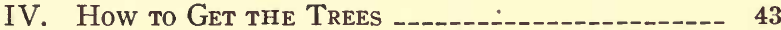

V. Orchard Planting _._-_-_-_-_ 57

VI. General Management _-_-_-_-_-_-_-_-_-_--- 67

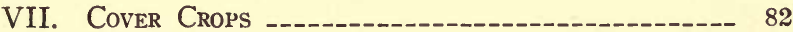

VIII. The USE of FerTilizers _-_-_-_-_-_-_-_-_-_ 93

IX. Pruning and Renovation..-_-_-_-_-_-_-_-_ 105

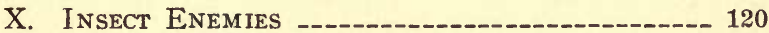

XI. Diseases of Tree and Fruit --_-_-_-_-_-_-_-- 134

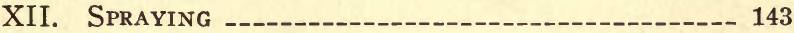

XIII. Marketing the CROP _-_-_-_- 160

XIV. The Family Orchard _._.

XV. Botanical and Pomological Status _-_._-_-_-_ 185

XVI. Choosing Varieties _-_._-_._- 191

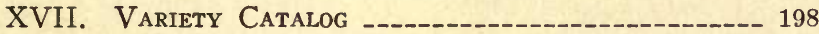

XVIII. The Nectarine -_- 210

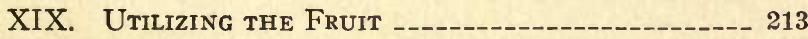

XX. Historical Sketch _-_._- 233

INDEX -.-- 



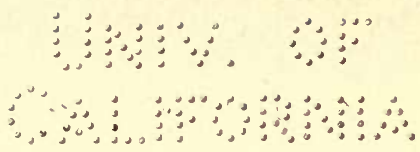

I

\section{PEACH GROWING GEOGRAPHY}

THE peach is generally understood to be a tree of southern climates. Its geographical distribution, therefore, runs to the southward of the apple, and yet the difference between the northern limit of peach culture and the northern limit of apple culture is much narrower than would justify the common opinion. As a matter of fact, the peach will grow successfully in all those central latitudes where the apple is most successful. There are a few commercial apple orchards north of the limit of peach culture, but there are not many.

Beginning at the northeast, a few peaches can be grown in protected localities in southwestern Maine. The line marking the northern limit of peach culture then passes across New Hampshire, leaving a few orchards in the southeastern part of that state. Vermont is practically outside the peach district. Peaches may be grown in all sections of Massachusetts except high altitudes and in the northern towns. Passing westward, we find the northern limit of peach culture turning northward along the Hudson River to about the region of Saratoga and Albany, N. Y. The line then swings southward around the mountains, and northward again to the region of the Great Lakes. The lake region of New York has long been engaged in the peach business, though in recent years its importance in the markets has been eclipsed by heavy crops from many other localities.

Passing westward, the line of limitation now en- 
ters Canada to include an important peach-growing section in the Niagara district of Ontario, lying at the head of Lake Ontario, and a less prominent one on the northern shore of Lake Erie toward the western end. The peach district also includes southern Michigan and southeastern Wisconsin. The line then tends southward, touching the southern border counties in Iowa, passes across Nebraska, Colorado and Utah, and after an important break in crossing the Cascade and the Coast ranges of mountains, runs

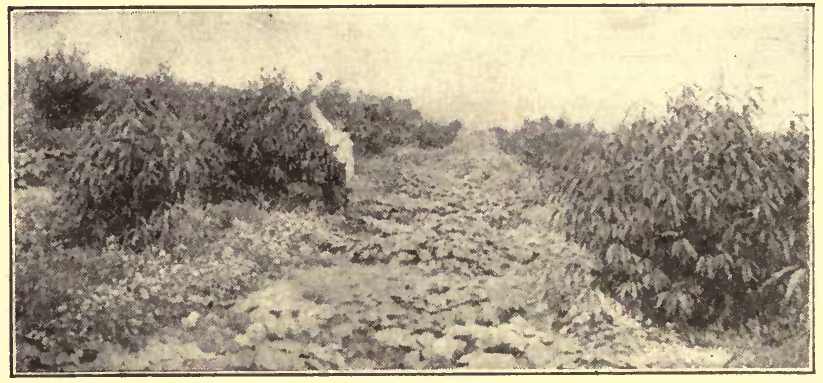

TWO-YEAR-OLD MASSACHUSETTS ORCHARD

upward along the Pacific coast into British Columbia.

There is a southern limit also to the cultivation of the peach, though this is less well marked and less important. The ordinary varieties of peaches will not succeed on the low, warm lands of Florida and other sections immediately bordering the Gulf of Mexico. Certain varieties of the Peen-to type carry the limit somewhat farther south, but these varieties have never gained any standing in the commercial markets.

It will be seen, therefore, that the peach-growing region occupies practically the entire United States, 
with the exception of the northern tier of states, and that in two places the northern limit runs up into Canada. It is indeed a fact that the peach is peculiarly the fruit of the United States of America. It is grown much more extensively and more successfully in this country than in other parts of the world. More good named varieties have originated in the United States than in all the rest of the world put together. In Europe the peach is only a hothouse luxury, while in Persia, China, and Asia generally (the original home of the peach) its culture is so crude as not to compare with what we have in America.

The distribution of peach culture throughout the United States, however, is by no means uniform within that zone marked off by the northern and southern limits as described above. There are many places where peaches cannot be grown at all, and a great many more where they are not grown to any considerable extent. The distribution of peach culture is extremely spotted. If one could put down the peach-growing regions on the map of the United States, it would look as though the country had broken out with the hives.

These local developments of peach culture are determined by various conditions, which conditions are very various and deserve critical study. So far as the writer knows, no pomologist has yet given the matter the close attention it deserves, and no one has pointed out the reasons for the curious localization of peach growing, except in a few special and minor instances.

Speaking very roughly, we may say that some of these local peach sections have been developed on account of favorable soil conditions. It may be that two or three counties or a dozen farms are espe- 
cially favored in the way of peach soils, and these advantages being recognized, the peach has been developed in these particular sections.

In other cases the cultivation of peaches has been localized by the presence of favoring bodies of water. The peach is notoriously sensitive to winter freezing and to damage by spring frost. Both of these elements of climate are ameliorated to some extent by proximity to large lakes, and this doubtless accounts for the development of peach culture in such regions as the Niagara district of New York, the lake shore of western Michigan, and in the Niagara district in Ontario.

In a good many cases, however, the determining reason seems to have been extremely human. There have been men at the bottom of the whole business. These men have had faith in peach growing, faith in themselves, and the brains and the grit to make a success of the business. Nearly all industries, especially agricultural industries, go by neighborhoods. When two or three men succeed in a given line, they open up a market for their products and at the same time they teach their neighbors the methods of growing and selling. Thus a great many industries are developed more because there are suitable men to take the lead than because natural geographical or meteorological conditions are especially favorable.

It may be worth while to run over the map hurriedly and point out where some of these small peach-growing districts are located. It is manifestly impossible in a small compass to make a complete and comprehensive statement of the question, so the peach-growing localities pointed out in this essay must be accepted merely as samples of what 
may be found on careful and detailed study of the map of any particular peach-growing state.

Beginning on the northeast, with Massachusetts, we find that the commercial development of peach culture is confined almost wholly to the town of Wilbraham and its immediate vicinity, in the south central part of the state. In Connecticut, the principal peach-growing regions are in the Connecticut Valley, in New Haven and Hartford Counties, and to some extent along Long Island Sound. The towns which have received most notice are, South Glastonbury, Wallingford, Middlefield and Durham.

In New York state, the principal peach-growing regions are along Lake Ontario, in Wayne, Monroe, Orleans and Niagara Counties; along Lake Erie; in the central lake regions along the shores of Lake Cayuga, Lake Seneca, Lake Canandaigua, and Lake Keuka ; and in the southeastern portion of the state, especially in Ulster County. In New Jersey, peaches are grown extensively and in most parts of the state, and although the southern part has had the reputation in the past of being the peach-growing region, orchards are now being developed extensively in the north central portion of the state, especially in Hunterdon County.

The southern central portion of Pennsylvania supplies the chief peach-growing section of that state, including York, Adams, Franklin and Cumberland Counties. The old peach-growing region of Maryland was along Chesapeake Bay, where, in fact, peaches are still grown extensively, although there is no part of the state where peaches do not succeed. The recent successful commercial development has been in the mountains of the western section, especially in Washington County. Delaware, being a small and very uniform state in the very center of 
the peach district, can hardly be divided up into different sections. Peaches are grown commercially all over the state.

As we go southward into Virginia, we find, as we might naturally expect, that the peach-growing region recedes from the coast toward the mountains. Therefore the best peach regions are among the foothills of the Blue Ridge, and especially in the Piedmont section and the Shenandoah Valley. In West Virginia, Hampshire, Berkeley, Morgan and Mineral Counties have become noted for the commercial production of peaches. This in general means the extreme eastern panhandle of the state, although peaches are grown locally in many other parts of West Virginia.

In North Carolina, peaches are grown commercially in small spots, especially among the foothills of the mountains. The central districts about Southern Pines, Candor and Leavitt have grown the most peaches in recent years. South Carolina also has important peach districts in the neighborhood of Ridge Springs, in Spartanburg County, in Aiken County and elsewhere.

Georgia has received more notice as a peachgrowing state in recent years than almost any other spot on the map of North America. This has been on account of the large development of orchards in the central portion of the state. The points most mentioned have been Marshallville, Fort Valley, Rome and Mount Airy, the last being in the northern part of the state.

Considerable quantities of peaches of the Honey and Peen-to types are now being grown in northern and central Florida, though the common kinds of this fruit are hardly known in that state.

In Alabama, peach-growing regions have been de- 
veloped in Cullman County, Winston County, and the northwestern portion of the state generally. Mississippi has not gone so far as neighboring states in modern commercial peach growing, though fruit is produced successfully in many parts of the state, particularly in the northeastern section.

The principal peach-growing section of Ohio is along the shores of Lake Erie, in the northern part of the state. Kentucky peaches are produced mostly in the eastern and western portions of the state. In eastern Kentucky, there are many small spots along the foot of the mountains where peaches grow very successfully, although in the past the principal orchards have been developed along the lower levels in the western portions of the state. Tennessee also has its thousands of acres of splendid peach land, both along the foothills of the mountains of east Tennessee and in the Cumberland Valley. The localities where peaches are now mostly grown are Bradley County, Rhea County, Hamilton County and McMinn County.

The peach-growing industry has been developed for a great many years in Michigan, the bulk of the crop coming from the shores of Lake Michigan and southwestern counties. Grand Rapids, Kalamazoo, Grand Haven, South Haven and St. Joseph have been generally known as peach markets. The principal peach-growing regions of Indiana are in Washington County and the southern portion of the state. In like manner Illinois grows most of its peaches in the southern one-third of the state.

Iowa is generally considered outside the peach belt, but a few counties in the southern tier and especially in the southwest corner of the state have developed a considerable peach business. Missouri is extremely varied in topography and thus presents 


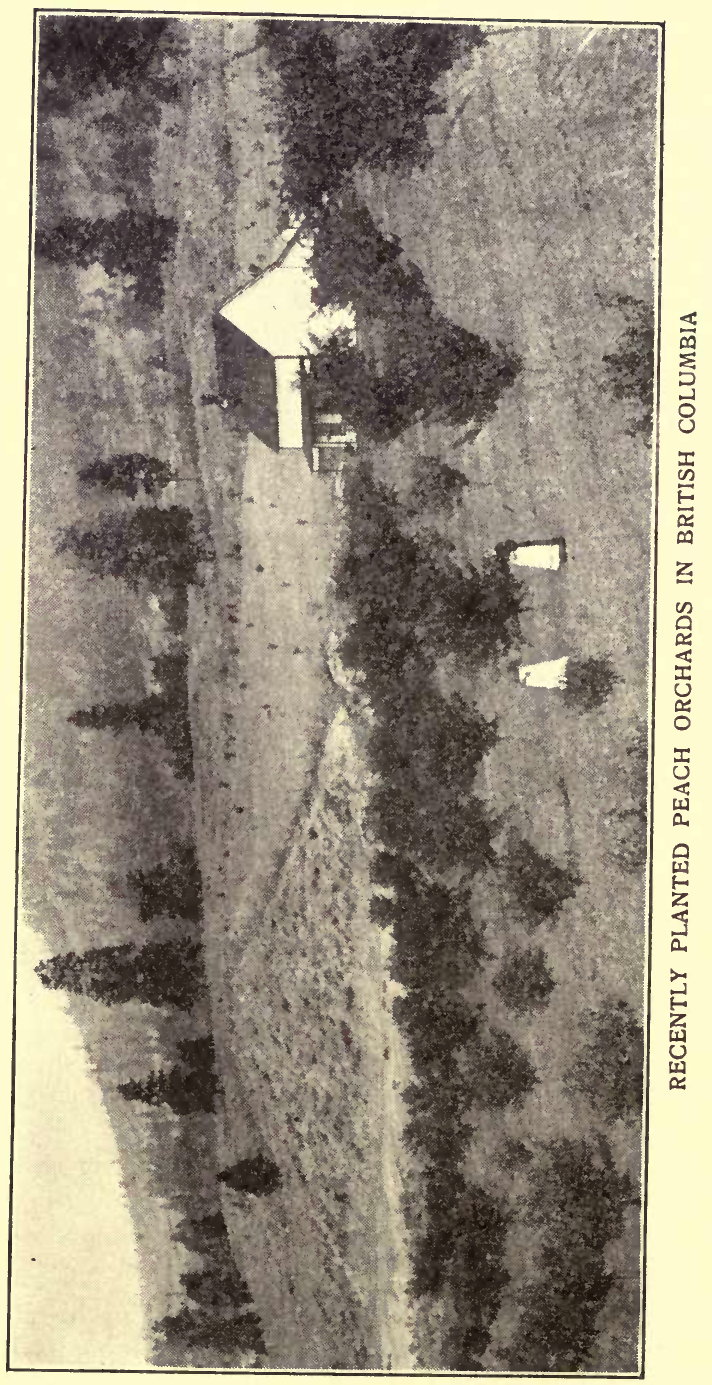


a particularly spotted appearance with regard to the production of peaches. The southern counties of the state in the Ozark region-for instance, Howell and Oregon Counties-have made special reputation in the past few years. There are, however, many such localities throughout the southern half of the state and along the Missouri River where peaches can be successfully grown. Likewise Arkansas has made a mark in the peach trade during the past few years, the districts particularly attracting attention being those in the hilly northern portions of the state. The regions along the Arkansas River in the western part of the state including Crawford, Franklin, Sebastian and Johnson Counties have been planting large orchards, and bringing them into successful bearing.

In Nebraska and Kansas peaches are a fairly uncertain crop, but they are grown chiefly in the eastern counties. The eastern counties of Oklahoma grow peaches successfully, but no commercial districts have been developed to the extent of receiving special notice. Many places in Texas grow this crop with success, but the most important commercial sections recently developed are in the northeastern portion of the state about Tyler, Morrill, Jacksonville and Garrison.

Colorado, Utah, and the other states of the Rocky Mountain regions grow quantities of very fine peaches, but the sections are usually small and confined to narrow valleys, between the mountains, where excellent soil, irrigation facilities, and protection from winds combine to produce most favorable conditions.

In Oregon, the conditions are somewhat the same as in the Rocky Mountain section; that is, the peach-. growing districts are highly localized by conditions 
of soil, irrigation and protection by mountain chains. The noted fruit-growing sections in the Willamette Valley, the Hood River Valley, the Rogue River Valley, and the Umpqua Valley, although their reputation rests chiefly on the production of apples, also grow peaches very successfully.

California has long been known as a peach-growing state, having produced quantities of peaches for consumption throughout the central and eastern states. The Sacramento and the San Joaquin valleys are generally known as the chief peach-growing regions, but Fresno and Placer counties, and many other sections of the state produce peaches commercially.

What does all this peach geography mean to the man who wants to grow peaches and trade them for silver dollars? Does it mean that he must move into one of these highly developed localities and merge his business with that of the successful men who have already established reputations? This depends a good deal on the man and on his present surroundings. Doubtless the beginner who is footloose would do better to produce peaches where he knows that peaches can be grown and where some one else has done the pioneer work of developing methods and opening up markets. From the nature of the case, the production and marketing of peaches can be better managed in those localities where the trade is centered.

At the same time, there is a fine opportunity for any man who is a level-headed fruit grower to produce and market peaches in regions outside the present recognized peach districts. There are in this country hundreds of thousands of acres of land which will grow peaches successfully and which have never yet been tested. If a man is willing to 
make mistakes, and can afford the expense of doing it, he has the chance to develop a local market of his own and make good money out of it. It is rather important, however, in going into the business in this manner to have a suitable local market in view. In the big peach-growing centers the sale of the product depends upon long shipments, and these can be most successfully arranged in those districts where the offering of a large product gives the opportunity for special fruit trains, refrigerating stations and all the highly organized facilities of modern marketing.

As a matter of fact peaches ought to be grown much more extensively for local markets. The peach is a fruit which suffers severely from long shipments, and it has been in many ways a misfortune that the modern peach-growing industry has been so largely developed in the wholesale way. Those men who are able in the next few years to develop small orchards in localities where the peach is not now grown, and who can place their product directly upon the home markets, without the damage of long shipments, and without the expense of multiplied middlemen, will find more profit in it than many of the big growers in the most famous peach regions. 


\section{II}

\section{CLIMATOLOGY}

THE principal horticultural fact in the climatology of the peach, is the relative tenderness of the tree toward cold. The peach is generally rated as distinctly less hardy than the apple tree, though commercially considered this difference is less than the popular imagination has painted it. Practically speaking, the northern limit of commercial peach growing does not lie so very far south of the northern limit of commercial apple production. Still, it does lie distinctly to the south, and the peach tree is obviously more tender during severe winters than the apple.

Twenty degrees below zero may be taken as the practical limit of cold resistance for the peach. When temperatures run lower the peach trees are always in danger and usually sustain greater or less damage. The amount of this damage is influenced by many collateral circumstances, chiefly the following:

I. Duration of the cold weather. Long-continued low temperatures do greater injury than those which last for only an hour or two.

2. Varieties. Some varieties are considerably hardier than others.

3. Condition of trees. Vigorous, healthy, wellgrown trees will stand a good deal of freezing, while weak, starved trees and those which have been allowed to overbear will die outright in very moderate weather. It has often been claimed that peach trees easily make a too vigorous growth, and that in 
such cases the new wood does not mature properly and is therefore especially liable to winter injury. The writer, by extended experiments and observations on this point, has fully satisfied himself that this danger either does not exist or has been greatly over-magnified. The instances of trees made susceptible to winter injury through too much vigor are rare; the cases of damage through weakness and starvation are to be seen by thoușands every year. Good orchard management should endeavor to secure sound wood with well-formed terminal buds before the leaves fall in autumn, but any further worry on this point would be like the anxiety of a man who should fear that his pigs or calves were growing too fast.

4. Character of the soil. Trees on deep, welldrained soil will stand more freezing than those on thin, dry land or on heavy, wet land.

5. Ground protection. In certain cases the protection of the ground by snow or by a good cover crop helps the trees materially to withstand inclement winter weather.

It is possible at this point to make a distinction of no very great significance between two forms of freezing damage which occur on peach trees. The first form is that of twig injury, only the tips of young and immature twigs being killed. This may be really serious, but is not so grave a matter as the second form, which consists in the killing of main branches or trunks. Even in the latter type of damage, and in what appear to be extreme cases, trees may make recovery. That is, they will not die outright, but may be rejuvenated and made to bear commercial crops for several years. They will be weakened, however; the tops will be straggling and ill-balanced, the trunks will usually be black and 
dead at the core, and the trees will soon break down under loads of fruit or stress of wind. This question of the recovery of frozen trees is treated further in the chapter on Pruning, page i 16.

The northern limit of peach culture has been defined as the line of twenty degrees below zero. As a matter of fact, the peach is grown in home gardens in an amateur way as far north as those regions where twenty-five degrees below zero is an experience of every few years, but commercial orchards are hardly a safe proposition where even twenty degrees below zero may be expected every winter.

There is also a southern limit to peach growing, and if this limit is not so precise, it is none the less positive. The southernmost areas in the United States, for example, are outside the peach belt. This fruit is practically unknown along the Gulf of Mexico, and in Florida can be grown only on the highest lands in the most northern counties. Peaches of the Honey type, and especially of the Peen-to grour (see page I88), may be grown much farther south than the common sorts; but as these are not market varieties and never likely to become such, we may understand that the southern bound of the peach section runs approximately along the northern line of Florida, across the southern counties of Alabama and Mississippi, crosses Louisiana somewhere amidstate and sets off a zone of 50 to 100 miles wide all along the Texas coast. In Arizona, New Mexico, and California the limits of peach culture are fixed by a multitude of local conditions so variable and so complex that they cannot be safely stated in general terms.

The commercial grower of peaches, however, is not so much interested in the extreme limits of cul- 
ture as in the range of profitable peach growing. Looking at this question, we find that this fruit succeeds over a great range, and that the limits of successful commercial culture run pretty close to the actual bounds of physiological safety on both the northern and the southern edge. Perhaps it will be instructive to make a comparison with the apple, a fruit which has been much more carefully studied. We may say, then, that the commercial culture of the peach runs not quite so far north as the successful culture of the Baldwin apple and as far south as the successful culture of any kind of apple. Now Dr. J. K. Shaw has shown that the best development of the Baldwin apple lies along that line which receives an average temperature of fifty-six degrees during the growing season, March to September. The most southern apple zone, that in which such distinctively southern varieties as Yates and Shockley succeed, is characterized by a longer growing season and by an average summer temperature of sixty-six to sixty-seven degrees. So we may say that these two thermal zones mark the real boundaries of practical peach growing.

Our comparison with the apple ought to be carried one step further in order to bring out an important difference. In the studies already referred to, Dr. Shaw has shown that for each variety of apple there is an optimum summer temperature, and that most varieties come to their best development only when grown pretty closely under these conditions. Thus the luscious Grimes is at its best when it has an average summer temperature of sixty-two degrees, the Yellow Newtown pippin requires an average of sixty degrees, while Northern Spy gets along with only fifty-five to fifty-six degrees.

The various varieties of peaches, however, are 
much more versatile. Carman or Mountain Rose or almost any other variety may be grown in full perfection from central Georgia to central New York and Michigan. There are some varieties, of course, which are plainly local in their preferences; but such localizations do not seem to be due chiefly to requirements of temperature. It is possible, of course, that a closer study of the physiology of the leading varieties of peaches will reveal more definite preferences, and that further experience will tend to localize varieties, as it has in the field of apple culture; but it still seems fairly certain that all the standard varieties of peaches may be grown indifferently over a pretty wide range of territory.

\section{KILLING OF BLOSSOM BUDS}

The commonest form of winter injury occurs in the killing of the blossom buds, rather than in the outright killing of the trees. 'This trouble is more frequent for the simple reason that the blossom buds are killed by much shorter and milder periods of freezing.

Bud killing falls into two very distinct cases, and the distinction at this point is of material importance. In one type of injury the buds are killed by freezing while in a more or less dormant state during the winter; in the other type the buds are killed by frost after they have partially or fully opened. Temperatures of nearly twenty degrees below zero, sometimes more, are necessary to kill dormant buds of hardy varieties during the winter. On the other hand a frost which lowers the temperature to twenty-eight or thirty degrees for an hour or two at blossoming time will sometimes serve equally well to wipe out a crop and make the peach grower 
postpone for another year the purchase of his new automobile.

These two forms of bud killing have often been confused in the discussions of peach climatology, but such confusion is wholly unnecessary. Special attention should be drawn to the fact that the killing of peach buds by late spring frosts is distinctly a local trouble, and that the localities seriously affected are much less widely distributed than is popularly supposed. There are thousands of square miles of good peach country in North America where budkilling spring frosts are unknown, and thousands of miles more where they are so infrequent as to be almost negligible. There are other regions, to be sure, where the crop is too often lost in this stage; hut on the whole the peach-growing industry has suffered a serious slander in this matter.

Winter freezing of buds cannot be prevented by any methods which are practicable in commercial orchards. In small private gardens, where a little extra trouble and expense can be put to the problem, reasonably good results can be attained. These methods all look toward the protection of the buds and the young wood from the action of the cold weather. The simplest attempts are made by wrapping the fruiting branches of the trees just as they stand in the garden, in much the same manner as rose bushes are sometimes wrapped for winter.

One of the commonest and best materials is corn stalks, which are tied on the fruiting branches in large bundles; or the whole tree may be completely encased in corn stalks until it becomes one immense corn shock. Coarse swale hay is also used very appropriately for this purpose. Other materials which come in suitably to this undertaking are floor mattings, old clothes, gunny sacks and newspapers. 
Newspaper is a famous non-conductor of heat, as everyone knows who has ever buttoned a paper under his coat to save him on a cold ride. A modern Sunday paper furnishes material enough to cover several trees four layers deep. The colored "art" supplement is especially recommended for weak and diseased trees. A certain farmer told me that he always used Republican papers on his trees, but he did not state that this was because of their superior insulating properties.

A more elaborate method of protecting peach trees in that geographical zone where they are liable to winterkilling, consists in laying them down upon the ground and covering them there. The writer has seen this method practiced with entire successwith such success, in fact, as to make it a profitable commercial transaction. With this method in view the trees should be headed low and should be maintained with small bushy heads, but not too thick. The laying down should be practiced every year, beginning with the third or fourth winter.

The method is as follows: Just before the ground freezes a trench is dug about 5 feet long and 18 inches deep along the south side of the tree and 3 feet distant from the base of the stem. A similar trench is dug parallel with the first and running along the north side of the tree. The roots encountered in digging these trenches, especially the northern trench, are cut off with the ax. The tree is then pulled over to the southward until it lies practically flat on the ground. It is pinned in this position by two or three forked pegs carefully driven over the main branches. The entire top is then covered with any good material which happens to be at hand. The best of all material, wherever it is available, is evergreen boughs. In sections where a rea- 
sonably heavy snowfall may be expected, the snow is the chief dependence, but the evergreen boughs are needed to catch and hold the snow. When pine, spruce or hemlock trimmings are not to be had, corn stalks, straw or waste hay can be used. Unless the snow drifts can be induced to lie upon the peach trees this covering of corn stalks or hay will have to be pretty liberal.

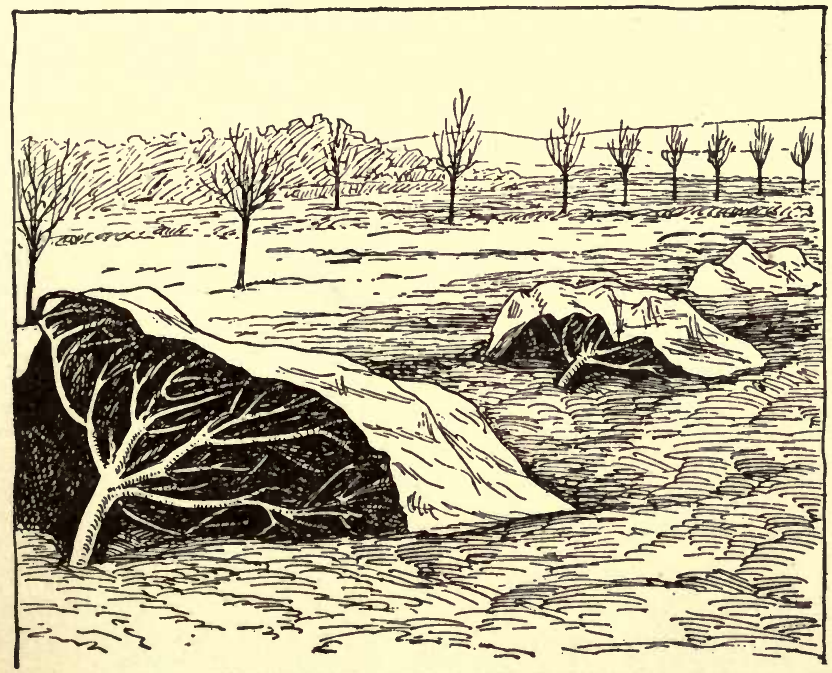

TREES LAID DOWN FOR WINTER

As late as possible in the spring, usually after the blossom buds begin to open, the covering must be removed and the trees set upright again in their places. It will be necessary to hold them erect by tying them to strong stakes or posts set to north and south of each tree; and it is of considerable importance in making these ties to see that the ropes do not chafe or cut the trees. Usually the trees will 
have to be protected with burlap bandages under the rope ties. Moreover, these stays usually require readjustment and repair several times during the summer. It is a taxing and puttering job, and no one should undertake it who does not like to be always fussing about in his garden. There are a good many such men; and it will not be quite off the point if $I$ add here that I never knew a mean or dishonest man in the lot.

Perhaps those who have not tried it will be shocked at the severe root pruning involved in the prescription. It is true that three or four main roots have to be severed in preparing some trees for laying down. But root pruning is just exactly what these trees need under the circumstances. The tops require to be closely pruned to keep them in bounds for the laying down process, and the root pruning only serves to restore the balance between top and bottom. If it happens to go somewhat farther in particular cases its influence is to induce greater fruitfulness in the trees, and a high degree of fruitfulness is plainly to be desired in trees with which so much pains are taken. The timid amateur horticulturist will be further reassured when he begins digging for the second year's laying down, for he will find that the tree has very largely repaired his supposed injury by the formation of great masses of fine active fibrous roots. Thus when this practice is carried out annually certain trees soon become habituated to it, as it were, and thrive under it.

A somewhat different method of arriving at the same end was invented several years ago by an old Vermont friend of mine, Mr. Joseph Macomber, a very capable horticulturist in many ways. By this method Mr. Macomber has been able to eat his own Vermont-grown peaches almost every summer for a 
good many years. The tree is taken in hand during its first year in the garden and the main stem is bent to a horizontal position, the bend being made as near the ground as possible. The tree is then trained so as to develop this horizontal trunk to a length of 6 or 8 feet in a manner very much like that employed in training horizontal pear or apple trees. It is simply necessary to have a wooden rod or pole set horizontally at the proper height (8-I4 inches) from the ground, and to keep the young leader tied to this as the tree stem grows. This will require a little attention every week or ten days during the rush of the growing season.

When this main stem has reached a horizontal length of 6 or 8 feet it is given another right-angled bend and turned to its natural upright direction. On this upright shoot the head is formed in the usual manner. The complete tree, therefore, consists of a normal bushy head connected with a normal root 8 feet to one side by an abnormal horizontal trunk.

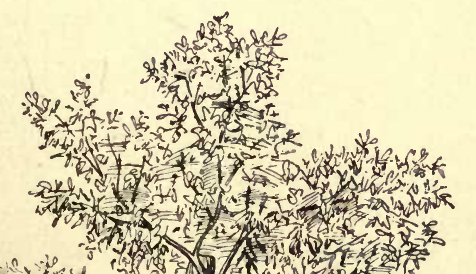

By a simple, safe and easy process of torsion this head can now be turned sidewise down to the ground, staked there and covered in the same manner as described for the foregoing method (page I9). When the blossoms begin to open in the spring the cover-

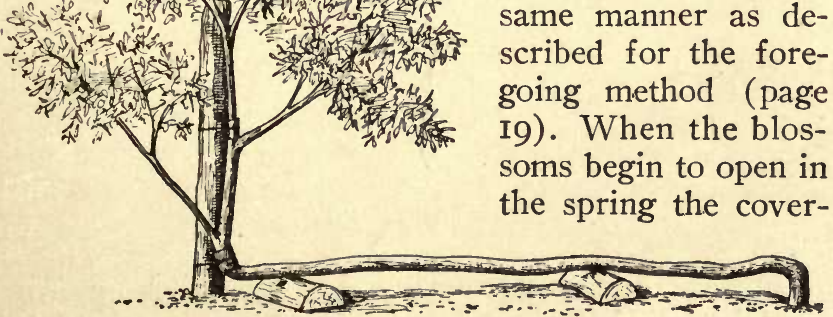

MR. MACOMBER'S METHOD OF TRAINING 
ing can be removed, the tree top easily returned to an upright position, tied to its necessary stake, and the summer begun in the pleasant prospect of a crop of peaches in September.

This method of Mr. Macomber's avoids the rude necessity of trenching and root pruning, accomplishing the same ends by milder practices. The annual laying down and setting up is rather easier; but it need not be forgotten that this is partially offset by the labor of training the tree to form its peculiar horizontal trunk. And once more it may be observed that these methods are only for the devoted amateur gardener, not for the cow farmer nor the commercial fruit grower.

DAMAGE BY SPRING FROSTS

The killing of opening buds or expanded blossoms by late spring frosts is quite another story, and a serious one, especially for the reason that it most frequently occurs in regions where peach growing is otherwise safe and profitable. The methods already outlined for the prevention of damage by winter freezing will usually serve also to carry the trees past danger of spring frosts, though not always. But these methods are too difficult and expensive to be of much avail in commercial orchards, so that when spring frost injury is to be directly prevented different methods are adopted. Those most widely used are whitewashing, smudging and heating.

WHITEWASHING

The method of protecting peach trees from frost by whitewashing seems to have been invented by 
Dr. J. C. Whitten, of the University of Missouri. At any rate Dr. Whitten has been the chief exponent of this method and has made the most extensive experiments with it. It consists in spraying the bearing parts of the peach tree with whitewash during winter and spring on the theory that the white stems reflect instead of absorb the heat from the sun's rays. It has been shown by Dr. Whitten and other experimenters that the blooming of peach trees and other fruits is dependent upon the local absorption of heat and is almost absolutely independent of root action. For instance, the branch of a fruit tree brought into a greenhouse will blossom even while the portion of the tree outside the greenhouse is exposed to zero temperatures and while the roots still stand in frozen soil.

The experiments have shown further that peach twigs which have been whitened will actually maintain a temperature several degrees lower than twigs covered with black or left in their natural color. Furthermore-and this is by far the most important practical test-the blossoming of peach trees is actually retarded by this method by a period of from 2 to Io days. Dr. Whitten has recently stated that in the orchard of the Missouri Experiment Station peach trees have been treated by the whitewashing method for Io successive years. This treatment has been given to alternate rows, adjoining rows of trees being left always without treatment. During this Io-year period there have been four good peach crops and five failures on the non-treated orchard and one partial crop. The whitewashed rows have failed but twice during the same time. In other words, the treated trees have yielded three crops more in Io years than the untreated trees. In this connection one should not overlook the fact that a 
crop saved in a year of general disaster brings a large price in the market, so that these three extra crops of peaches may be credited with more than average returns.

The method has not been widely adopted, though it is rather hard to see why it should not be more popular. Whitewashing is easy and cheap, and the results seem to be such as to pay well for the work.

Whitewash for treating peach trees is made in the usual way from stone lime, the object being, of course, to get the heaviest coating of white lime on the peach twigs. It has been found that the whitewash will adhere better if a considerable amount of skimmed milk is added to the water. Salt will also serve the same purpose. The whitewash is always applied with a spray pump, using a fine nozzle. From two to four sprayings are commonly required, though the former number is likely to suffice, if applied at the proper time; that is, just before warm weather may be expected in the spring. From four to six quarts of whitewash are required for the treatment of each tree at each spraying. Dr. Whitten estimates that the total cost of four sprayings does not exceed io cents a tree.

In this connection we should not entirely lose sight of the fact that there are occasional beneficial secondary effects from this lime spraying. It has long been customary among unskilled farmers to whitewash trunks and branches of fruit trees with a view to kill insects and fungi. This purpose is actually served to a considerable extent. Mr. W. T. Macoun in his Canadian experiments found that spraying with whitewash in the manner recommended for frost protection would almost completely clear apple trees of oyster shell bark lice. It would seem feasible, furthermore, to combine the 
whitewash treatment with the spring application of lime-sulphur so essential in fighting the San José scale.

\section{SMUDGING}

There has long been a theory among fruit growers that orchards could be protected from late spring frosts by the use of smudges. The principle on which this treatment rests is that a heavy blanket of smoke lying over an orchard prevents the radiation of heat from the soil and that a slight economy of heat secured in this way at the proper time will be sufficient to save the trees from damage. This method has probably been used more frequently in the United States for the protection of citrus orchards than in any other connection. It has never proved very successful nor found general favor in actual practice. It is doubtful if any practical peach grower of sound judgment is placing any reliance on this method at the present time.

It is to be observed in connection with this method, of course, that the purpose is to produce a smudge and not a heat. Material is used, therefore, which emits a dense smoke rather than that which blazes and burns easily. The old-fashioned method is to start a series of fires along the windward side of the orchard using good strong burning kindling at the outset. As soon as these fires are fairly under way they are blanketed with considerable quantities of wet brush, wet hay, old, damp straw or any similar material which is conveniently at hand.

\section{ORCHARD HEATING}

In recent years there has come into somewhat extensive use in certain sections, especially in Rocky 
Mountain districts, a different method, namely, orchard heating. This method depends upon the direct temperature secured by burning the necessary amount of fuel in the orchard. Four fuels have been generally used: ( $a$ ) wood, $(b)$ coal, ( $c$ ) briquettes, $(d)$ oil.

Where wood is plentiful and cheap, as it is in many sections of the Rocky Mountain states and the west coast, it is prepared in convenient sizes and placed in piles throughout the orchard ready for lighting. When frost is threatened these piles are fired and the blaze kept going by the addition of more wood until the sun warms the air beyond the danger point.

In many sections coal is available at a low price and can be used in the same manner, except that special fire pots are usually required. These are offered for sale by western manufacturers and serve to burn the coal rapidly and economically. The usual estimate is that where coal can be had at $\$ 2$ to $\$ 3$ a ton, this method will be more economical than the use of oil at $\$ 5$ to $\$ 6$ the Ioo gallons. There is a good deal of argument over this point, however, the estimate not being accepted by all fruit growers.

Briquettes which are not available in many parts of the country, vary considerably in composition, so that their value cannot be easily estimated. They are composed of coal dust, tar, sawdust and other refuse materials made into the size and form of ordinary building bricks. If they have a considerable proportion of good inflammable material, they will burn well and give a reasonable amount of heat. They are not widely used, and not likely to be.

The standard fuel for heating is oil. However, there are many different kinds of oil and many grades in the market, and one of the most serious 
problems at the present time is to secure the right kind. Experience agrees that only the best grade of oil should be used, oils with a paraffin base being greatly preferred to those having an asphalt base. The best of these pass under various commercial names such as "smudge distillate" and "slop distillate." Oils which leave a considerable amount of unburned residue are difficult to use and less economical than the higher priced oils. In many cases, also, the oils are found to be mixed with a greater or

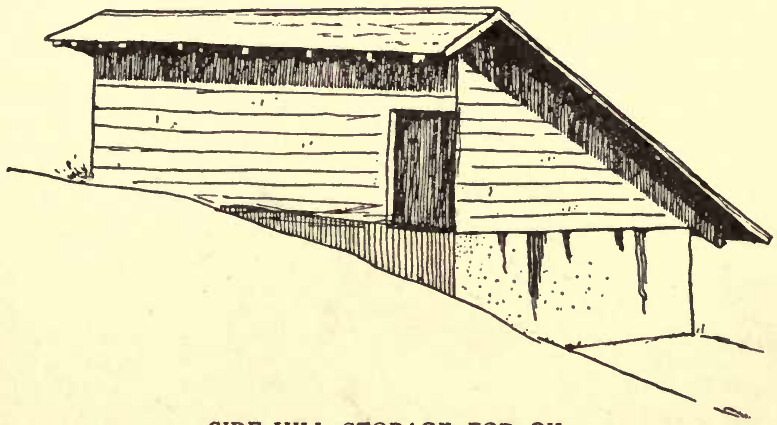

SIDE-HILL STORAGE FOR OIL

less proportion of water, which is a serious detriment. The water makes the fires sputter, and in many cases causes the pots to boil over. In every case, of course, the water absorbs a large amount of heat from the fire during its evaporation, thus wasting the fuel enormously.

At the present time it does not seem possible to direct any fruit grower to any particular brand of oil which he can buy with the certainty that it will be perfect. It is necessary, therefore, for every man to take the most stringent precautions on his own behalf, remembering that the high-priced oils are pretty certain to be better than the cheap, heavy oils. 
If a car of oil can be allowed to stand for 48 hours after delivery before it is drawn off from the tank, the oil will largely separate and leave the water at the bottom. The oil can then be dipped or drawn off the top, leaving a certain amount of water behind. This same precaution, however, ought to be exercised by the shippers before the oil is forwarded.

When the oil is received it is usually necessary to store it in some sort of a tank. Two types of tanks are now in common use: $(a)$ cement, $(b)$ galvanized iron. The cement tanks are generally preferred, where they can be constructed. They should be placed at some distance from other farm buildings on account of the dangerously inflammable character of the oil which they are to hold. Such tanks should always be arranged so the oil can be drawn off by gravity into the tank from which it is distributed to the orchard. If the storage can be placed on a fairly steep side hill, it will be possible both to fill and to empty this reservoir by gravity. Such an arrangement is obviously most economical.

The typical method of using is to burn the oil in small galvanized iron pails about the size and shape of a Io-pound lard pail. The ordinary commercial pail holds about one gallon of oil, but larger sizes are offered in the market and are preferred by some growers. Various modifications of this form have been invented and patented and are now being sold in large quantities. Each has its advantages and its disadvantages. One of the most important improvements is the introduction of an air draft by which the oil is more fully consumed. The best heater is the one which gives the most hot flame and the least smoke, for in this method the smudge is not sought for, the object being to heat the air directly. 


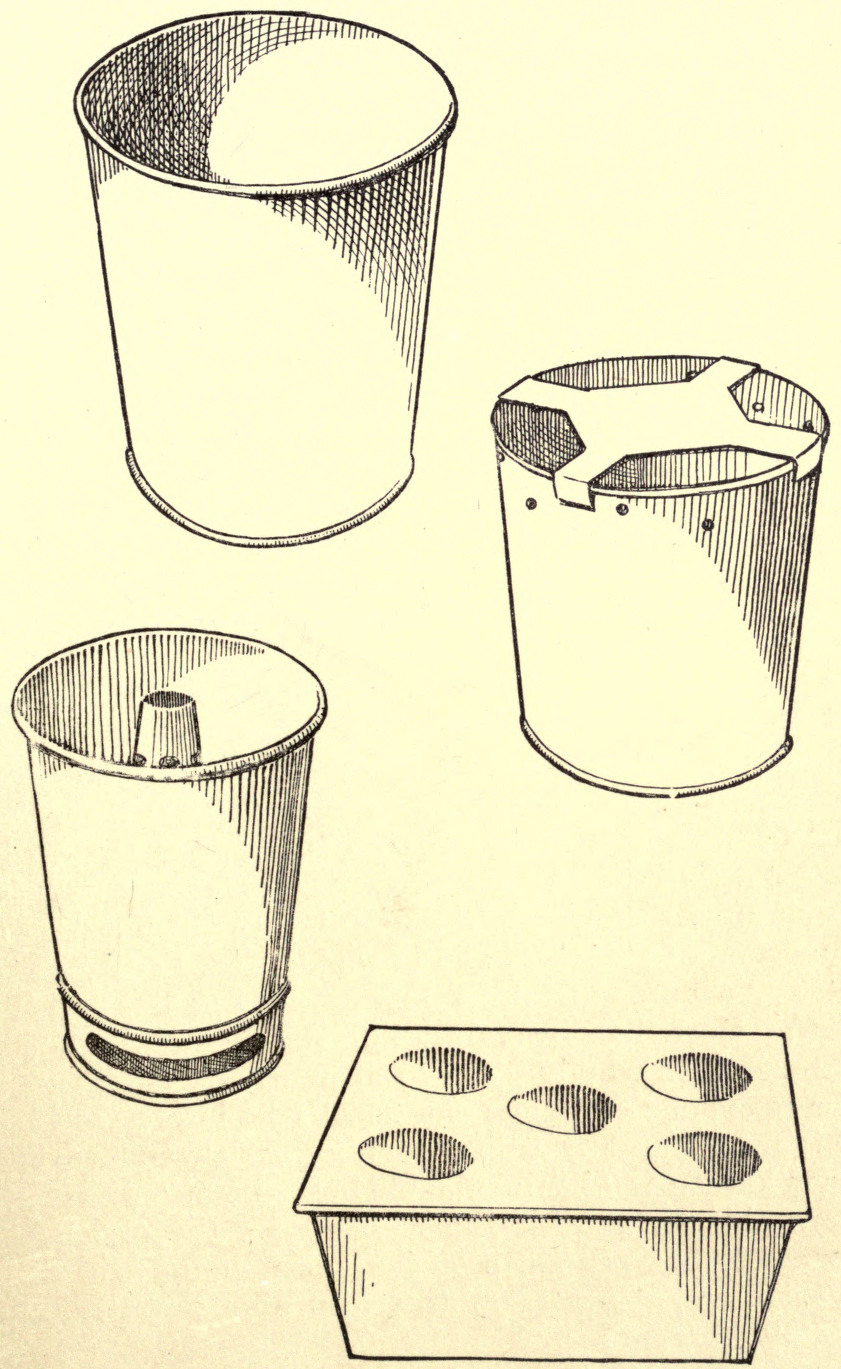

OIL BURNERS FOR ORCHARDS 
These fire pots are placed throughout the orchard early in spring before the danger season arrives. They are used at the rate of from 50 to 100 to each acre, and it seems to be good practice to lean toward a larger number. It is sometimes claimed that I5 to 20 heaters to the acre will do the trick, but experience does not sustain this view.

Some care needs to be exercised also in placing the individual burners so the flame will not injure any tree. They should not be placed, for instance, directly beneath an overhanging branch. The natural and proper place for the burner is at the center of the square equally distant from four trees, but this precise spot is not always available. In all such cases judgment must be exercised, which simply means that cheap hired help cannot be used for setting out the oil burners.

It is usually desirable to have some definite plans for frost warning. In sensational magazines it is easy to read stories about automatic frost alarms which touch the button and ignite all the oil pots by an electric current, thus taking care of the orchard while the owner snores comfortably in bed. Such stories, however, are useful only for the consumption of credulous and unsophisticated city people. An automatic frost alarm working like a \$I alarm clock has its value, but should not be depended upon wholly. The local weather service and the telephone exchange can usually be interested in this matter in any fruit-growing district, and have been known to give invaluable help at times of danger. At any rate, it is necessary for the orchard owner to be very much on his guard at the critical season, and if necessary to sit up nights watching his own orchard.

As soon as it appears that a frost is imminent the 
fire pots have to be lighted. If there are several acres of orchard with 50 to Ioo pots to the acre, this becomes somewhat of a chore of itself, as the work has to be done rapidly and at two or three o'clock in the morning when the land is apt to be dark and the work otherwise unpleasant. Special lighting torches have been patented and are offered for sale, and these are probably well worth while. At any rate it would be found very trying to strike a separate match for each fire pot.

This method of orchard heating has apparently come to stay. In all those regions where there is constant danger of late spring frosts and where conditions are otherwise favorable, this seems to be the most certain and economical method. Something depends, however, upon the topography, upon the presence of currents of air and other local conditions. A good deal remains to bc learned about orchard heating, and even after the general principles are better understood than they are today, there will always be need of careful adjusting of the methods to the requirements of each particular orchard. 


\section{III}

\section{SOILS AND EXPOSURES}

THe American fruit books have always promulgated the theory that the peach tree requires a light soil. In fact, a sandy soil has often been mentioned as the most desirabe type, though this has nearly always been modified to exclude poor, dry, sandy land and such as is deficient in plant food. Probably this represents the popular conception of good peach land, but the experience of leading peach growers in the United States in recent years does not altogether bear out this theory.

As a matter of fact, the peach tree does prefer a reasonably light, warm soil. A fair comparison would be made by saying that the peach should have soil somewhat warmer and lighter than that required for the apple. No fruit tree will flourish on soil that is wet. Proper drainage is absolutely indispensable. Both upper soil and subsoil must be free from water, and an impervious subsoil anywhere within 2 or 3 feet of the surface will render the land worthless for peach growing. While it is true that peaches have been grown to some extent in light, sandy soil, such locations have been successful only when the soil contained also a reasonably large amount of available plant food.

A study of the situation as it prevails throughout the whole United States shows clearly that the lighter, warmer soils are more successful in the northern states, while farther south heavier soils are more commonly chosen. This fact appeals to horticultural judgment as being sound in theory 
also. In general, however, the question sums up in the statement that peaches require medium soils, neither very light nor very heavy, and that, especially in the southern states, any well-drained soil of good physical texture will be successful with peaches, no matter how much clay it contains.

An old rule which has often been given by the author for the choice of apple soils cannot go very

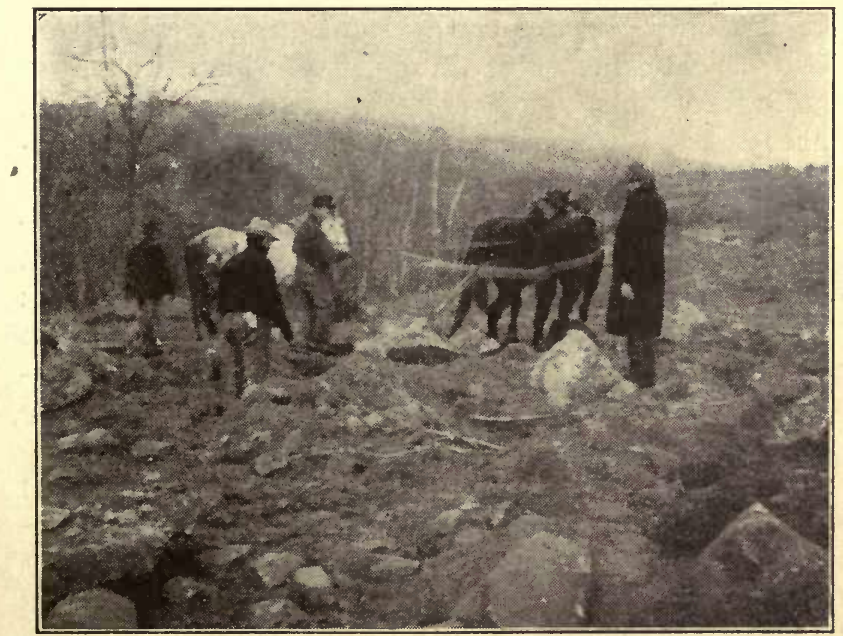

CLEARING STONY PEACH LAND, HALE ORCHARDS

tar wrong also in the choice of peach soils. According to this method of judgment, one would choose for apple growing any soil-which is thoroughly well adapted to potato growing. In the middle and the northern states this means rich loam and gravelly well-drained soils. All such land, however, is well suited to peach growing also, and if we modify the rule in favor of somewhat warmer, 
lighter, sandier soils for northern climates, we will have marked out a standard of judgment which will be fairly saf.e in selecting peach lands anywhere north of Pennsylvania, Missouri and Kansas.

In order to give a somewhat simpler basis of comparison to a wider geographical range, we may say that so far as soil quality is concerned, land well suited to corn and cotton growing will prove satisfactory for peaches. This refers to the quality of the soil only and not to the location, altitude or exposure. The best corn lands, to be sure, are often the flat bottoms along rivers, whereas peach orchards succeed only on similar soils placed on higher elevations and suitably drained slopes.

My friend, Mr. H. J. Wilder, of the U. S. Department of Agriculture, when asked about this subject of soils for peaches, made the following statement:

"It is a matter of common cbservation that peaches require a deep, mellow soil; but what constitutes those conditions on a soil that could be classed as fairly strong, thereby favoring a satisfactory growth of tree to yield a maximum amount of high quality fruit, with lowest ccst for maintaining the productivity of the soil, is not so easy to determine. Bed rock anywhere near the surface is bad, though stones do no harm. Many orchards in West Virginia, western Maryland and Pennsylvania are underlain by unbroken shale at 18 to 30 inches. They suffer in all weather extremes-either wet or dry. Impervious, clayey subsoils are nearly as bad. Friable clay loams or sandy clays are the heaviest subsoils that should be used, and when overlain by a foot or so of sandy loam or fine sandy loam, they give good results. Many of the Georgia orchards are so located.

"A desirable range of soils adapted to peaches 
might be thus stated: A surface soil ranging from sandy loam to a friable, mellow, light loam from 8 to 12 inches deep, underlain by a subsoil ranging from heavy, sandy loam to very friable clay loam. Light, sandy soils underlain by subsoils equally light are in much less favor than formerly. They are too susceptible to lack of moisture to maintain a uniform tree growth, and in a dry year the average grower rarely secures fruit equal in size to that from a soil somewhat more loamy. With a loam surface soil the subsoil should not be heavier than a loam. A friable and mellow clay loam or loam subsoil, on the other hand, is desirable where the surface is a sandy loam or sand, unless early ripening is desired, in which case a lighter subsoil might enable one to gain a day or two in the marketing of early varieties - an advantage which at times would prove very profitable.

"Good color of fruit is most easily obtained on light, sandy soils. Good size of fruit and yield to the acre are most easily secured on soils more loamy, such as fine, sandy loams and light, friable loams. On the latter soils, well-balanced soil management and open pruning will help the coloring. In general such a combination will probably yield the highest profits, though varieties vary somewhat in their adaptation to soils."

Taking up the country throughout, a great diversity of soils are available for peach growing, although they nearly all fall under the broad definitions given above. In the New England states light, sandy or gravelly soil is nearly always preferred. This is commonly spoken of as light, sandy loam, though it must be remembered that the soils of New England are so diverse and are located in such small areas that it is very difficult to specify closely. 
In New York state, the preference for sandy or gravelly loam is still more emphatic. The value of a clay subsoil, very widely recognized in states farther south, begins to make itself felt in the more successful peach regions of New York state. In New Jersey the sandy or gravelly type of soil is preferred, underlaid either with gravel or friable clay. In Delaware and Maryland, the sandy loams of the Chesapeake Peninsula are found to be excellent for the growing of peaches. About the only point to be guarded against in choosing soils of this type in this locality is a deficiency of plant food. Except in extreme cases such deficiencies can be made good by careful soil management, the use of barnyard manures, green manures, cover crops, etc.

In the important peach regions of West Virginia and a part of old Virginia, special soils have been developed with great success. These are known as the black cherts and the sandy red shales. These soils, full to overflowing with small broken stone, and which seem to be on first sight almost impossible of cultivation, have proved to be remarkably adapted to fruit growing, and especially well suited to peaches.

In the Canadian peach regions, as one might expect, the sandy loams are particularly preferted, and open gravelly subsoils are found more satisfactory than softer clay. The same conditions prevail largely in the peach-growing regions of Michigan, where there are thousands of acres of sandy loam devoted to this crop. Gravel and clay lands are used more frequently than in Canada, and are not considered desirable unless exceptionally well drained and in the best of physical condition.

In the central states, Indiana, Illinois, Iowa, Kentucky and Tennessee, the reddish clay and the roll- 
ing sandstone soils are generally preferred. This seems to be, however, more a question of topography than of soil composition. Throughout these central states the sandy and loamy soils are presented mostly in flat, level prairies or in low-lying bottom lands,

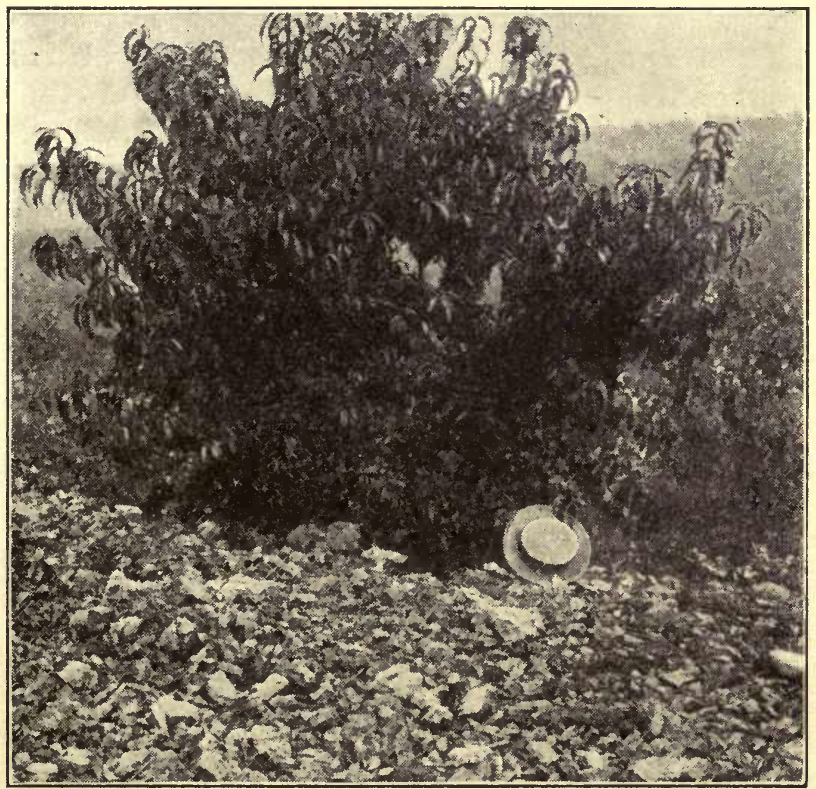

TYPICAL WEST VIRGINIA PEACH LAND

which are unavailable for peach culture on account of altitude and exposure.

The famous peach regions of Georgia and neighboring states are mostly upon sandy loam with clay subsoil. There are, however, in these southern states many excellent peach orchards on red clay, meaning in this case the red soils of the rolling foot- 
hills. The light, sandy coast lands of the Carolinas are used to some extent for peach growing, but in general are not so successful as the red loams and clays on higher altitudes, as mentioned already. Once more, however, it should be pointed out that this is probably less a matter of soil than of topography.

Texas and Arkansas are developing important commercial peach orchards at the present time, chiefly upon warm, sandy land or on sandy, alluvial loam underlaid with clay subsoil. In this latitude a certan amount of retentive clay is desirable either in the peach soil itself or within easy reach in welldrained and friable subsoil.

In Nebraska, Kansas and Oklahıma light, warm, surface soils with strong subsoils are largely preferred. In the mountain states where peaches are now an important crop the soils are extremely varied. It is impossible to specify any one type as representing the development of the peach industry in that section. Red, sandy loams have been found very successful in Colorado. The rich mesa soils are generally desirable, but this is partly on account of their value for irrigation. California has long produced peaches in commercial quantities, chiefly on deep sedimentary loams, usually of pronounced sandy type. A state, however, covering such a wide range of latitude and such great ranges of altitude, with such diversity of soil, would naturally use land of very different types.

It ought to be said, in summing up this general consideration of peach soils, that the value of any particular type seems to depend more upon physical character than upon actual chemical composition. The plant food may easily be supplied in the form of fertilizer, since the peach tree is one of the easiest 
of all orchard trees to feed. The peach is, however, if anything more sensitive than the apple to defects of drainage or to the presence of hard, impervious strata of improper physical condition.

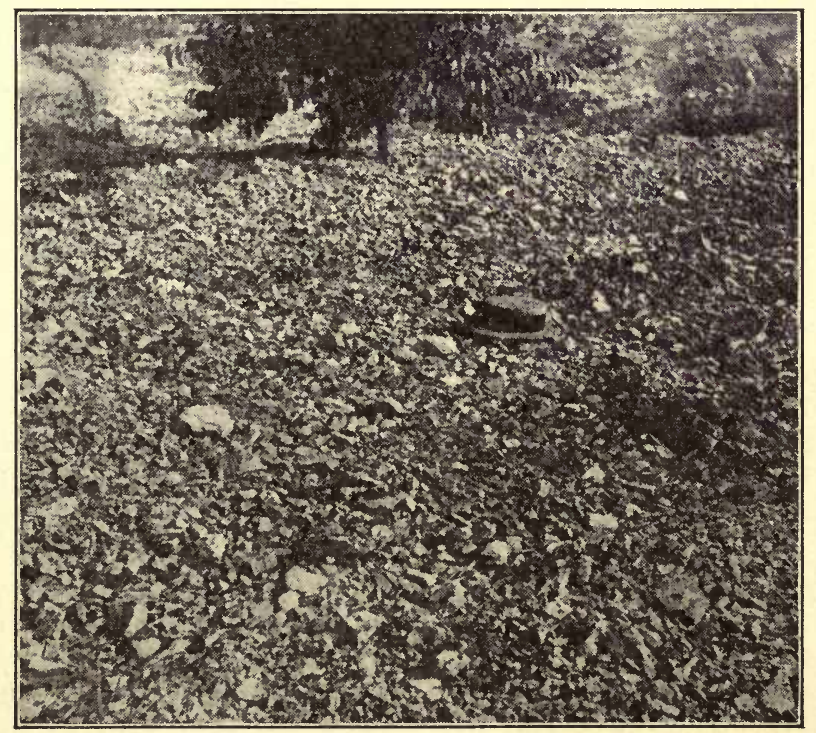

GOOD PEACH LAND IN WEST VIRGINIA

\section{EXPOSURES}

All the farmers' institute speakers on orchard management, and on peach growing in particular, have from time immemorial made $a$ great point of exposure. We refer here to slope, the direction in which the ground slants. The recommendations on this matter have been very positive, and the only trouble has been that they did not agree. A careful review of present knowledge shows conclusively that this point has been greatly over-emphasized. 
So much would easily appear from the contradictory nature of the advice given. One peach grower (perhaps it would be better here to refer to peach lecturers rather than to peach growers) has insisted vehemently on an east slope; the next man has spoken earnestly in favor of a north slope, and has warned his hearers against the dire disaster which always comes to peach orchards on south slopes; while another lecturer or magazine writer has said that the south slope is best by all cdds. I have recently sent a questionnaire to leading growers in all the peach regions of Canada and the United States asking, among other things, which exposure they found best. With a deep suspicion that all this exposure worry was fol-de-rol anyway, I asked point blank this question, "Does exposure make any difference?" The ${ }^{5} 5^{2}$ replies to this direct question were distributed as follows:

$\begin{array}{ll}\text { No, } & 60 \\ \text { Yes, } & 49 \\ \text { Not much, } & 43\end{array}$

Probably these figures put the case quite as strongly in favor of the exposure theory as the facts would warrant. Michigan and New Jersey gave the largest number of votes in the "Yes" column, and it is fair to believe that exposure makes more real difference in these districts than in some others. Yet the force of the positive answers (those voting "yes") is considerably weakened by the diversity of ideas among the voters. Some recommended north slopes, while other men in the same states recommended south slopes.

As nearly as any guiding principles can be sifted out of this large mass of genuinely expert testimony the case seems to stand as follows. 
I. The importance of exposure has been greatly exaggerated. In a large majority of cases the points of the compass may be ignored.

2. Nevertheless there are exceptions to this rule. These exceptions apply to particular localities. The question is an extremely local one.

3. Slope is most important in middle latitudes, and in districts where weather damage (either from spring frosts or winter sun scald) is most frequent.

4. South slopes may be desirable in infrequent cases, especially for early ripening varieties, or where high color is a matter of prime importance.

5. North slopes may be best in a few cases where the principal dangers are climatic, especially the danger of sun scald.

6. Most persons who consider exposure to be a factor in the location of peach orchards prefer east or west slopes, or frequently quartering slopes, as northeast, or northwest.

7. Under any circumstances a moderate slope is to be preferred to a steep one, both with respect to the effect of the slope itself and especially with regard to the management of the soil.

\section{ALTITUDE}

The discussion of exposures is frequently confused with the question of altitudes. Sloping land gives much better air drainage than flat land; and high sloping land is therefore commonly preferred for orchards of all kinds, simply because the cold moist air easily runs off such territory to lower levels. This problem of air drainage, however, is quite a different one from the question of exposure toward particular points of the compass. All growers prefer land slightly elevated and such as lies so 
as to have this good atmospheric drainage. Perhaps the value of this factor is also over-estimated in some cases, but it is well to be on the safe side in this matter. A good circulation of air probably has some value in keeping down certain diseases; and in localities where frost damage to buds and blossoms is to be apprehended during the spring, this air drainage has a most decide 1 value.

However, it is never safe to lose sight of facts, and the fact here is that many of the successful commercial orchards of the present day are growing on perfectly level land and sometimes at distinctly low altitudes. Bottom lands surrounded by higher hill lands do not come into this classification. 


\section{IV}

\section{HOW TO GET THE TREES}

THE first problem in starting a peach orchard is, of course, to get the trees. They may be bought or they may be propagated on the farm where they are to be grown. Each method has its advantages and disadvantages. Home propagation has generally been undertaken either by men starting large orchard enterprises or by amateurs having small gardens. Those of the former class have had in view such advantages as reduction in cost of trees, certainty of delivery when wanted, securing trees reliably true to name and immunity from damage which often occurs in shipment. Men of the amateur class have propagated their own trees for the sake of getting special varieties which they could not buy from nurseries, in order to have trees true to name, but chiefly for the fun of the work.

Probably the home propagation of peach trees has fallen off considerably within the last few years, although it would be hard to prove this by statistics. There appears to be a growing tendency among the large orchard companies, however, to leave propagation to the nurserymen. The nurserymen really have many important advantages in growing peach trees, such as soils especially adapted to the business, experienced workmen, and all the facilities for digging and handling stock. The nursery business has been so well systematized in the last few years, errors in naming have been so largely eliminated, deliveries have so far improved, and the prices of nursery stock have been reduced so near to the 
cost of production that it hardly seems feasible for the fruit grower to compete with the nurseryman. Either business is a big undertaking by itself and very few men can succeed in both lines, no matter how good their opportunities.

However, the peach trees have to be propagated by some one, and a brief description of the best methods should be given here. This will be less directly useful to the nurseryman than to the amateur who amuses himself with a few trees in his own garden. This book is written primarily for fruit growers, and the author hardly has the presumption to suppose that he can teach the nurseryman anything about the propagation of peach trees.

\section{PROPAGATION}

The propagation of the peach tree begins with the planting of the seed. It must be understood at once that this seed is not intended to develop into a tree itself and reproduce its kind. The seed is simply planted for the growing of a stock which is afterwards budded to the desired variety.

Any sort of peach seed will do, and the home gardener going at the business in a small way need give himself very little concern in selecting his pits. It will be well, of course, if he can secure seed from healthy, vigorous trees. Experienced growers have a prejudice in favor of taking seed all from one variety and some have especial preference for Crosby in this connection. However, this point is too trivial to occupy much attention. The two customary sources of supply for the big propagators are $(a)$ the canning factories, $(b)$ and the collectors of so-called southern "wild" seed. When peaches are canned at the canneries, the seeds taken out constitute a more or less important by-product. 
They are dried, packed and extensively sold to nurserymen. These seeds vary enormously in quality. Some are very large and run few to the bushel; others are small and give fully twice as many trees for each bushel of seed; some have a high percentage of viability; others germinate very poorly.

The southern or natural seed is collected from "wild" peach trees, mostly in North Carolina, South Carolina and Tennessee. These pits are much smaller than those from the budded varieties such as are sold from the canning factories. They there-

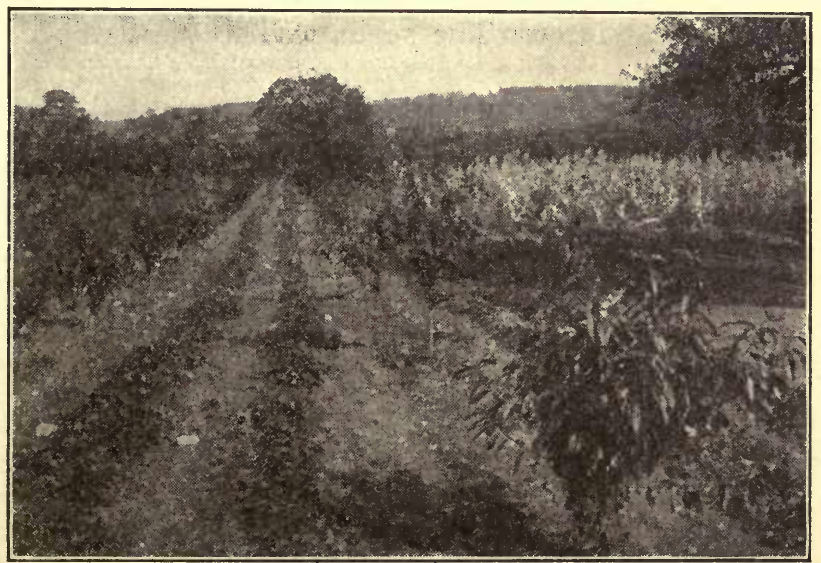

YOUNG TREES INTERCROPPED WITH STRAWBERRIES

fore yield from two to four times as many trees to each bushel of seed. This is a consideration of considerable importance to large propagators. The seed also gives a large percentage of germination and a very vigorous, even growth of stocks for budding. Nearly all nurserymen consider it distinctly superior to the canning factory seed; but the old theory that seed from a wild tree was necessa- 
rily stronger, hardier or healthier than that from the budded tree never was anything much but superstition.

The peach pits are bought in autumn and should be clean and dry when received. Customary practice, at least among small growers, is to bury them in a moist, well-drained soil for the winter. They are placed in holes of any convenient size dug in the ground and covered with 4 to 6 inches of earth. The soil should be of such a character as to keep the pits moist, and the locality should be such as to prevent water draining into the hole and covering the pits during the winter. The seeds will freeze and thaw more or less during the winter. This has the important advantage of cracking the hard shells and assisting materially in the germination.

The pits are dug up at potato planting time in the spring, are sifted out of the soil and should then be immediately planted. In case the pits are not frozen, and so have not been cracked or softened, they may be gently cracked with a hammer before planting. This treatment, if carefully given, will greatly increase the percentage and evenness of the stand, but it is, of course, a slow and expensive job. Freezing is sometimes said to be necessary to germination, but this is not the fact.

The seeds are planted in drills 3 to $3^{\mathrm{T}} / 2$ feet apart so as to allow for horse cultivation. They are placed in the rows from 2 to 4 inches apart. They should germinate promptly and give a good even stand. The soil should be thoroughly and evenly worked and a liberal amount of fertilizer used. Indeed, the soil should be enriched before the seeds are planted. Applications of nitrate of soda between the rows during the early part of the summer will often be advantageous. It is of the greatest importance to 
keep the young trees growing rapidly throughout the summer until budding time. For this reason seeds should never be planted except upon light, warm, well-drained, rich soil, in a high state of cultivation. The budding season begins, according to locality and weather, from August I to September I, and continues until perhaps the latter part of September. Whether they are ready for budding or not must be determined by inspection of the stocks themselves and not by reference to the calendar or consulting the moon. The trees should be grown to the size of a lead pencil or larger and be in a vigorous state of growth, and the bark near the base of the stock should peel up easily when cut as the bark peels from a willow at whistle-making time. The easy slipping of the bark is the critical test.

The propagator now supplies himself with a suitable budding knife, with some strips of raffia and with scions in the form of budding sticks cut from reliable fruiting peach trees of the variety which he wishes to reproduce. Usually he takes with him a healthy boy with freckles on his nose to do the rough work. The job then proceeds.

The boy with the straw hat goes ahead and rubs the branches from the stocks for a space of 6 or 8 inches above the ground. This work should not be done much in advance of the man who is setting the buds as it will cause the bark to "set." The budder carries his budding sticks over his back in a moistened sack, which serves the double purpose of keeping the scions moist and cooling his back against the blazing heat of the August sun. It really becomes something of a chore to creep along the ground for Io hours a day during August with one's back turned directly toward the sunlight. Each budding stick is a shoot of the current year's 
growth, usually 12 to 18 inches in length and having at the base the diameter of a very small lead pencil. From this the blades of the leaves are clipped immediately when the stick is taken from the parent tree. The petioles of the stems of the leaves are left to serve a very useful purpose in setting the buds.

The budder kneels or sits beside the row of stocks and begins his work by cutting a $\mathrm{T}$-shaped incision through the bark of the stock, preferably on the shady north side and as near the surface of the ground as he can conveniently work. If the stock is in proper condition, the two lips of this incision peel up smoothly from the wood beneath, so as to allow the easy insertion of the bud. The propagator then cuts a single bud from his budding stick. This little bud has attached to it a shield-shaped portion of bark and the stem or petiole of the leaf. The shield is slipped down into the T-shaped opening made upon the stock and the budder slides along to the next tree, leaving the work to be finished by the boy already mentioned, who follows after and ties the bud securely in with a strip of raffia.

These ties must be examined from time to time and should be removed as soon as the buds "take." This will usually be in one or two weeks. If the ties are not removed within a month, they will begin to choke the stocks, which continue to expand rapidly in diameter at this season. The tie is cut by running a sharp knife longitudinally up the stem of the stock on the side opposite to the bud.

These buds should grow fast to the stocks within two or four weeks after setting, but under proper conditions will remain dormant through the first winter. They should start into vigorous growth the following spring. As soon as growth is assured, 
the stock should be smoothly cut off about an inch above the inserted bud. Care is required throughout the year to protect the bud from the encroachments of the stock. Very often suckers start from the stocks and quickly choke out the engrafted bud unless they are rubbed off. This work requires an inspection of the entire field with considerable care from two or four times during the early part of the growing season.

JUNE BUDS

For some years American nurserymen have been practicing a special method of propagating the peach, known as June budding. This differs from the process already described in the earlier insertion of the bud and in the different results which follow. The buds are set as early as possible in the season, which means in middle and southern latitudes, during the month of June. Of course the stocks are planted early and forced to their utmost growth in order to be ready for this extra early budding. While the bark of the stock does not slip as well during June as during favorable weather in August, it may, nevertheless, be handled successfully by an expert budder. Some care is to be exercised, moreover, in securing scions on which the buds are sufficiently mature for use at this time. It is customary to set the buds considerably higher in this form of budding and to leave a few good leaves on the stock below the bud. As soon as the bud has grown fast the top above the bud is cut away. Sometimes this is done at two or three operations, a little at a time, as the Dutchman cut off his dog's tail, in order not to give the tree too severe a check. The raffia ties have to be removed very 
quickly, usually within 5 or Io days, as the stocks are necessarily growing very rapidly at this season.

The buds will now start into growth within two to four weeks after setting, and with a favorable season will make a growth of 2 to 4 feet in the same year they are set. Thus we come to the most important practical advantage-namely, that we can secure a merchantable peach tree one year earlier than can be done by the usual methods. These trees are universally known as "June buds." A few years ago when there was a special fever of peach planting nurserymen produced enormous quantities of June buds in order to meet this special demand. At present the production of June buds is falling off considerably, partly because of reduced plantings of peach trees and also because fruit growers generally dislike to use them. The regular one-yearold trees, propagated in the usual manner, are distinctly preferred by nearly all tree planters. June buds are chiefly used now in Tennessee, North Carolina, South Carolina and Georgia. In the northern peach districts, such as Ontario and Michigan, they are practically never used.

\section{DWARF STOCKS}

A word should be said here with regard to dwarf peach trees. Few dwarf peach trees are known in this country. They serve, in fact, no very important purpose. They need not be expected ever to assume any importance in commercial peach growing, but a certain number of dwarf trees are desired by the owners of the small gardens. Such dwarf peach trees are very valuable under such circumstances and may easily be propagated.

The general method of propagating dwarf peach 
trees is to set the buds on plum stocks. Almost any species or variety of plum will answer, but some are naturally much better than others. In Europe the Myrobalan plum is chiefly used, although St. Julien is sometimes recommended. Experience in this country shows that native American plums are usually much better adapted to this purpose. The two best dwarf stocks are the native American plum (Prunus americana) and the dwarf Western Sand Cherry (Prunus besseyi). Further-

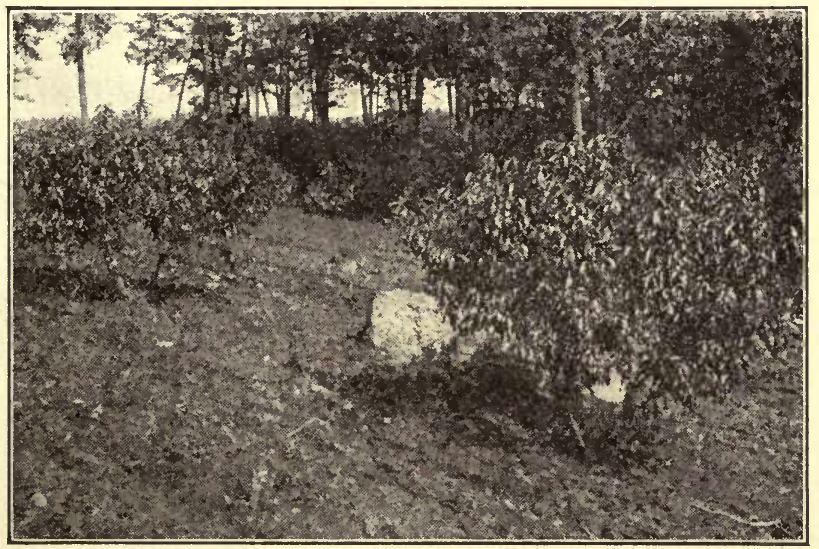

LOW-HEADED TREES-HALE ORCHARDS

more, these are the stocks which it is easiest to buy in a nursery. Peach buds are set upon such stocks in precisely the same manner as upon peach stocks. They grow very rapidly for the first year or two. Sometimes their growth even outstrips that of similar varieties on regular peach roots, and the gardener begins to wonder whether he has not been fooled on his dwarfing process. The second or third year, however, the dwarfing shows itself unmistak- 
ably. The trees, if properly handled, develop low round-topped bushes and come into bearing earlier than standard trees of the same varieties.

\section{BUYING TREES}

Most peach growers will find it strictly to their advantage to buy their trees from some reliable nurseryman. In saying this, however, we have given the most important specifications. If one deals with a thoroughly reliable nurseryman (and this includes a great majority of the firms engaged in the business), most other matters may be referred to the judgment and advice of the man who sells the trees.

There is a strong prejudice among peach growers in many parts of the country favoring locally grown nursery trees. This prejudice is particularly strong in the northern states. It is doubtful if it has any foundation whatever. Experience seems to show conclusively that the best trees will make the best growth regardless of where they spent their infancy. Conditions in the nursery trade are such at the present time that a large majority of all peach trees are grown in the southern and south-central states. These are distributed to all parts of the country, and very often the buyer who supposes he is getting northern grown trees simply because his bill is made out on a northern letterhead, is really planting stock which grew in Huntsville, Ala. Usually he is much better off than if the trees had been grown at the North Pole. The only advantage of buying trees from a local nursery is gained by minimizing the possibilities of injury in transit. A good many trees are carelessly packed, and when delayed during long freight shipments, dry out and 
are thereby seriously damaged. This danger is, of course, reduced by buying trees near home. There is, moreover, some satisfaction in dealing with a nurseryman who is one's own acquaintance, particularly if it so happens that the nurseryman is an old and trusted neighbor. These considerations need not be overlooked, but at the same time it is not necessary to claim that such home-grown trees are intrinsically superior to those grown a thousand miles farther north or south or east or west.

\section{AGE OF TREES}

Peach trees are planted at one year old. They are usually dug in the nurseries in the fall, sorted, graded, put into bundles and heeled in or placed in cold storage. Sometimes they are left standing in the nurseries and are dug early the following spring immediately before transplanting. In any case the important point is to see that they come through the winter in good condition. If they are frozen while standing in the nursery rows, or if they dry out in the trenches or in the storage house, they will come to the planter with distinct evidences of these injuries, usually in the form of blackened bark. Sometimes the bark is dead and will slip off the tree when pinched by the fingers. All storage damages of this sort are serious, and trees of this kind should be refused whenever offered.

A few growers still prefer a two-year-old peach tree, but in most cases it is safe to say that such preference indicates a distinct ignorance of the business. It is the opinion of nearly all fruit growers that any peach tree more than one year old is worthless for planting. The June buds are here included 
as one-year-old trees, but as a matter of fact they are only half a year old.

\section{GRADES OF TREES}

Peach trees are graded in various ways. Sometimes they are offered as first grade, second grade and third grade. In fact, this is a common method of selling. Doubtless it is feasible for a nurseryman to sort any block of trees into these three grades. First grade would then mean the best trees; second grade would mean those of smaller size and less well-branched tops; third grade would mean those which were still smaller and less symmetrical. Below these three grades there should still be certain culls to be thrown on the fire and burned.

From the standpoint of the buyer, however, this classification into first, second and third grades is not satisfactory, and it has now been given up by most wholesale handlers in favor of the classification based strictly on the size of the tree. This is usually given with respect to the height. Trees will be offered at 5 to 6 feet high at a certain price; those 4 to 5 feet high constitute the next grade and are offered at a very slightly lower price; those 3 to 4 feet high form another grade; those 2 to 3 feet high another grade. Trees I to 2 feet high are seldom offered, but are by no means unknown in the trade. This grading into even feet is not recognized as having any special significance. Indeed, nurserymen often quote trees $I \mathrm{I} / 2$ to 3 feet high or $2 \mathrm{I} / 2$ to 4 feet high according as their stock may justify. This is the best basis on which to classify and buy trees.

Sometimes the measurement is given from the diameter of the stock just above the bud. Trees 4 to 5 feet high should caliper $1 / 2$ to $3 / 4$ inch and other 
grades in proportion. If one has given the height and the caliper measurement of trees, he can form some judgment as to whether they are tall and spindling, or short and stocky. Otherwise the caliper measurements are of very little interest to the buyer.

The important issue of the whole transaction is to secure healthy, vigorous, clean trees grown in a section where yellows is not prevalent, and otherwise free from diseases and insects such as San José scale. It is also important, of course, to secure the varieties ordered true to name and to have the deliveries made when the trees are wanted. In actual orchard experience these questions come up frequently and sometimes with great seriousness.

\section{NURSERY INSPECTION}

Along with the handling of peach trees as with other fruit trees the question of nursery inspection arises. At the present time some kind of nursery inspection is provided in nearly every state of the Union and most states require a certificate of such inspection before trees will be admitted to the state from outside. This inspection system has been the outgrowth of a good many years of careful experiment, both as to its practical entomological and its legal aspects. At the present time we have a fairly well-matured system, which is probably as efficient as any such system can be. Doubtless this inspection serves to prevent to some extent the dissemination of San José scale, yellows, rosette, little peach and other insects and diseases. At the same time it has its limitations.

It is well known that this inspection is not perfect, and nobody expects it ever will be. No in- 
spection will absolutely guarantee the freedom of the trees from diseases and insects, and most of all it does not pretend to say whether the trees are true to name and whether they are in a good merchantable condition. In other words, the fruit planter must be the final and the most important judge of his own trees. If he cannot tell a dead or a diseased tree from a live and healthy one, he had better go into the retail clothing business. Peach growing is no profession for him. 


\section{V \\ ORCHARD PLANTING}

THE planting of a peach orchard is as fine and delightful a job as a man ever undertook on a farm. The fruit grower comes to it with high hopes and bright anticipations. The work is pleasant in itself, and when well-organized goes on rapidly.

The ground should be thoroughly prepared before planting begins. This will usually require thorough, though rough, plowing the fall previous. Then, if planting is to be done in the spring, the land should be carefully fitted with the most appropriate tools immediately before planting begins. This selection of tools will depend largely on the character of the soil. The choice may be either the spading harrow, the disk harrow, the spring-tooth or the smoothing harrow, or the land may be replowed if it is not too soddy.

It is very important that the land be in a good state of cultivation and well plowed to a considerable depth. This enables the young trees to make a good start, a thing which is very important in the setting of a peach orchard. Deep cultivation also increases the water-holding reservoir. This is important throughout the life of the peach orchard. Thorough fitting of the land by the use of the tools already named is of great value also. A field in first-class surface condition can be more rapidly and neatly planted than one which is rough, half plowed, full of stones and stumps.

The soil should be dry enough to work without puddling. Planting in wet, muddy soil may be a 


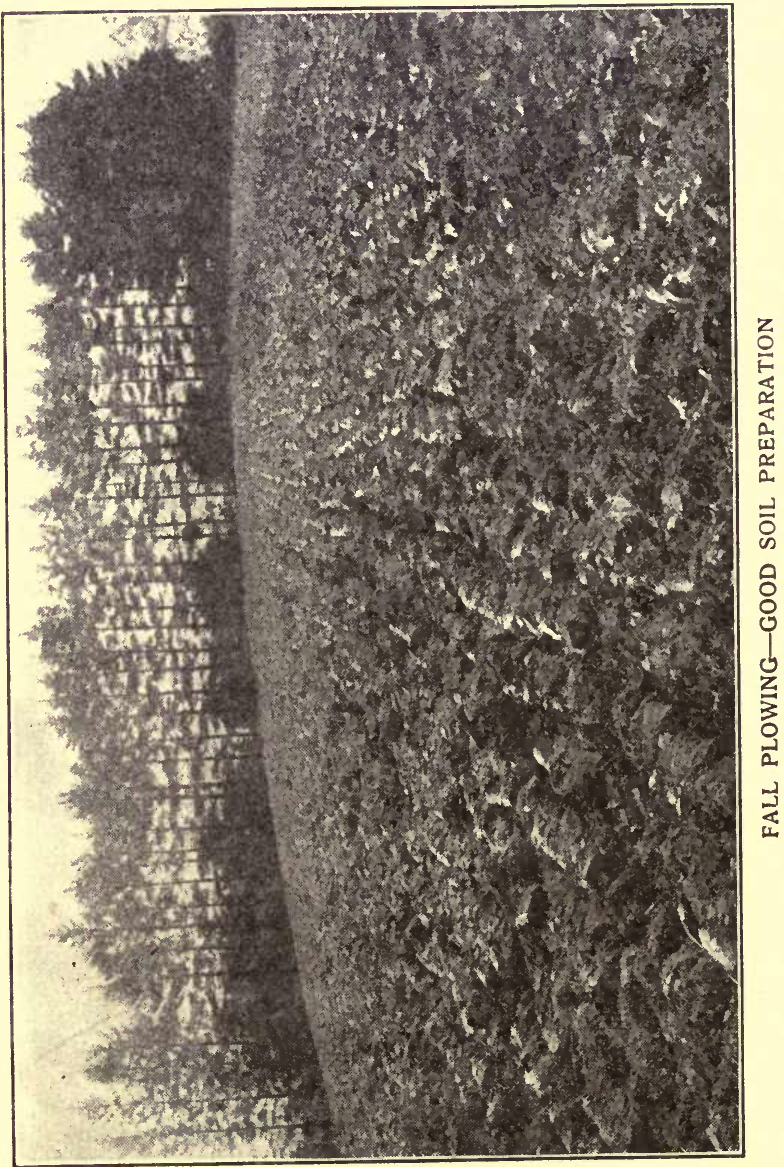


serious damage to young peach trees and is sure to cause a large percentage of loss in land which has a natural tendency to bake. On the other hand the soil should not be dried out to a powder.

At this point we may refer to the old practice of watering the trees at planting time. There is no serious objection to the practice, nor is there any great advantage in it, especially if it is carelessly done. If watering is to be done at all a liberal amount should be given to each tree after the first shovelfuls of soil are thrown in, but before the filling in about the tree is completed. The water can be poured on at this middle stage of the planting, allowed to soak away and a fine soil covering applied a few minutes later. This, of course, causes extra trouble, and while it may be desirable when planting on a small scale, it is usually disregarded with profit when large orchards are being put out.

\section{TIME TO PLANT}

There has been a good deal of argument as to whether fall planting or spring planting is best for peach trees, but the question seems to settle itself practically without much difficulty. In some peachgrowing latitudes fall and spring plantings succeed almost equally well. It depends a good deal on when the trees can be secured and the ground put into condition. Whenever good trees can be put into well-prepared ground anywhere between late fall and the beginning of the growing season, they are apt to succeed. Fall planting is undesirable in the most northern latitudes. It is very rarely or never practiced in Canada, Michigan, New York state and New England. It is also undesirable on heavy, cold land; but such land should never be used for peach 
orchards anyway. Fall planting is largely preferred in middle latitudes, particularly in southern New Jersey, Maryland, Tennessee, North Carolina, etc. In the most southern commercial peach districts, as Georgia and Alabama, winter planting is generally practiced, and is correct. There are substantial advantages in fall and winter plantings where it can be safely practiced. The work can be done more leisurely and the trees become fixed to a considerable degree in the soil before they are called upon to begin their spring growth.

\section{DISTANCES FOR PLANTING}

Peach trees are always grown relatively close together in orchard practice. The tree is naturally smaller than the apple tree, it is shorter lived and usually receives more restrictive pruning. Whereas 30 to 35 feet may be looked upon as a standard distance for planting apple trees, 18 by 18 , or 20 by 20 feet should be regarded as a standard distance for planting peach trees. There is even more variation in practice among fruit growers, however, regarding the planting of peach trees than regarding the planting of apple trees. No very settled practice is followed in any peach-growing region. This variation may be seen somewhat from the following tabulation of replies received from peach growers in various parts of the United States. About 200 replies were received. Among them there were a good many scattering votes, suggesting irregular distances and giving other information which could not easily be tabulated. A fair view of the situation, however, can be secured from the table which shows the number of times each method was voted for: 


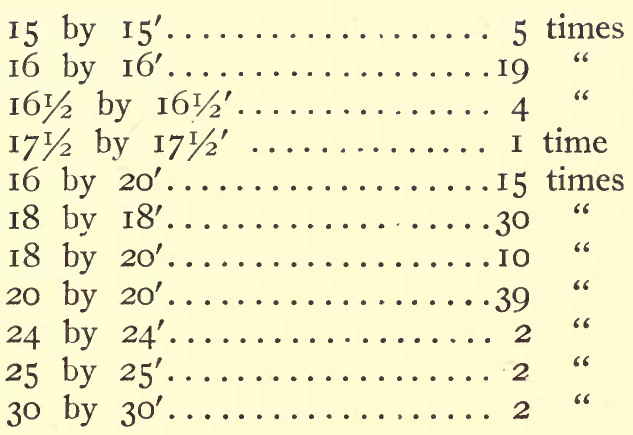

It may be remarked that the most advanced and expert growers show a tendency toward the smaller distances; but it may be laid down as a general recommendation for beginners and for those whose own personal experience does not settle this question, that 18 by 18 feet is a safe distance.

\section{PEACH TREES AS FILLERS}

Thus far we have spoken only of pure peach orchards, that is, those made up of peach trees alone. The practice of planting peach trees as fillers in apple orchards remains to be noticed. It is a practice by no means rare. The men who make these mixed plantings are mostly apple growers seeking a quick profit from the temporary peach trees while their apple trees are growing. Still, in the aggregate there are hundreds of thousands of commercial peach trees now growing in these mixed stands. From the standpoint of the apple orchard the method has its disadvantages as well as its advantages, and, of course, cannot be adopted as primarily suited to peach growing. When this style of planting is used the apple trees should be set about 
40 feet apart, with peaches between in both directions. This makes 27 apple and 8I peach trees to each acre.

THE WORK OF PLANTING

When the trees are on hand and the ground ready, the planting enterprise should be organized and directed with considerable care. The field to be planted should first be laid off accurately. The best method of doing this is to mark out the first row carefully on the long side of the field, taking the measurements with a surveyor's chain, a strong tape line (steel preferred) or a light bamboo pole cut to 16 or 18 feet, or to whatever distance has been decided upon for spacing the trees. At right angles with this first base line another row of trees should be laid off. The second row may be along one end or across the middle of the field, and should be laid and spaced with equal care, considerable pains being given also to see that it lies at right angles with the first base line. From these two base lines intersecting at right angles, the entire field may be rapidly laid off.

A common way, and perhaps the best one, is to have at hand two light poles cut to the necessary length representing the distance between trees. Beginning with these poles at the intersection of the two lines already mentioned, a second row can be laid out parallel with the first one in the following manner: The first pole is laid at the second tree of the base line, the second pole is laid at the second tree of the cross line, and the free ends of the two poles brought together. At the point where they meet a stake is set representing the second tree in the new row, forming, with the poles lying toward 
the other trees, a complete square. With this new peg as a point of departure the poles are moved up one space. The end of one pole rests on the peg, the end of the other pole on the third tree in the base line, and where the tips of the poles meet, a peg is set representing the third tree in the second row.

Two men working together with these poles can set out the pegs for each succeeding row as fast as they can walk across the field, and with a little time given to correcting irregularities, these rows can be made very straight, and the work will check up with surprising accuracy at the finish. Of course, this method does not work so well on uneven land, but on such land the greatest accuracy is not expected anyway.

It is common practice in many places to lay off the field with a plow and a steady

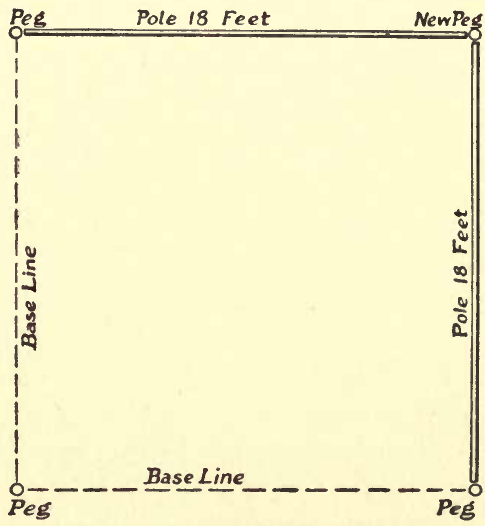
team of horses or a good mule. Stakes are set at the ends and across the middle of the field by which the driver of the horses or the mule is able to sight. He then plows furrows lengthwise of the field representing the new rows. Stakes are then set crosswise of the field, enabling the planters to sight out the rows at right angles to the furrows. Trees are put in sometimes without the preliminary work of setting stakes. This method is not as accurate as the former, but is a little cheaper and more rapid. 
When a field has been set out with stakes representing the points at which the trees must be planted, it is necessary to use a planting-board for getting the trees in the exact positions of the stakes. This convenience has been so frequently described that it hardly needs to be referred to again. The planting-board or tree-jack consists of a light, strong board about 4 feet long and 4 inches wide cut with a notch in either end and a third notch exactly in the middle.

In use this tree-jack is laid on the ground with the middle notch set upon the peg which marks the position of the prospective tree. Two light stakes are then driven in the notches at the end of the planting-board, after which the board may be taken to the next peg and the transaction repeated. After these end stakes are set the hole for the tree may be dug, the center peg being taken up and thrown to one side. After the hole has been dug large enough for the roots, the tree may be placed precisely in its correct position by bringing back the plantingboard, placing it on the two end pegs in its former position, and holding the stem of the little tree firmly in the center notch while the roots are covered and trodden down. This method sounds a little bit complicated, but can be used rapidly in the field by experienced workmen.

\section{HANDLING TREES}

The trees are taken from the bundles and pruned. This pruning consists in removing all broken roots and in cutting back the tops. The most common practice nowadays, and the one by all means best, is to prune each tree top to a whip or a stub. All side branches are removed and the main stem is cut 
back to any height which suits the taste of the fruit grower, from 6 to 30 inches. It should be said, however, that some fruit growers prefer to do this pruning after the trees are planted in the orchard. In the opinion of the writer the work may be done more cheaply and expeditiously before planting. It is a great deal easier to prune a thousand peach trees on a saw horse at the sunny side of the barn during the afternoon than it is to walk all over six acres of new-plowed land and look them up later.

At this point it may be well worth while to notice the Stringfellow planting method, which has caused a good deal of discussion in this country and even in Europe. It is by no means as unreasonable as it sounds. According to Mr. Stringfellow, the best method of handling trees, and particularly trees of this kind, is to cut off all roots except the tap root, shorten this latter to the length of 4 inches, then cut off all the top, except about 4 inches of the main stem. The tree is thereby reduced to the form of a mere cutting, except that it has portions of both root and stem from the original nursery tree.

It is, furthermore, specifically recommended that these trees be planted in holes made by a crowbar and not in soil loosely dug up with a shovel. The soil is firmly trodden down about the newly planted stubs. This method has been extensively tried by experimental and practical fruit growers, and although it has not proved a great discovery and has not even achieved any special popularity, it has proved to be successful in a large number of cases. On good, light, warm soil it succeeds admirably. Of course, it has some manifest advantages. The trees are easier to handle and the holes are cheaper to dig. While the present writer does not give the Stringfellow method a general recommendation, he 
believes that it is entitled to great respect; and this seems to be the general attitude of the best men who have investigated the subject.

The trees should not be exposed to sun and air any longer than necessary during the planting process. As fast as they are prepared for planting they should be placed in a tub or a barrel of water, to which may well be added a considerable amount of loose soil. The tub of water, therefore, becomes a tub of thin mud. This mud adheres and effectually prevents the roots of the trees from drying out during the planting process. The tub or barrel can be put on a stoneboat or a suitable wagon and carried into the field. This makes a convenient manner of distributing the trees about the field for planting.

The work of planting can be done very rapidly if the men are properly assigned and given a little preliminary training. The work should become almost automatic. The planting gang should consist of three men, one to carry the trees and two to use shovels. The two men with shovels will sight the tree into its position, one sighting off in one direction and the other in the cross direction. While the two shovelers throw in the soil the third man holds the tree and tramps it into place. A thorough tramping of the soil about the roots is a matter of serious importance. A light surface cultivation should be given the land as soon as the trees are planted. 


\section{VI}

\section{GENERAL MANAGEMENT}

A SYSTEM of management for an orchard consists of a series of practices nicely adjusted one to another. These several practices cannot be considered separately, although it is a common defect of discussion and practice to try to do so. Cultivation will be influenced by the cover crop, and the application of fertilizer will depend similarly upon the amount of nitrogen secured by this means. Fven spraying will be influenced by cultivation. It is necessary for every fruit grower to have a fully considered system of practice in which each several operation dovetails into the others, all co-operating toward one great result, namely, the production of a crop of marketable fruit.

Several of these cultural practices are of such inportance that they have been considered in separate chapters of this book. This may also be because they are difficult or involve a certain amount of detail which requires elucidation. Other practices which do not require so much discussion are grouped together in the present chapter, but this is not necessarily an indication that they are of minor importance.

\section{TILLAGE}

Cultivation of the soil is now generally recognized as one of the most important features of agricultural practice, but the application of this gospel to the business of fruit growing has been rather tardy. Al- 
though there has been some disposition in influential quarters during the last few years to deny the necessity of cultivation as a regular orchard practice, the great majority of opinions still stand in favor of tillage. Moreover, the leading insurgents against the tillage program have hardly dared to recommend a system of mulching or no-tillage for peach trees. The necessity of thorough annual cultivation for peach orchards is still almost universally recognized.

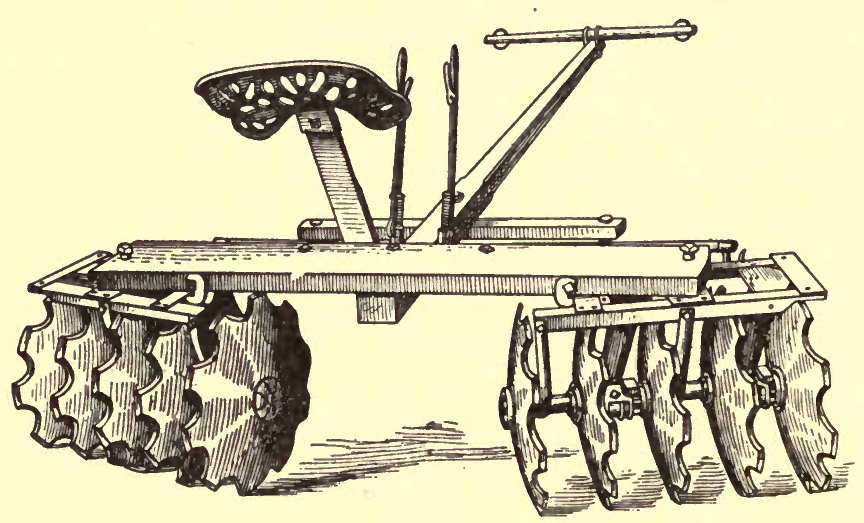

THE SPADING HARROW

In the old view of cultivation the work was done wholly for the purpose of killing weeds. According to the modern view there are many other and more important purposes to be served. In the first place, good tillage deepens the available soil in which the trees may profitably forage. This not only opens up a larger area for the action of the roots and a larger amount of plant food is made available, but the water-holding reservoirs are deepened and enlarged. This is of the utmost consequence, since 
the trees suffer for water oftener than for plant food. Proper cultivation does not merely allow the soil to catch and hold more water in the first place, but it helps to conserve the water when it is once taken up by the soil. This is particularly the office of surface cultivation.

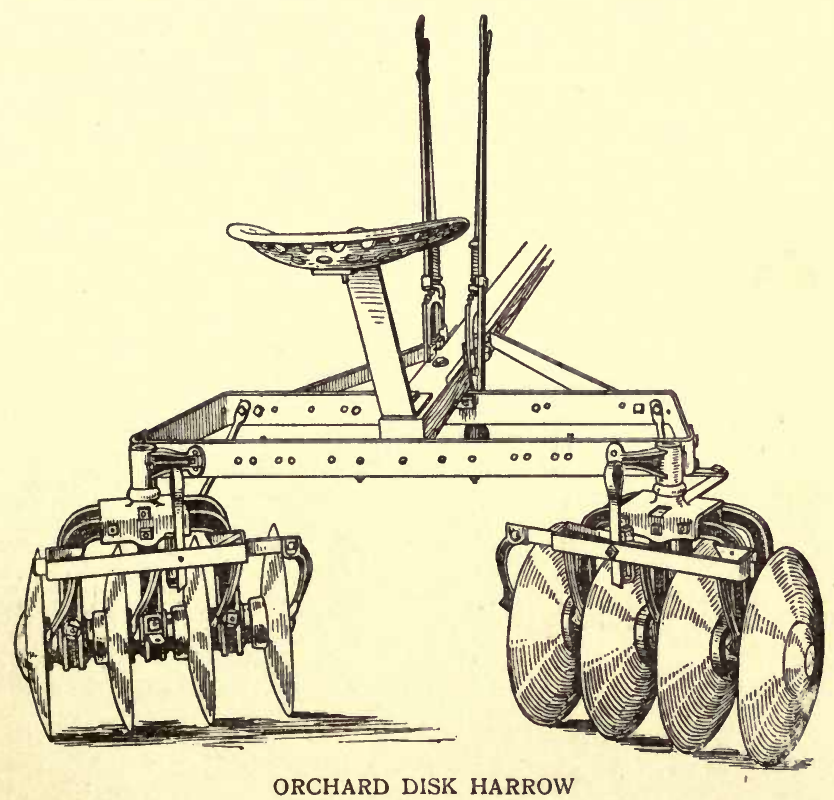

As a general statement we may say, therefore, that the first tillage of the year should be a good plowing; that is, as deep as can be practiced in fruit orchards. The intention of this is to loosen the soil to a considerable depth, to provide the water-holding capacity required and to loosen up plant food to the action of water and air. The subsequent cultivations will be of a different character. They 
will be given with light tools and applied to the surface, the intention being merely to maintain a light dust mulch upon the land. The purpose of this dust mulch is to prevent the evaporation of water.

It is well understood at the present time that the soil is a great laboratory in which all kinds of chemical and even biological processes are going on, all of which processes are infinitely important to the peach tree. These chemical and bacteriological processes cannot take place except when a certain amount of moisture is present, and especially do they require a constant supply of air. The presence of fresh air enables the bacteria to live and thrive and serve their various beneficent uses in the soil. The air also assists in the necessary chemical changes, and especially in the conversion of nitrogen in the soil into available forms as nitrates. Until the nitrogen is changed into these available nitrates it cannot be taken up by the trees. The necessity of these changes brought about by action of the air applies to much of the nitrogen which is given in the form of fertilizer.

Of course, it is still recognized that tillage kills the weeds and that this is an important office. No man wants to have a weedy orchard unless he purposes to leave a heavy stand of weeds in the latter part of the summer to take the place of a bettergrown cover crop. The handling of the cover crop is discussed elsewhere, but it is to be observed at this point that the cover crop following at this period has a definite part in the program of orchard work. The scheme of management will, therefore, provide for a heavy plowing in early spring, for several successive surface cultivations at periods of 5 to Io days apart, and finally for the introduction of a cover crop. The time when this cover crop will 
be sowed depends largely upon latitude. In the southern states it is customary to sow the cover crop in May, June or July, the proper month being regarded as June. In the northern states the practice is to put in the cover crop about the middle of July, although this should be regarded as the latest feasible date.

\section{TILLAGE TOOLS}

Various tools are required to carry out the tillage herein recommended. Early plowing in the spring may be done with a light turning plow. A good, steady team and a plowman of temperate Christian habits are required. In other words the work has to be done carefully, slowly, with great restraint and in such a manner as not to injure the trees. Of course, this plowing will not be so deep nor so thorough and smooth as practiced in the preparation of the field for crops outside of the orchard, but it may be made efficient for the purposes in hand. In most loose, workable soils the early spring tillage may be given with a spading harrow. "Such a harrow can be made to cut the soil to a depth of 6 inches, or even more. This will be sufficient in any orchard. It has many substantial advantages over a plow where it can be used, but it will always be well to keep the plow in mind and put it in where a more thorough tillage of the soil is required than can be given with a spading harrow.

The disk harrow, which does not cut so deep as the spading harrow, may be used on hard soils for second, third and fourth cultivation and may be brought into use at other times when the judgment of the fruit grower dictates. As a rule the disk harrow is not used for preparing and maintaining a dust mulch. 
The spring-tooth harrow is especially adapted to heavy gravelly soils or those which have a considerable amount of loose stones. On such land it is invaluable and is to be used almost exclusively for everything except the early spring cultivation.

On gravelly land, or soils subject to surface baking, the acme harrow often serves a very useful purpose. It is particularly adapted to the production of a suitable dust mulch on refractory soil. But the use of this tool seems to be largely a matter of personal taste, some men preferring it, while other men choose not to use it at all.

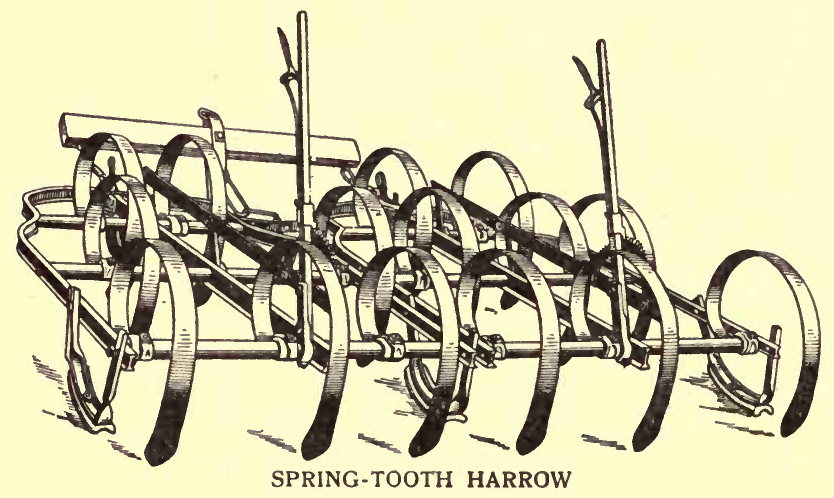

The smoothing harrow or spike harrow is most efficient of all for producing and maintaining a dust mulch on light land which is in a good state of cultivation. It will cover more acres of land in a day with less wear and tear of horse flesh than any other.

Various weeders are supplied by dealers and are well liked by some men. As a rule they are available only for very light cultivation, unless the soil is in the very pink of condition. 
This practice of thinning out the fruit crop by hand is everywhere recommended, but seldom adopted. It has been shown, however, by repeated experiment and by careful test under commercial conditions that this is one of the most profitable practices that can be undertaken by the ordinary fruit grower. Thinning out the fruit increases the vitality of the tree by lessening the production of seed, tends to cause the tree to bear crops more

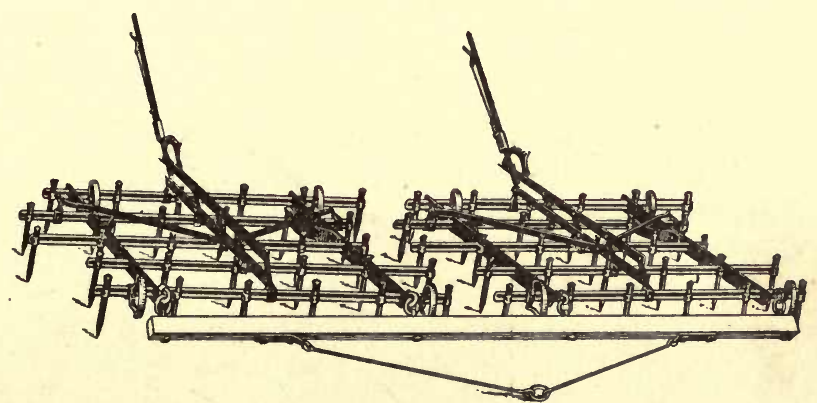

THE USEFUL SPIKE-TOOTH HARROW

regularly, lessens the loss caused by rot and other fungous diseases by eliminating the danger of infection by contact, brings larger and better-colored fruit which can ripen up more uniformly, produces a more salable and higher-priced fruit and prevents the breaking of overloaded branches. In nearly every case where a fair test has been made it has been shown that the tree carefully thinned will produce a larger quantity of first-grade fruit than a tree from which no fruit has been taken.

It has been shown, moreover, that it is almost impossible to overdo this work of thinning; that is, that no ordinary man would remove too much fruit 
at thinning time. In other words, it seems to be profitable at an early thinning of the tree to remove not merely one-half or two-thirds, but perhaps threefourths of the crop then hanging. A common rule is to leave fruit every 4 inches on the branches, but it seems the better practice in most cases to thin the fruit out to 6 or even 8 inches apart. Some men say as much as Io or 12 inches apart is better and produces more first quality fruit which will sell at a higher price.

This work shoula be done rather early in the season, at least as soon as the June drop is completed and when the fruit is not larger than small walnuts. Early thinning seems to be much more satisfactory than late thinning. The best way of doing this thinning is to prune the tree, but trees which have received rather strenuous pruning will still require thinning of the fruit after fruit-setting time. This work must be done by hand. Any such makeshift as taking off the fruit with a hand rake or a baseball club has been found to be unsatisfactory.

\section{JUNE DROP}

In speaking of artificial thinning we have already mentioned the June drop, which name has been given to the natural thinning of the crop which takes place every year during the early part of the growing season, usually in June. During this period a considerable portion of the fruit set falls to the ground. The amount may vary from 2 per cent to 95 per cent, or the whole crop. As a rule, however, the amount runs from 5 to 50 per cent.

June drop is due to various causes, the most important ones being as follows: (I) The curculio, which undoubtedly is responsible for much the largest por- 
tion in most cases. The fruits, in considerable number, though not nearly all of those punctured by the curculio, fall to the ground at this season. (2) The monilia, or fruit rot, which attacks fruit and twigs, and which causes a certain proportion of the young fruit to fall. (3) The leaf curl, another disease which also injures fruit twigs and stems and causes a certain amount of drop. (4) A lack of pollination, which in other fruits, as the plum, causes a large proportion of June drop, and may have some influence also on the peach, although it certainly cuts a much smaller figure here than in the case of the plum. (5) There is further to be considered the natural crowding of the fruit thickly together upon the stem. Once more, as so frequently happens in Nature, it is the survival of the fittest. The best and strongest fruits cling to the stems and crowd off the smaller and weaker ones.

June drop is often spoken of as if it were a disease. It is not. It is simply the result of a series of causes working together on the overstocked tree. The June drop is also often spoken of as though it were something very detrimental to a fruit grower's interest and something which he should prevent if possible. Quite the contrary is the fact. The June drop is usually one of the fruit grower's best friends. Very rarely, indeed, does it remove such a proportion of the crop as seriously to reduce the final harvest. In the very large majority of cases these natu- ral causes take off a large part of the fruit which very much needs to be removed, and by so much diminishes the important and almost necessary labor of hand thinning which would come soon after the time of the June drop. 

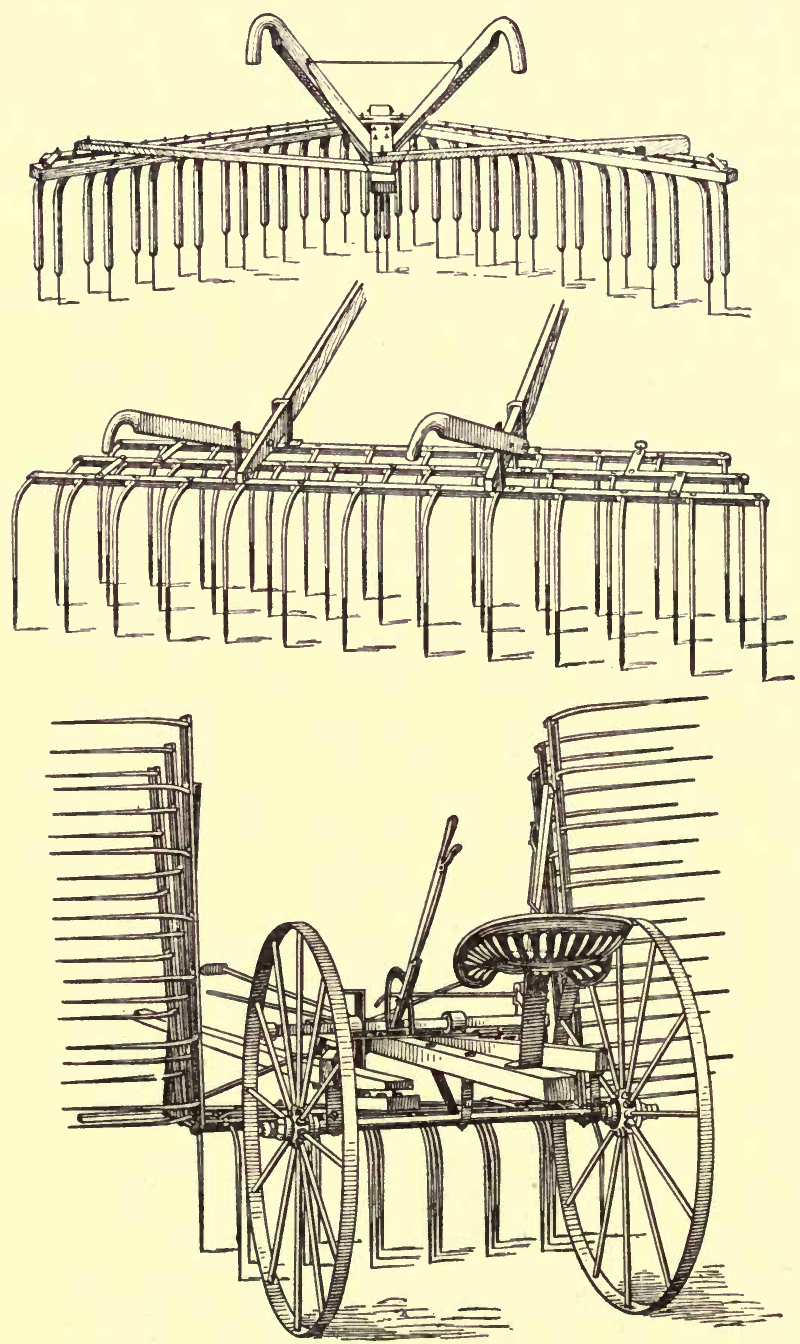

WEEDERS SUITED TO SURFACE CULTIVATION 
Besides the insect and plant diseases which are considered in their appropriate chapters, there are some other peach enemies which deserve mentioning. In certain sections rabbits are so numerous as to do considerable damage, although this is always less on peach than on young apple trees. When rabbits are numerous, trapping and shooting should be resorted to, but the best and most satisfactory protection is furnished by tying up the trunks either with corn stalks, newspapers, or with strips of thin wood veneer especially made for the purpose. These thin wood veneer strips sell at $\$ 5$ a thousand, and are certainly the best means of protection. They should be removed in the spring after growth starts. In fact, any other protection which is tied upon the tree trunk should be removed at this time.

In many of the states, and curiously enough in the older settled eastern states, wild deer have done much more damage than rabbits during the last few years. There seems to be no practical method of circumventing the deer. Fencing them out has proved ineffective. Keeping a good dog will often hold the deer at a distance, but if the dog should happen to chase the deer, the owner of the dog would become liable to the owner of the deer; that is, he is liable to be arrested by the officers of the state and heavily fined. A number of instances of this kind have been known. There is a manifest tendency at the present time to protect the farmer rather better by legislation than he has been protected in the past, but for the present the men who set out young orchards have to take into consideration the presence of these deer, which may be, in- 
deed, a very serious problem in many of the best orchard sections of the northeastern states.

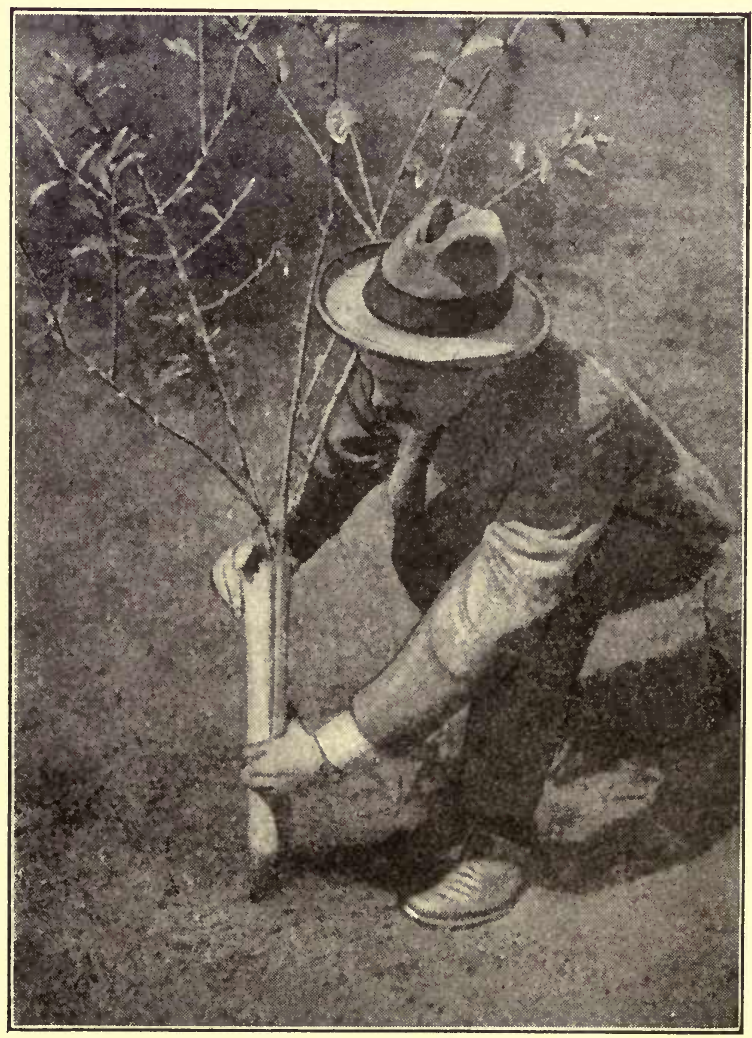

WOOD VENEER STRIP PROTECTOR

Wind and ice storms also do considerable damage to young orchards at certain times and also to old and decrepit orchards. The use of windbreaks has been strongly recommended as a means of re- 
ducing the damage by wind storms, but this method is now largely given up especially by the planters of large orchards. It is perfectly feasible to establish a good windbreak for the protection of small family orchards, but it is manifestly impracticable in the case of plantations which cover hundreds or even thousands of acres. There seems to be no way of preventing or mitigating the damage done by ice storms. The orchardist simply has to take them along with his regular year's medicine.

\section{ORCHARD ROTATION}

It may be well to mention here in connection with the general management of a peach orchard the fact that some sort of rotation of trees has to be practiced. There is a feeling among the old-timers who used to plant apple trees for their grandchildren that an orchard is a permanent investment - that a plantation of trees once set out will last forever. This is not the case with any sort of orchard and least of all with a peach orchard. As we have elsewhere pointed out, the peach is a comparatively shortlived tree and cannot be expected to thrive and bear profitable crops more than I2, I5 or 20 years. The man who goes into the business, therefore, with the intention of staying and making it a permanent success should bear this in mind and be prepared to dig up old orchards when they become unprofitable and eventually to replace them with young and more profitable plantations. Such a rotation has, in fact, been already worked out and put into more or less definite practice by many of the best peach growers. Professor Bailey in the "Cyclopedia of Agriculture" makes some interesting suggestions which are worth quoting. He says : 
"Rotation, between the fruit plantations themselves, may be very desirable in some cases. If one has a hundred-acre farm on which he wishes to make a specialty of peaches, he might set aside six fields of Io acres each, and set them in I2-year rotations or blocks, planting a new orchard every three years. In this way there would always be a new orchard coming into bearing, the grower could apply the experience of one orchard to the succeeding one, and he could prepare the land thoroughly in advance of each setting. This preparing of the land is exceedingly important in most cases and is usually neglected. It often should include thorough underdrainage. The following display shows how this plan would work out. The black face figures

ROTATION SCHEME OF PEACH ORCHARDS

Black figures represent bearing years

\begin{tabular}{|c|c|c|c|c|c|}
\hline$\underset{\text { Orchard }}{\text { First }}$ & $\begin{array}{l}\text { Second } \\
\text { Orchard }\end{array}$ & $\begin{array}{l}\text { Third } \\
\text { Orchard }\end{array}$ & $\begin{array}{l}\text { Fourth } \\
\text { Orchard }\end{array}$ & $\begin{array}{c}\text { Fifth } \\
\text { Orchard }\end{array}$ & $\begin{array}{l}\text { Sixth } \\
\text { Orchard }\end{array}$ \\
\hline $\begin{array}{l}1900 \mathrm{z} \\
1901 \mathrm{~b} \\
1902 \mathrm{c} \\
1903 \\
1904 \\
1905 \\
1906 \\
1907 \\
1908 \\
1909 \\
1910 \\
1911\end{array}$ & $\begin{array}{l}1903 \mathrm{a} \\
1904 \mathrm{~b} \\
1905 \mathrm{c} \\
1906 \\
1907 \\
1908 \\
1909 \\
1910 \\
1911 \\
1912 \\
1913 \\
1914\end{array}$ & $\begin{array}{c}1906 \mathrm{a} \\
1907 \mathrm{~b} \\
1908 \mathrm{c} \\
1909 \\
1910 \\
1911 \\
1912 \\
1913 \\
1914 \\
1915 \\
1916 \\
1917 \\
\\
\\
1924 \mathrm{a} \\
1925 \mathrm{~b} \\
1926 \mathrm{c} \\
\text { etc. }\end{array}$ & $\begin{array}{l}1909 \mathrm{a} \\
1910 \mathrm{~b} \\
1911 \mathrm{c} \\
1912 \\
1913 \\
1914 \\
1915 \\
1916 \\
1917 \\
1918 \\
1919 \\
1920\end{array}$ & $\begin{array}{l}1912 \mathrm{a} \\
1913 \mathrm{~b} \\
1914 \mathrm{c} \\
1915 \\
1916 \\
1917 \\
1918 \\
1919 \\
1920 \\
1921 \\
1922 \\
1923\end{array}$ & $\begin{array}{l}1915 \mathrm{a} \\
1916 \mathrm{~b} \\
1917 \mathrm{c} \\
1918 \\
1919 \\
1920 \\
1921 \\
1922 \\
1923 \\
1924 \\
1925 \\
1926\end{array}$ \\
\hline
\end{tabular}


show orchards in bearing; it will be seen that there are always three orchards in bearing after the plan is in full working maturity. It is assumed that six years intervene between the plantings on the same ground. The letters $a, b, c$, show how the elements in a three-course crop-rotation would combine with the orchards, if it is assumed that it would be safe or desirable to crop the orchard lightly for the first three years. The blank or treeless years would be used in general field-crop practice. It must be understood that this plan is not recommended, but is given to illustrate the discussion and to suggest a line of study." 


\section{VII}

\section{COVER CROPS}

Probably cover crops of some kind have been grown by careful fruit growers ever since peach orchards have been planted in this country, but the cover crop as a definite, rationalized part of a system of cultivation is comparatively new. The name itself was not brought into use until 1893, and the practice has attained general recognition since 1900 . Even yet there are many men who have not adopted it.

A cover crop may be defined as any temporary crop sown at the end of the tillage period and plowed into the soil at the beginning of the tillage period the following spring. A permanent growth of grass or clover does not constitute a cover crop, and a heavy stand of oats or buckwheat sown in the orchard and cut and removed for hay at maturity does not constitute a cover crop.

The cover crop is definitely and intimately related to the practice of tillage, and is always to be considered in relation to the cultivation of the soil. The usual practice is to sow the cover crop broadcast at the time of the last cultivation, viz., from July Io to 20 . The crop then grows more or less vigorously according to its nature, the fertility of the soil and the temperature; it stands upon the land during the winter, at this time performing a valuable service; it is plowed into the soil as soon as cultivation can begin in the spring, then performing additional services.

\section{USES OF THE COVER CROP}

The various benefits which the cover crop renders 
relate both to the physical nature and the chemical qualities of the soil. They may be summarized as follows :

I. The cover crop prevents the erosion of the soil. Well-cultivated fruit lands are apt to wash away rapidly during spring rains and especially at the time when the snow goes off. Inasmuch as peach orchards are frequently planted on light loose soil and more especially upon high rolling land, they are particularly subject to spring erosion. Very serious damage of this character is to be observed in many American orchards. The erosion trouble is so great, in fact, that it cannot be wholly prevented by the growing of cover crops, but at any rate these crops do serve a very important purpose in preventing the loss of the most valuable upper strata of the cultivated soil. Probably the mild forms of surface erosion which can be prevented by cover cropping are in the aggregate much more serious than the formation of deep cuts and gullies, which have to be corrected by more strenuous measures.

2. The cover crop also prevents the puddling and baking of the soil. These difficulties are not serious on most soils, especially at the period when the land is occupied by the cover crop. Nevertheless many of the light soils used for peach growing do bake, and bake hard, during the latter part of the summer. Such a condition is in a high degree detrimental to the soil and the growth of the tree. It can be almost wholly prevented by the cover crop.

3. The cover crop catches the snow and holds it on the land during winter. It thus prevents the roots from freezing as the frost does not penetrate so deeply into the soil when it has a liberal snow cover. In some northern sections this is a very important matter. The snow itself melting slowly 
in the spring is of some value to the land. The soil always comes out in better condition after a heavy snowfall than when it stands bare during the winter. The cover crop also catches the fall rains and allows them to sink slowly into the soil instead of running off. This may also be of considerable value in certain cases.

4. The cover crop is valuable in catching and holding soluble fertilizers. The nitrates in particular leach away rapidly into the soil. This loss is particularly great during the late autumn when the tree roots are not active. At this time soluble nitrates are almost certain to pass away in the drainage water, or to leach down out of reach unless they are taken up by the roots of cover crops. If taken up by the cover crops, they are held in the roots or the tops and subsequently returned to the trees in a highly available form when the cover crop rots. While this action is important with respect to nitrates, the same process takes place with all other soluble plant foods.

5. The cover crop adds fiber and humus to the soil. This also is a matter of prime importance. The most serious criticism which can be made of a general system of constant tillage in orchards is that cultivation depletes the humus and vegetable matter of the soil. The water-holding capacity of soil is greatly reduced by this means and presently the land becomes dead and lifeless. If it has a tendency to puddle and bake, this tendency is greatly increased. A good heavy cover crop grown annually on an orchard will prevent any trouble of this kind.

6. The cover crop may add to the soil nitrogen which is the most expensive kind of plant food. All the leguminous crops (those belonging to the pea 
family) have this characteristic of appropriating nitrogen from the atmosphere. Under proper management practically all of this nitrogen collected by a cover crop becomes eventually available for the fruit trees. In spite of scientific investigations there is still a great deal of question as to how much nitrogen any particular crop actually secures from the air. It is easy, of course, to analyze cowpeas or clover plants and determine the amount of nitrogen contained; multiply this by the amount of growth in tons to the acre, and say that the crop contains so much nitrogen. The fact is, however, that only a part of this nitrogen really comes from the atmosphere, the balance being taken from the soil. In a great many cases the amount taken from the atmosphere is small or insignificant.

Most of the leguminous crops do not form the necessary nodules to begin the bacterial action required for nitrogen assimilation until the soil has been inoculated with the appropriate bacteria. This inoculation comes about naturally, though slowly, after $a^{\cdot}$ time, but in many cases practical growers have found it desirable to use artificial inoculation. This is best accomplished by the distribution of inoculated soil over the orchard tract. For example, if one is to grow soy beans on land where they have never been grown before, he should commence by sowing a small amount of soil secured from a field where soy beans have been established for some time. By this means the necessary bacteria are introduced and the soy beans thrive from the start and (what is more important) are able to assimilate considerable quantities of atmospheric nitrogen. In actual practice too much faith is placed in the leguminous crop as such, and not enough attention is paid to bringing the cover crop up to its highest 
degree of efficiency as a nitrogen gatherer. At all events, such excellent cover crops as cowpeas, soy beans and the various species of clover do collect hundreds of dollars' worth of nitrogen and present it to the fruit grower without money and without price.

7. The cover crop also makes other plant foods available. In the course of time the cover crop breaks down considerable quantities of mineral matter, and takes up itself such portions of potash and phosphoric acid as are necessary to its growth. When it is plowed into the land these fertilizing elements are offered to the fruit trees in the most available forms.

8. The cover crop checks the late growth of the trees. In the opinion of the writer this point has been over-emphasized by many people, but at any rate it is desirable that the trees should stop growth not later than the middle of August, devoting the remainder of the summer to ripening up their wood and buds. Peach trees are particularly apt to make late summer growth and to go into the winter with large quantities of unripened wood and half-formed buds. Such immature growth is pretty sure to be frozen during the winter, and the tree may be seriously weakened in this way in certain cases. Usually, however, a tree making such vigorous growth will need to be severely pruned, and all the frozen portions will be removed during this pruning, so that the net result is of no serious consequence.

The cover crop may occasionally present some disadvantages. It is, of course, a matter of additional work and expense. The cost of seed itself is an item which cannot be overlooked, as it may amount to $\$ 3$ or $\$ 4$ per acre. Perhaps the greatest damage ever done by a cover crop comes in those 
cases where the crop has been started relatively early under trees bearing a load of fruit. If it begins to make a vigorous growth at the time when the fruit is swelling and ripening, and especially if the weather proves to be dry, the amount of moisture taken from the ground by it is necessarily stolen from the peach trees to the very great detriment of the fruit. In cases of extreme drouth, when it is plain that the cover crop exercises this maleficent influence, it will be a good practice to check the growth of the cover crop by running over it with a roller or even with a mower. It is customary, indeed, in apple orchards to mow such cover crops as buckwheat just before the picking begins, though this is usually for a somewhat different purpose.

\section{THE VARIOUS CROPS}

In view of the fact that the leguminous crops collect nitrogen from the air, they are always to be chosen when possible. It is a fact, of course, that certain non-leguminous crops have especial advantages and may be the best in certain emergencies. Doubtless buckwheat is the most common exception because it possesses advantages of germinating rapidly late in the summer in dry soils, and is especially valuable in breaking up rough soils before they are in a good state of cultivation. The clover crops in particular cannot be successfully used until the land is in a thoroughly good state of tillage. The following are the most important cover crops for use in peach orchards :

I. Cowpeas are used more than any other crop in southern latitudes and are unquestionably the one best crop. They are adapted to nearly all soils, though they are especially at home on light land. 


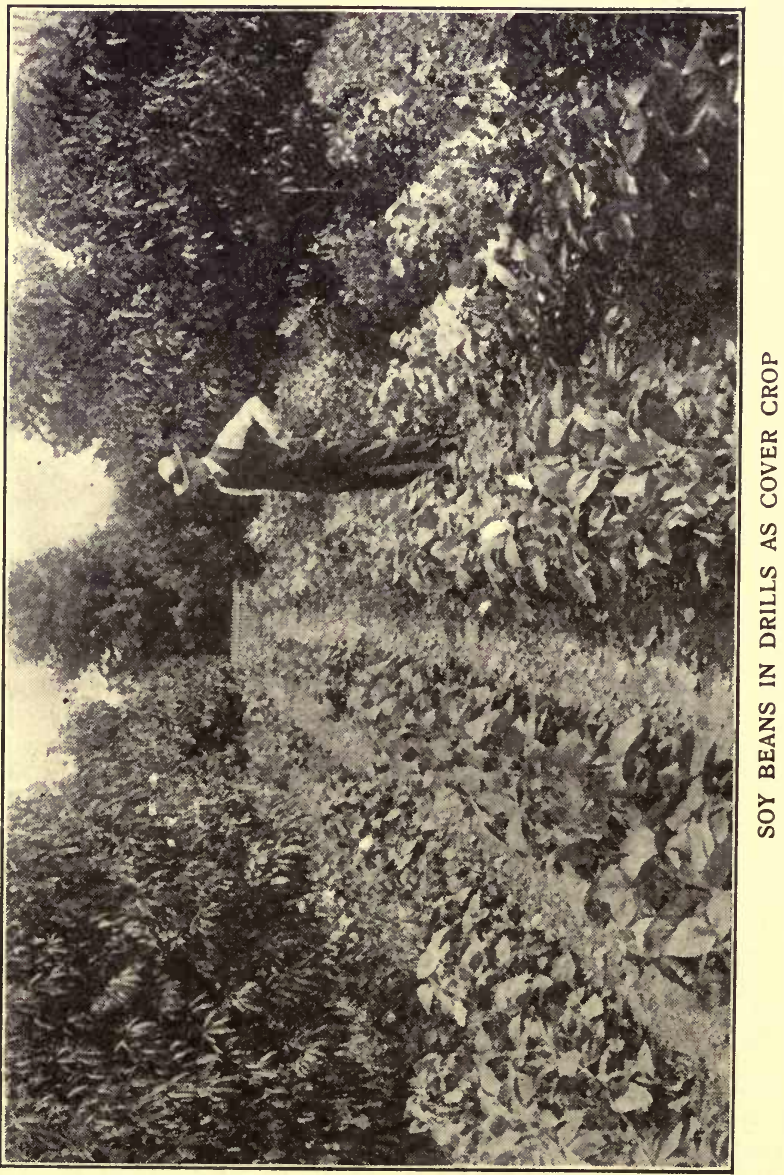


They are valuable in the improvement of run-down soils. They require a long growing season and cannot be used successfully north of New York city and Omaha. In fact, their best use is to be found in the country south of Mason and Dixon's line. As cover crops, nearly all varieties such as Clay, Whippoorwill, Red Ripper and Black, are used. The use of cowpeas in fruit growing and in land salvage generally should be strongly urged on all farmers in the southern states.

2. Soy beans take the place of cowpeas in the North. Care should be exercised to secure the early maturing varieties, as a rapid growth is very desirable in handling the cover crop. They succeed better when they are planted in drills rather than when sown broadcast. In the short growing seasons of northern states, it is desirable to make the tillage season lap over on to the cover crop season by cultivating the beans between the drills once or twice after they come up. In a good many places this method constitutes a substantial improvement of the usual cover crop practice.

3. Other kinds of peas and beans wherever they may be grown are satisfactory as cover crops. Common field peas, or Canadian peas make an excellent cover crop and are used to some extent in Ontario, New York and Michigan.

4. All kinds of clover are excellent as cover crops. On natural clover land in northern states the mammoth red clover is probably the best variety to use. Crimson clover is the great favorite in New Jersey, Delaware and Pennsylvania. In all parts of the country where it succeeds well it is one of the very best crops. It is especially valuable on poor, wornout soils. Alsike clover and sweet clover make fairly good cover crops, but are not to be preferred above 
mammoth clover and crimson clover. One or the other of these better crops can usually be grown in any soil. Alfalfa is sown sometimes as a cover crop, but is not to be recommended for this purpose.

5. The vetches are in some respects the best of all cover crops. They form a close solid mass of herbage which kills out weeds and holds the soil. The winter vetch lives through the hardest winters and makes a quick growth in the spring. The vetches accumulate great quantities of nitrogen under favorable conditions. A great drawback with these crops is the high price of seeds, especially in the case of winter vetch, which costs from $\$ 7$ to $\$ 8$ a bushel and

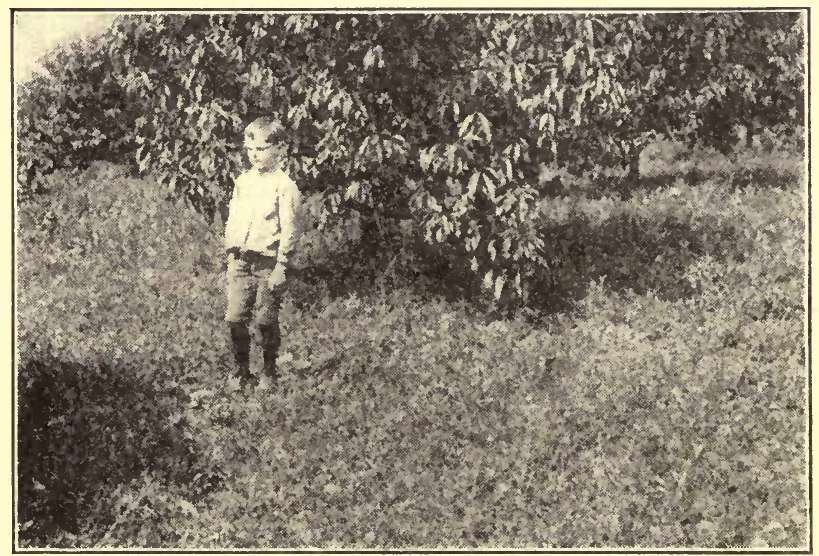

COVER CROPS OF WINTER VETCH

can then seldom be obtained pure. Aside from the difficulty of securing seed, however, the vetch is to be highly recommended as a cover crop in peach orchards.

6. Buckwheat has already been mentioned as one of the best of the non-leguminous cover crops, 
though this preference refers chiefly to the northern and northeastern states. It leaves the soil in excellent condition, and is to be especially recommended on new land which has not been brought into a good state of cultivation.

7. Rye, oats, barley and other cereals are occasionally used as cover crops, but are not to be recommended. Oats are especially detrimental to the land and should never be used. Rye may be sown in emergencies.

8. Corn and cotton are grown to a considerable extent between the peach rows in young or hards in the southern states. These do not constitute a genuine cover crop, however. They are grown, not primarily for the benefit of the trees, but for the sake of producing a marketable product aside from the peaches. They have scarcely any more value as cover crops than cantaloupe, watermelons or potatoes.

9. Rape is sometimes used as a cover crop, and has two genuine advantages; first, that the seed is very cheap (about 20 cents an acre as compared with $\$ 1.50$ for buckwheat or $\$ 3$ for soy beans); and, second, that it lives over winter and comes on promptly in the spring as good as new. It is sown broadcast rather late, say August I to September I. Turnips may also be used as a cover crop.

Io. Weeds are often allowed to come up in the orchard after the end of cultivation and occupy the soil until the beginning of tillage the following spring. A good growth of weeds does constitute a genuine cover crop, and is really considerably better than nothing.

The following table will show the usual amounts of seed to be used on an acre when cover crops are sown : 
QUANTITY OF SEED PER ACRE

Mammoth clover, pounds........ I2

Common red clover, pounds...... I2

Crimson clover, pounds.......... I5

Alsike clover, pounds........... I2

Alfalfa, pounds ............................

Cowpea, bushels ........... I I $12-2$

Soy bean, bushels $\ldots \ldots \ldots \ldots \ldots$ I $1 / 2-2$

Broad English bean, bushels....... I-I I/2

Summer vetch, bushels ......... I I $1 / 2$

Winter vetch, bushels .......... I

Canada pea, bushels ............... I I $1 / 2$

Buckwheat, bushel .......... I

Rye, bushels ................ I I/2

Barley, bushels ............ I $1 / 2-2$

Barley and peas, bushel, each....... I

Rape, pounds............. 2 


\section{VIII}

\section{THE USE OF FERTILIZERS}

AdVANCED agriculture now recognizes everywhere that plant food cannot be removed from the soil indefinitely in the form of crops without jeopardizing the success of subsequent crops. It must eventually be replaced in part by the addition of fertilizers. Moreover, it is perfectly safe to say, as it probably will not hurt anybody's feelings, that no good fruit grower at the present time has any idea of continuing in the business without some sort of fertilization. He expects to feed his trees. There are a good many men, of course, who do not do any fertilizing, but they are either just going into the business or just going out of it, usually the latter.

\section{ELEMENTS OF PLANT FOOD}

The elementary principles of plant nutrition are now pretty well understood by farmers and especially by men who are sufficiently advanced to undertake the commercial growing of peaches. It is known that the important elements of plant food which the tree takes from the soil are nitrogen, phosphoric acid and potash. While other elements are of great importance, and in fact indispensable to plant growth, they are always present in sufficient quantities so that the farmer or the fruit grower pays no attention to supplying them. The fertilizer business is based entirely upon the problem of supplying to the growing plants the three elements named. 
The plant uses nitrogen chiefly in making its growth of wood and leaves. This element is of very great importance and must always be present in sufficient supply. It is easily exhausted, and such exhaustion quickly shows in the growth of the tree. At the same time there is an inexhaustible supply of nitrogen in the atmosphere, though unfortunately it is not readily available. The use of the legumin-

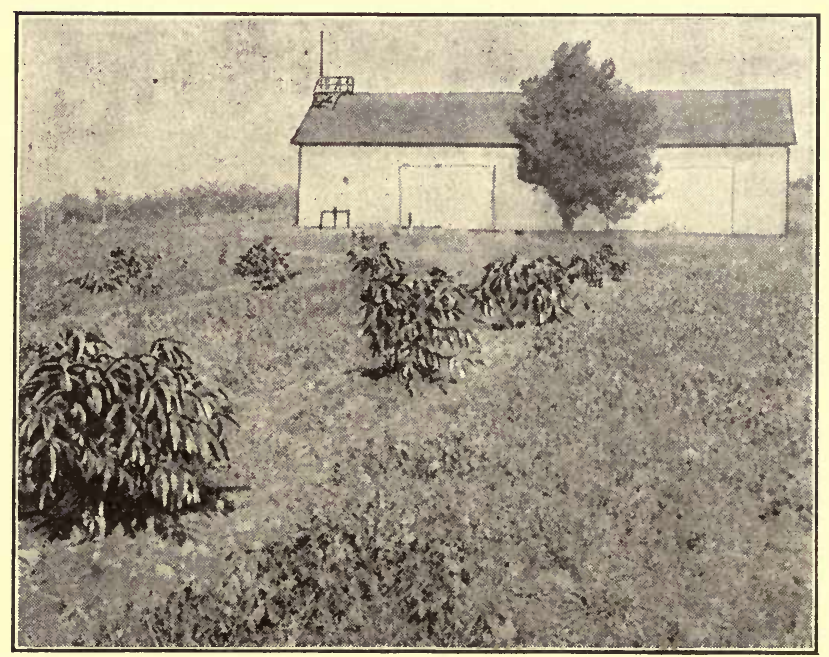

YEARLING TREES-HALE ORCHARDS

ous cover crop is the one well-known method of tapping this atmospheric supply. It is a method which should be used in fruit growing everywhere, and especially in peach growing. In fact, all the nitrogen necessary to many peach orchards upon good soils may be taken from the air by growing good cover crops of cowpeas, crimson clover or mammoth clover. 
Nitrogen is in many ways one of the simplest of plant foods to handle; that is, it is very easy to know when the trees need an additional supply of nitrogen. This may be told both from the growth of stems and the color of the foliage. Whenever a tree is not making reasonably good growth, and when the foliage is sparse and yellow, the need of nitrogen is indicated. Of course, nitrogen may be present in the soil, but unavailable because the roots of the tree stand in water, or for some other reason. Lack of drainage will always interfere with the availability of nitrogen. On the other hand, when a tree is growing vigorously and when the foliage is a thick, heavy, dark green, it is practically sure evidence that no additional supply of nitrogen is necessary In this way the fruit grower is enabled to keep close track of his nitrogen and to add more whenever it is needed.

Phosphoric acid is especially required in building up the fruit and should be given in relatively liberal quantities when trees have fruit ready for maturing. Potash is valuable for the assistance it gives in the physiological processes of growth, enabling the leaves to take up the carbon in the atmosphere. There is also a general theory that potash is very much needed in the formation of seeds and that it should be used liberally, therefore, upon a peach orchard when a crop is maturing. It is thought also to help in giving color. In fact, the general prejudice is strongly in favor of the use of a liberal amount of potash in fertilizers for peaches.

\section{FORMS OF FERTILIZERS}

These various chemical elements are available to the farmer in various forms. Nitrogen, for instance, 
can be bought in the form of nitrate of soda, nitrate of potash, tankage, etc., or it may be applied in barnyard manure. Certain forms are cheaper, while other forms are more effective. Generally the best form in which nitrogen can be bought is in nitrate of soda. This is being used by all practical and up-to-date growers, and while the cost by the ton is rather high, it needs to be used in only small quantities.

Nitrate of potash costs considerably more than nitrate of soda, but the potash is available for plant growth as well as the nitrogen, and for this reason as well as for others a few growers have undertaken the use of this rather rare chemical.

Tankage is a form of nitrogen which can be used in some cases. It is much less soluble than nitrate of soda, and its action is, therefore, spread over a longer time. It is also not so liable to be lost by leaching. Barnyard manure has an excess of nitrogen, and for this reason is not generally well adapted to the needs of orchard trees. However, it gives splendid results with peach trees where it can be supplied. On most fruit farms it is not available in sufficient quantities for orchard requirements, and on general farms it will often do more good applied to other crops, leaving the peach trees to be supplied their quota of nitrogen in the form of tankage or nitrate of soda.

The most common form for phosphoric acid is acid phosphate. This is known everywhere in the fertilizer trade, and is satisfactory for use on peach orchards. Its slight acidity is thought to be objectionable on land which is already sour. On this account a good many growers prefer to use basic slag (Thomas phosphate powder), which instead of being acid, has some lime in it, which helps to 
correct the acidity of the soil. This fertilizer is now becoming available in the United States at fairly reasonable prices. While the phosphoric acid still seems to cost slightly more a pound than it does in acid phosphate, practical growers prefer to pay the difference in a good many cases. Bone is a popular form of phosphoric acid. In many cases its use is economical and advisable. Its composition varies considerably, however, according to the method by which the bone is treated. Steamed bone contains

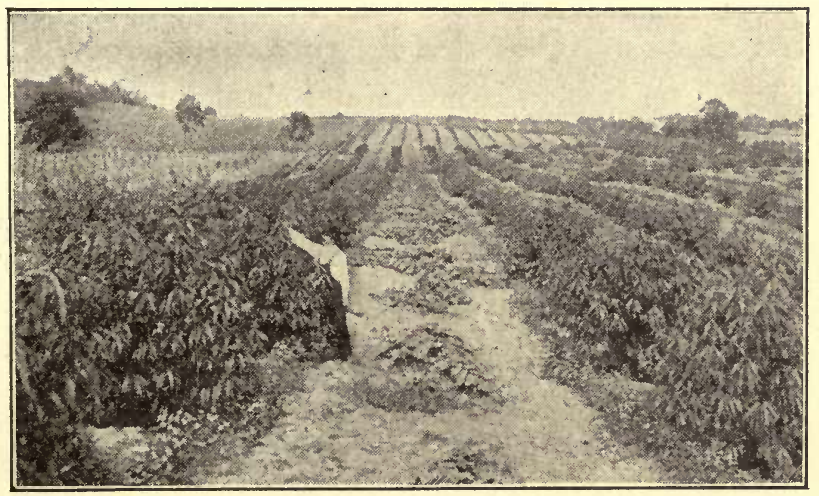

TWO-YEAR ORCHARD INTERCROP SQUASHES

relatively less nitrogen and relatively more phosphoric acid than that which has been ground without steaming.

The form of potash used most is muriate, which in the various grades contains from 45 to 62 per cent of actual potash. The muriate, however, is nearly always mixed with other salts, so that as it is applied to the land there is seldom more than 50 per cent of actual potash available.

Two sulphates of potash are known commercially 
as high grade and low grade. These are sometimes used as substitutes for muriate. Many good growers prefer them in spite of the fact that they cost somewhat more than the muriate. The old-fashioned potash supply came from wood ashes. These are still widely advertised for use on fruit trees, and there is a strong popular prejudice in favor of them, wherever they may be obtained. As a matter of fact, they can be secured only in certain places, and never in sufficient quantity for the needs of fruit growers. Moreover, wood ashes vary so greatly in potash content that they are extremely unreliable. As a rule potash costs more a pound in the form of wood ashes than in muriate or sulphate. The use of ashes has, therefore, been largely abandoned by the most careful fruit growers.

A few words ought to be said in regard to certain other kinds of fertilizers of which one occasionally hears. For instance, lime is often recommended upon fruit plantations, and certainly has its uses. Lime is particularly needed to correct the acidity of certain soils, for when the soil is acid it is inimical to all the physiological processes of growth in the fruit tree. For the purpose of correcting the acidity of the soil, lime may be applied at the rate of half a ton or more to the acre.

Kainit is a native potash-bearing rock which comes from Germany. It supplies a crude form of potash fertilizer and has been used to some extent because it sells for such a low price by the ton. The amount of real potash in it, however, is so small that the actual cost of plant food is considerably greater than in the more expensive forms of potash fertilizer. It is now never recommended and is not popularly used. 


\section{ACTUAL PRACTICE}

It will be very interesting at this point to see what the fruit growers of the country actually do in fertilizing their peach orchards. In a recent inquiry which the writer made among the peach growers of the United States and Canada, about I5O gave definite statements regarding their methods of fer tilization. The following tabulation shows the number of times each type of fertilization was mentioned in the replies:

None whatever .............. 69

Barnyard manure .............. 43

Mixed commercial fertilizer ........ 7

Cottonseed meal ............... 2

Tobacco dust ................ I

Lime ..................... 4

Nitrate of soda ................ 6

Ground fish ................ I

Potash, mostly muriate ......... 47

Nitrate of potash ............. I

Sulphate of potash .............. 4

Kainit .................... 3

Ashes ..................... 22

Acid phosphate ................ I3

South Carolina rock ............ 4

Bone ......................... 30

"Potash" .................... Io

One of the most remarkable things in this tabulation is the amount of bad practice shown. The fact that something over one-third of the peach growers who testified admitted that they used no fertilizer whatever is a very bad showing. The fact that 43 others used barnyard manure, which is not well adapted to the practical needs of 
peach trees, and one of the most wasteful that a farmer could use, is also very depressing. Not one grower mentioned basic slag, which is known to be one of the best peach tree fertilizers, and only

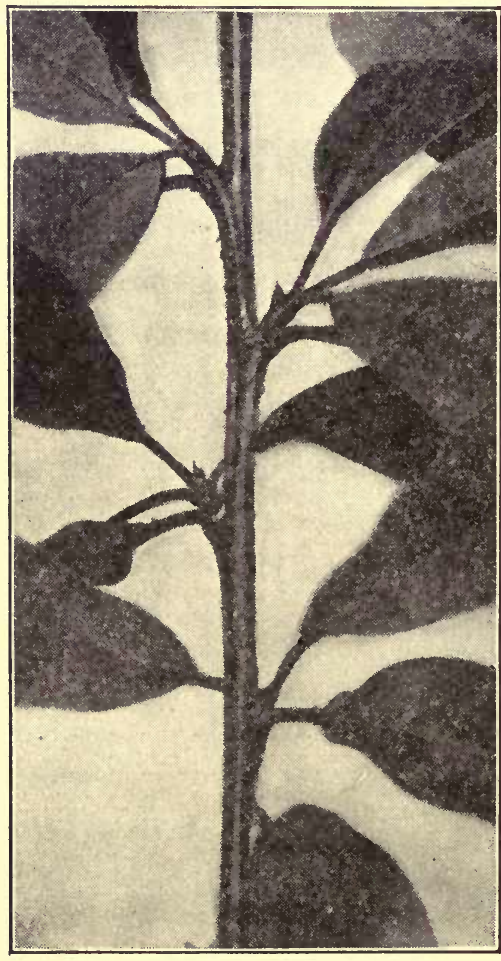

DUPLICATE LEAVES INDICATING GREAT VIGOR six men mentioned nitrate of soda, which is also one of the best things a $f r$ u it grower can have on hand and one which every fruit grower ought to use from time to time. The number of times which ashes are used also indicates a poor state of practice in this matter.

SPECIFIC FORMULAS

If we take up now the problem as to just how much of which kinds of fertilizers are to be applied annually to a peach orchard, we will find various recommendation s given by different men. The discrepancies, however, are not very serious, and are to be explained very largely by differences in soil and climatic conditions under which these recommendations have been given. Prof. M. A. Blake, of the 
THE USE, OF, 作RT

New Jersey Experiment Station, recommends that the following kinds and amounts of fertilizer be applied to each acre of the peach orchard annually and plowed under:

Sulphate or muriate of potash, I50 pounds.

Ground bone, Ioo pounds.

Acid phosphate, 200 pounds.

Where the soil appears to be deficient in nitrogen, especially if the trees fail to make a satisfactory growth the first season, he recommends that I 50 pounds of nitrate of soda to the acre be added to the above formula. For the first two or three years, during which time a vigorous growth is especially to be desired on young peach trees, the addition of a fair supply of nitrate of soda is rather important with this formula. When the trees come into bearing it is necessary to reduce the amount of nitrogen, or at least the proportion of nitrogen. It is possible for bearing trees to make too much growth. Excessive growth may interfere with the ripening of the current crop, and also with the formation of fruit buds for the succeeding crop.

Voorhees states in his textbook on fertilizers that on good soil no added plant food is needed on peach trees until the third year, but this must be understood with reference to potash and phosphoric acid rather than with reference to nitrogen, for a certain amount of nitrogen will certainly be required. On poorer soils, he would use equal parts of raw ground bone, acid phosphate and muriate of potash, applied at the rate of 400 to 600 pounds to the acre annually. He recommends that this amount be somewhat increased, and from 100 to 150 pounds of nitrate of soda added in those years when a heavy crop is expected. However, he emphasizes the danger of 
excessive wood growth caused by late applications of soluble nitrogen.

Mr. George D. Leavens, fertilizer expert, recommends the use of Thomas phosphate powder (basic slag) in connection with sulphate of potash. His general method of procedure would be to apply the

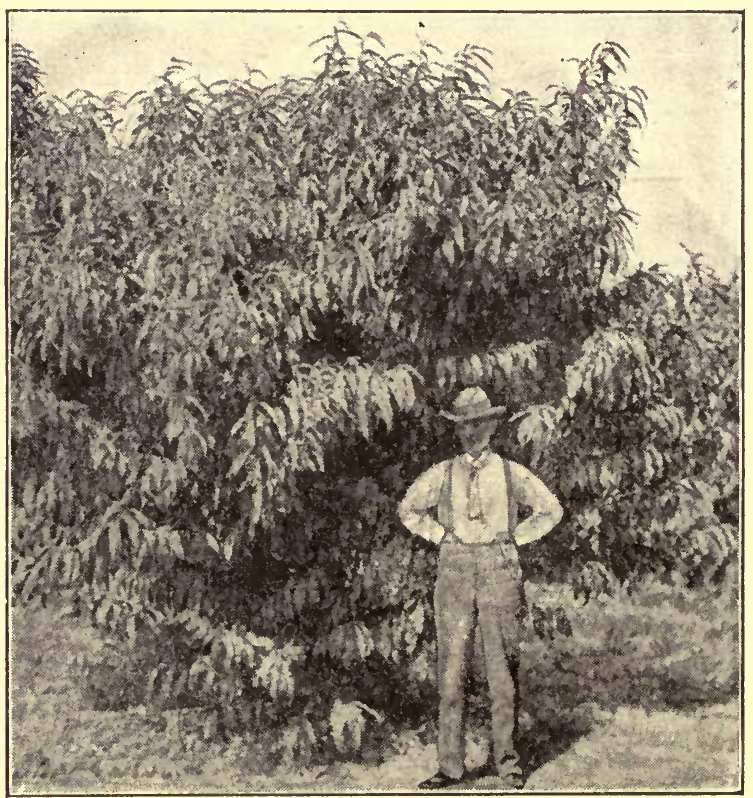

WELL-GROWN WELL-FORMED TREE

phosphate powder first at the rate of $I, 000$ pounds or more to the acre. After the first annual application 500 to 600 pounds an acre a year is thought to be sufficient. The first application of sulphate of potash he would give at the rate of 200 to 300 pounds an acre, reducing this to 200 pounds an acre a year after the first application. He would also use nitrate 
of soda, as would be indicated by the wood growth from year to year. Following the customary practice among good growers, he recommends the use of a cover crop such as cowpeas, clover or vetch to furnish as much additional nitrogen as can be secured in this way. Mr. Leavens also believes that nitrate of potash may be valuable in some cases.

In our own orchard our practice is to give each tree one ounce of nitrate of soda at the time it is set out. This is sprinkled on the soil about the tree as soon as the planting is done. The orchard is gone over later in the summer and a second application of nitrate is given to such trees as seem to be needing a little help. The second application may be from one-half ounce to one ounce to the tree. Soon after the first application of nitrate the trees are given one pound each of a mixture made from 300 pounds sulphate or muriate of potash and 500 pounds of basic slag.

The second year each tree gets from one to two ounces of nitrate, depending upon the indications. It is expected to get also two pounds of the mixture of muriate and slag mentioned above. In succeeding years the amount of nitrate is regulated chiefly by the growth of the trees, while the amount of the potash and slag mixture is increased at the rate of about one pound to each tree for each succeeding year. When the trees come into bearing, however, they are expected to have approximately 800 pounds an acre a year of the mixture already described; that is, three parts of muriate or sulphate of potash with five parts of basic slag.

The fact is that no very definite rule can be laid down for the fertilization of any crop, least of all for such a crop as peaches. Soils and climates vary greatly, and the variations of the soil and soil till- 
ing have a great influence on the methods of fertilization. Furthermore, the tastes and ideas of men vary, and these personal factors have to be taken into account also. They are of the greatest significance in fruit growing, for after all the man is more important than the soil, the climate or the peach tree. 


\section{IX}

\section{PRUNING AND RENOVATION}

THE peach tree requires more pruning than almost any other orchard fruit. It grows rapidly and is subject to many diseases and accidents which make pruning desirable. While many apple growers find it possible to continue in business with some profit for years without pruning their orchards, ' no one thinks of conducting a peach orchard in this manner.

It must be admitted, however, that with all this need of pruning no very definite or very reliable system has been evolved in the United States. We cannot even say that any practical peach grower in the country has settled upon a complete and satisfactory pruning system. Even the best growers, while they have fairly definite ideas of what they are trying to do, are ready to confess that there is a good deal more that they do not know. They are still blundering along pretty much in the dark. Out of this general mass of ignorance and diverse practice it is very hard to generalize a system of rules which may be confidently recommended to the novice. A few suggestions can be made, but the pruning of peach trees has got to be worked out largely by experience, every man for himself. This may not be a very encouraging way to put it; and certainly one who writes a book on peach culture ought to pretend to know all about the subject, but such a pretence would be the merest hypocrisy.

Pruning begins, of course, the moment the tree is planted, or even before. The tree is cut back at the time it is set with a special view to the 


\section{FORMING THE TREE}

formation of a new head. We may say that on this one point the practical peach growers of America are fully settled, that is, on the desirability of forming the head very low. While a few growers of apples and pears and plums still believe in developing forest trees with tall trunks, the peach growers have learned better. In the replies to a recent questionnaire from which the author received much valuable information from peach growers all over the United States, this desirability of forming the heads low was repeatedly asserted. Many

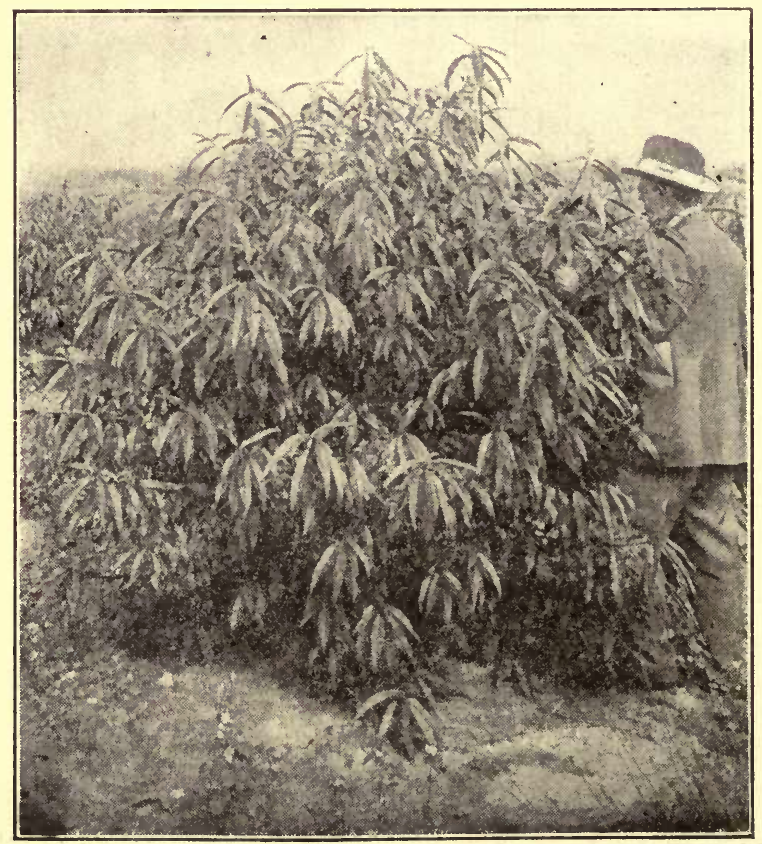

PROPERLY FORMED TREE AT TWO YEARS 
of the growers specified the height at which they preferred to have the heads formed. Out of 280 replies given in definite figures the very great majority believed in forming the heads at 2 feet or less. It is interesting to look over a tabulation of these replies, which stands as follows:

\begin{tabular}{|c|c|}
\hline $\begin{array}{l}\text { Head at } \\
6 \text { inches, }\end{array}$ & $\begin{array}{l}\text { Number of } \\
\text { recommendations } \\
\text { I0 }\end{array}$ \\
\hline I2 & 34 \\
\hline I8 & 88 \\
\hline 24 & 86 \\
\hline 30 & 34 \\
\hline 36 " & 18 \\
\hline 48 & 8 \\
\hline 60 “ & 2 \\
\hline
\end{tabular}

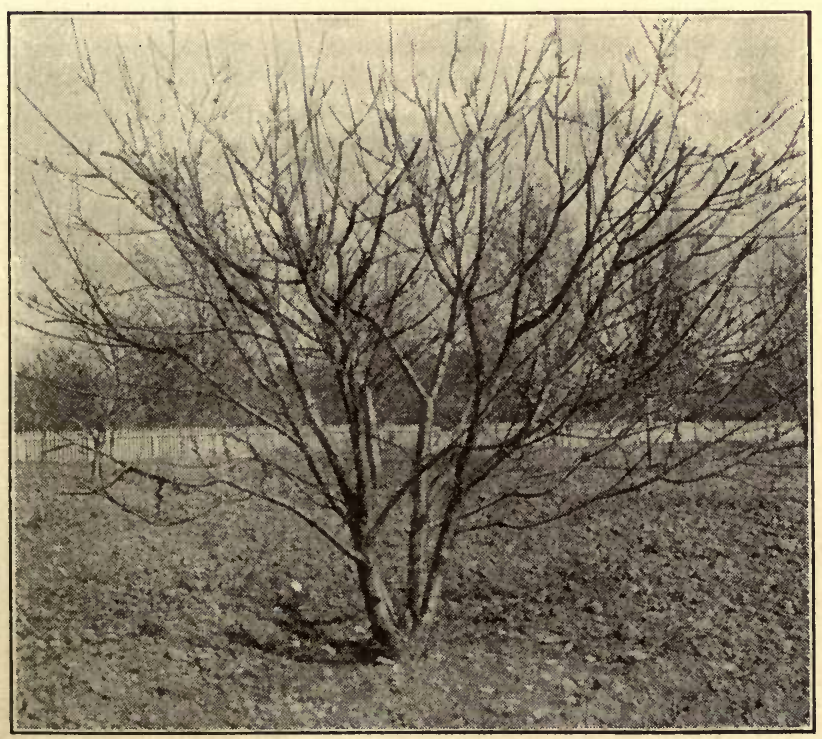

A GOOD LOW-HEADED TREE 
108

While this table shows a very striking preference for low heads, it does not do full justice to that opinion as expressed by my correspondents. A large number, in reply to the question as to how high they

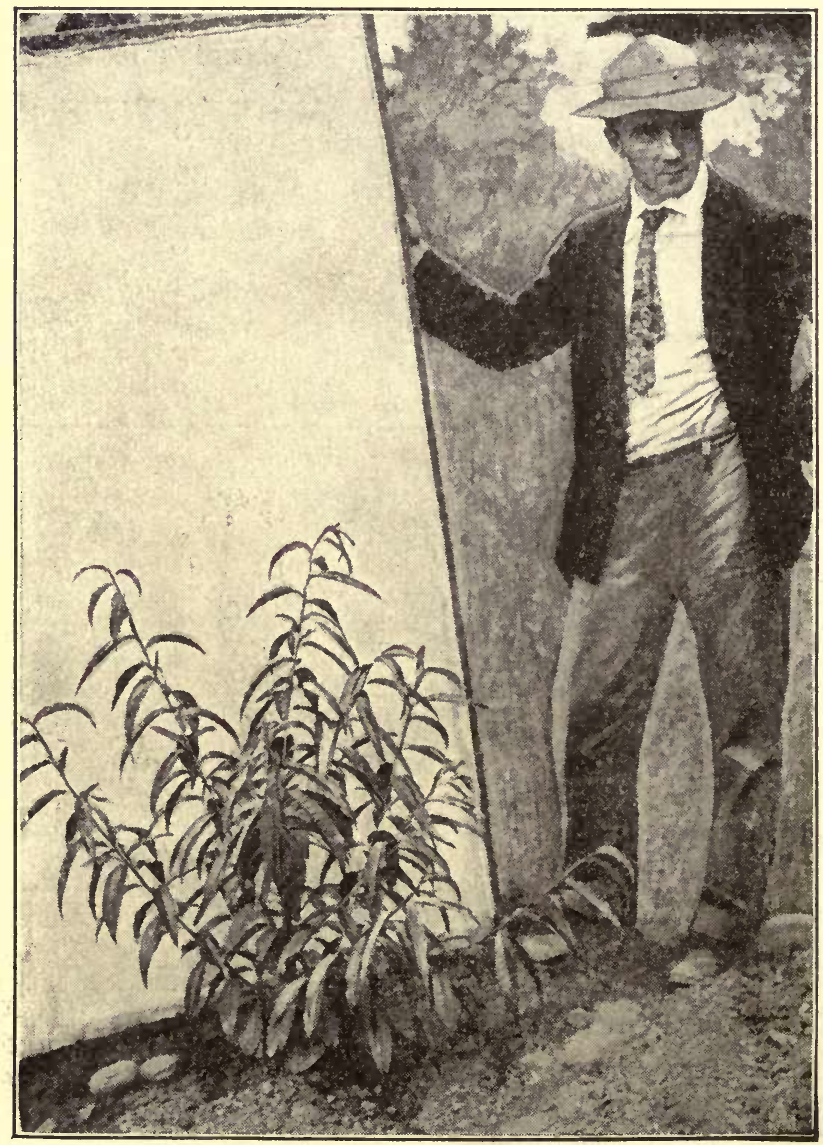

'HEADED TO THE GROUND AT PLANTING 
would head young trees, simply said "low" or "very low." There was some reason to suspect, also, that most of the men who recommended heads 4 to 5 feet

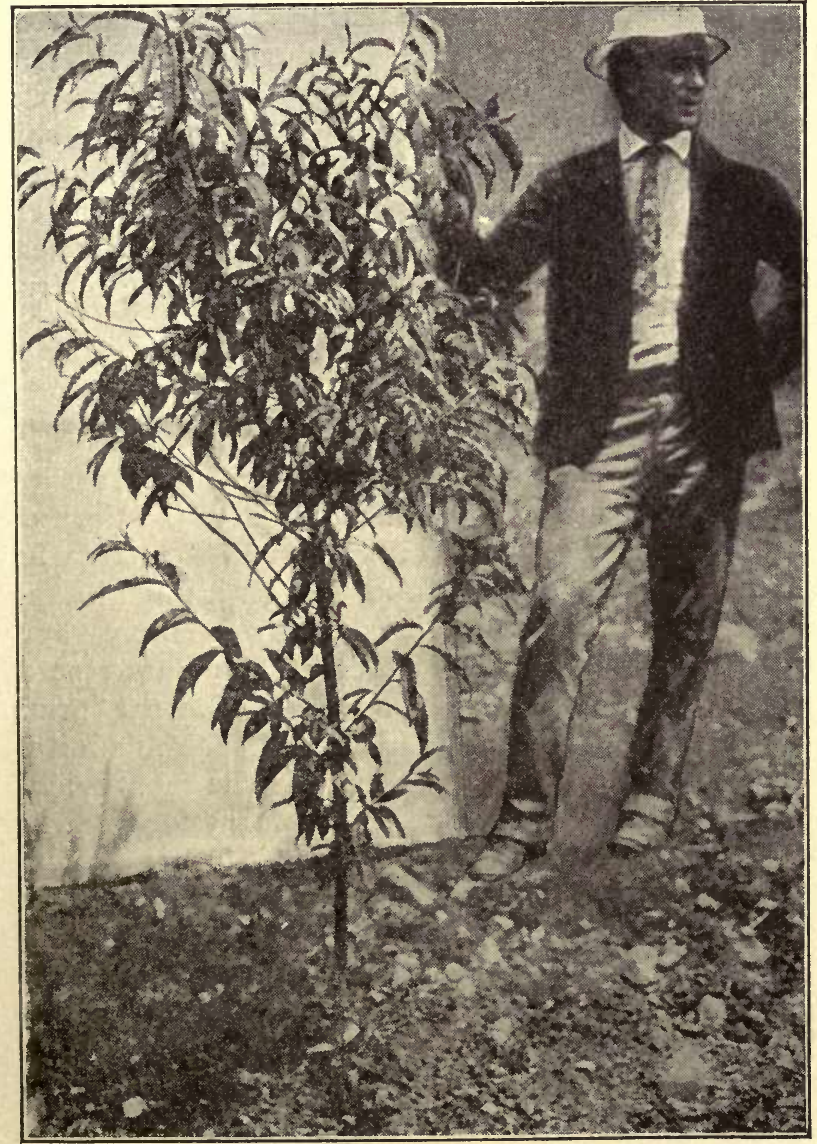

LEFT UNPRUNED AT PLANTING 
high misunderstood the question. The writer tends strongly toward the minimum heights here mentioned. His recommendation would always be to head young peach trees at a height of 6 to I 2 inches from the ground.

The advantages of low heading are many, and are more serious in the case of peach than of any other fruit tree. The peach tree forms poor, weak, brittle crotches which are particularly liable to split down when weighted with a load of fruit. When the head is formed at the surface of the ground or very near it the crotches are stronger than when the head is high. All sorts of damage by overloading of fruit or ice is greatly reduced.

FORMING THE HEAD

After the tree has been started on its very short trunk, the fruiting head has next to be formed. Different growers have different ideals as to what form these heads should take, though it must be said that a good many men's ideals are extremely vague on this point. Many of the correspondents already referred to gave their opinions also as to the formation of peach tree heads. Fourteen spoke definitely in favor of the vase form, which is the most widely known and definitely recognized form for growing peach trees in orchard plantations. Other growers spoke of growing trees in pyramidal form or cone form ; and it may be suspected that they had in mind the cone or the pyramid inverted, as there is really no such thing as a pyramidal peach tree in bearing. Among these curiosities of nomenclatures were also nine recommendations for the "umbrella-shaped" tree. These men probably had a vague idea of the vase-formed peach tree. Adding together the num- 
ber of men who spoke for vase, pyramid, cone and umbrella-shaped trees, we have 26 , or enough to say that this is widely recognized as a proper shape to give a bearing peach tree.

Several growers said that they pruned their trees in such a manner as to secure a spreading tendency of the top, and somewhat the same idea obviously belongs to those men who recommended an open top. The largest number of replies in the whole series definitely recommended the open top. A very large number also spoke emphatically in favor of the low top. These replies may be summarized briefly as follows :

\section{FORMS OF BEARING TOPS}

Spreading tendency desired..........6

Upright tendency favored ........... I

Low heads desired .............. 35

Open heads desired $\ldots \ldots \ldots \ldots \ldots \ldots .66$

Vase forms ....................26

Goblet or globe forms ............ 3

Dehorn every four or five years....... I

Not much of any pruning........... 3

This little tabulation really gives a pretty fair view of modern American practice in peach tree pruning.

\section{THE FRAME WORK}

When the task of forming the head in any desired shape actually begins, it is necessary first to secure a suitable framework. This is commonly built upon three or four supporting branches set out from the original stem as near as possible to the surface of the ground. These main laterals should be formed 
during the first year of growth in the orchard, and considerable pains should be spent at this time to see that a proper beginning is made.

In the first place, the tree should be kept growing vigorously in order that a sufficient number of straight, clean branches may be thrown out. It is then well worth the time and money which it costs to go through the orchard two or three times during the growing season, rubbing out by hand weak, misplaced shoots. Early in the season the tree grower can select the three, four or five desired main shoots, seeing that they are symmetrically placed. All the others can be quickly snipped out or broken out with the bare hands. It is much more difficult to make such selections if the work is left until the following spring, and if it be neglected for two or three years, a proper framework can never be designed.

At the beginning of the second spring each young tree should, therefore, consist of a very short central stem surmounted by three, four or five, preferably four, fine, strong, fairly upright lateral shoots. These should be symmetrically placed so as to carry the well-balanced head. The shoots should vary in length from 8 inches to 2 feet, a fair average growth being 12 inches. Early in the spring they should be gone over with a pair of hand pruning shears, the main shoots shortened in one-third to one-half the previous year's growth, and the whole head shaped up as smoothly as possible. The orchard should then be gone over from one to three times during the growing season of the second year. At these prunings, the growth of the tree can be consistently regulated, the general ideal being to secure two or three clean, straight, well-placed secondary branches on each of the main laterals of the year before. 
After the second year, attention will be given merely to keeping the heads clean and open, to removing injured and crossing branches and to the general development and maintenance of whatever ideal the fruit grower has set before him.

Of course, the most precise and definite forms ever given to peach trees are those developed in formal fruit gardens of the European style. These trees are usually dwarfs, being preferably propagated on some species of plum stock. They are then trained against walls or trellises or along wires in hothouses. The fan form is the one usually adopted for the peach or the nectarine, though the simpler espalier forms may be developed if sufficient care is given. However, these artificial forms for the training of peach trees have little value in American practice, and none whatever in commercial peach growing.

\section{HEADING IN}

It is very desirable to keep the peach tree heads within the smallest practicable compass. I have seen large orchards of thousands of trees in full bearing where the entire crop could be harvested without the use of a single stepladder. This is a great advantage and economy in every way. In order to keep trees within this small compass, though, it is necessary that the head should be frequently. and rather severely cut back. On the desirability of this point there seems to be little difference of opinion, but a considerable diversity of practice in the methods of securing the result.

Many growers recommend that the annual growth of the tree be headed in from one-third to one-half its entire length. This is perhaps as good practice 
as can be stated in a single rule and in general terms. However, even at this rate the trees will still soon outgrow their bounds and will require additional shortening. In districts where an occasional crop is lost through frosts or winter freezing, advantage is taken of the fallow year to cut back the trees much more severely. Considerable portions of the heads are removed, the operator cutting back into wood two, three or even four years old. Such severe pruning, however is hard on the trees and tends to make them shorter lived. It may be worth doing in spite of that fact, inasmuch as the peach is a short-lived crop under any circumstances.

\section{SUMMER PRUNING}

This necessity for the repression of growth in the peach tree has caused many practical men to experi-

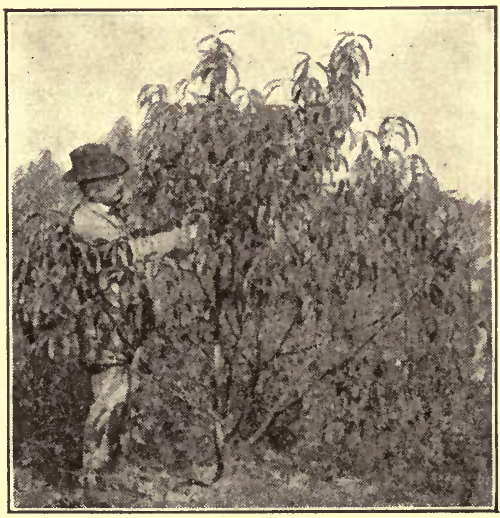

TWO-YEAR PEACH TREE ment carefully with summer pruning. In fact, this method of summer pruning is coming into considerable favor in the best peachgrowing sections, though it must be confessed that no one has a very satisfactory and wellsettled system of carrying on $t h e$ work.

Summer pruning should be practiced relatively early in the growing season, that is, when the shoots have made about 
two-thirds of the annual growth. In central latitudes, such as New Jersey and Pennsylvania, this will mean June $I$ to $I 5$. In southern latitudes the work will fall from two to four weeks earlier.

The summer pruning gives an opportunity for curing any defects of growth; so the first work to be given to each tree should be directed to the removal of suckers, water sprouts and badly placed limbs. The remaining work is of two sorts; first, the removal of entire undesirable branches; second, the heading back of well-placed branches which are to be left. Both methods are extensively used.

The removal of entire branches may be very rapidly done, usually with gloved hands instead of with pruning tools. This is the best opportunity of all for keeping the center of the tree open. The center of the tree will usually be found filling up with soft, weak shoots which take more food material from the growth of the tree than they return. These can be broken out very rapidly and effectively with the hands.

Especially on young trees, however, the method of heading back growing shoots may have considerable value. Well-placed shoots which have made a growth of 2 feet or more will be much better off if the tops are broken or snipped off during this general pruning. Commonly a few side buds will start into growth, but the shoot will ripen up and will become much stockier than if left to grow throughout the season. When left without heading back, a large part of the shoot has to be removed and thrown away the succeeding spring.

In theory, this summer pruning has a tendency to check the superabundant growth of the tree, to encourage the formation of fruit buds and to make the tree generally more fruitful. When the work is done 
carefully, it doubtless has this result. It is possible, however, by summer pruning to force a weak growth from side buds which might otherwise develop into fruit buds. Such a course naturally tends to diminish the fruitfulness of the tree.

\section{SPECIAL PRUNING PROBL.EMS}

It often happens that trees are seriously damaged by wind storms or ice storms or are badly broken down under heavy loads of fruit. Such injuries have to be remedied as far as possible by pruning. Dead and broken branches have to be taken out. No directions have to be given about this work, as it is a matter of individual judgment in each case.

Another problem which arises frequently is that of handling orchards that have been severely injured by winter freezing. Trees in such orchards are usually very much weakened. They always recover with difficulty, but in many instances die. Rather extensive experiments have been made all over the country in dealing with cases of this kind. It has been found that a moderate heading back is the best pruning treatment which can be given. Trees severely headed back or dehorned rarely recover and never make desirable trees even when they live. On the other hand, frozen trees which are left without any pruning are not able to support the entire old top. The growth starts very weakly and irregularly. Trees which are headed back rather evenly to wood of two or three years usually make a well-balanced growth and soon recover. The recovery is not always complete, but is nearly always better than under other methods of pruning. 
The reclamation of old, neglected peach orchards is sometimes worth while. It is not, however, so promising or profitable a practice as the renovation of old apple orchards. Peach trees, which have simply been neglected for two or three years, which are on good land, which are good varieties, which are under no or I2 years of age, and which are not seriously attacked by yellows, little peach or San José scale, can

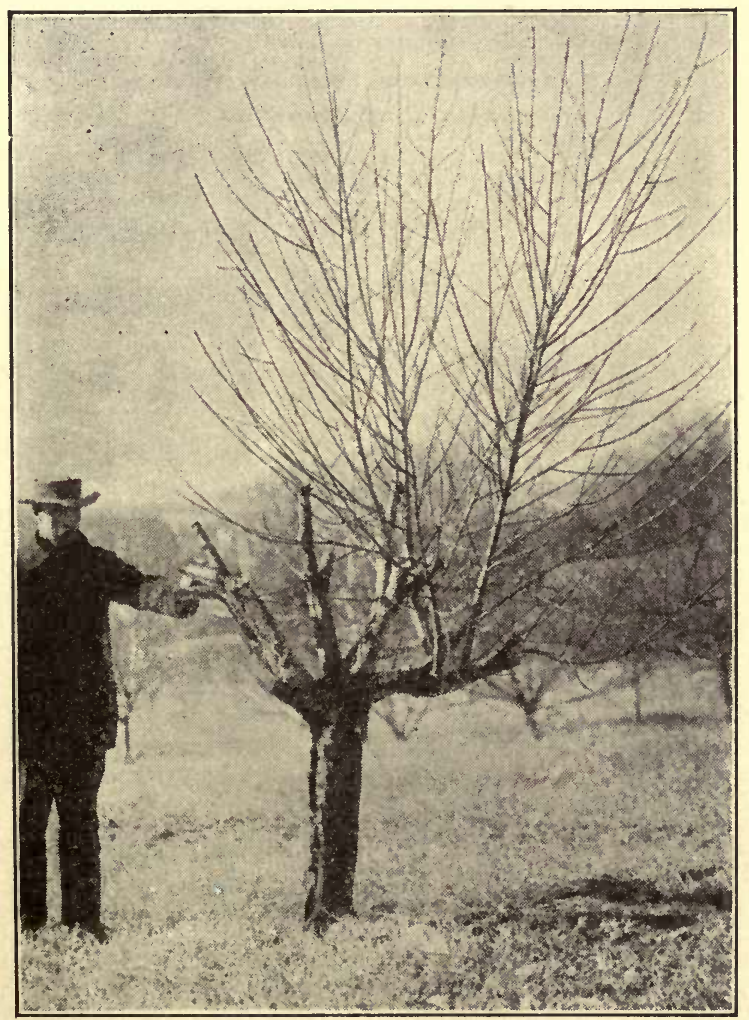

A "DEHORNED" TREE-IT HAS FAILED TO MAKE A NEW HEAD 
be brought around for a few years of profitable business.

Efforts should first be directed to cleaning up the ground and putting the soil under a good system of clean cultivation. The trees should then be moderately headed back, the pruning following rather closely the lines suggested above for the treatment of frozen trees. A severe spraying campaign should follow, directed toward the subjugation of scale and other insects and the elimination of fungus diseases. This work can usually be begun in the fall or the winter. Profitable results should show within two years. Two or three market crops, however, are all that any man should expect to receive from any orchard saved from a term of serious neglect or experience of severe winter freezing.

\section{PRUNING TOOLS}

Probably the best of all pruning tools is the human hand. The important work of summer pruning can be very largely accomplished with it alone; and if the workman finds it a trifle wearing on his bare palms, he can put on a pair of coarse gloves such as western cornhuskers wear. Then the work will go as easily as any labor ought to.

Next to the original implement the best pruning tool is the hand shears. These are made in various sizes and at various prices, but the shears of medium weight and very best manufacture are best. At least it does not pay to buy the cheap hand shears sometimes offered in the department stores.

Larger shears to be operated with two hands are sometimes convenient. More generally useful, however, is the tool known in all the catalogs as a pole pruner. This has a handle in the form of a 
pole 6 to 12 feet long. The cutting blade works within a sort of hook at the top, and is actuated by a wire running down to a hand lever near the base.

Pruning saws should seldom be used in the peach plantation, but in some instances they are, of course, necessary. They should be light and strong, of the best steel, with coarse teeth and wide "set." The coarse-grained brittle character of the peach wood makes the coarse saw almost indispensable.

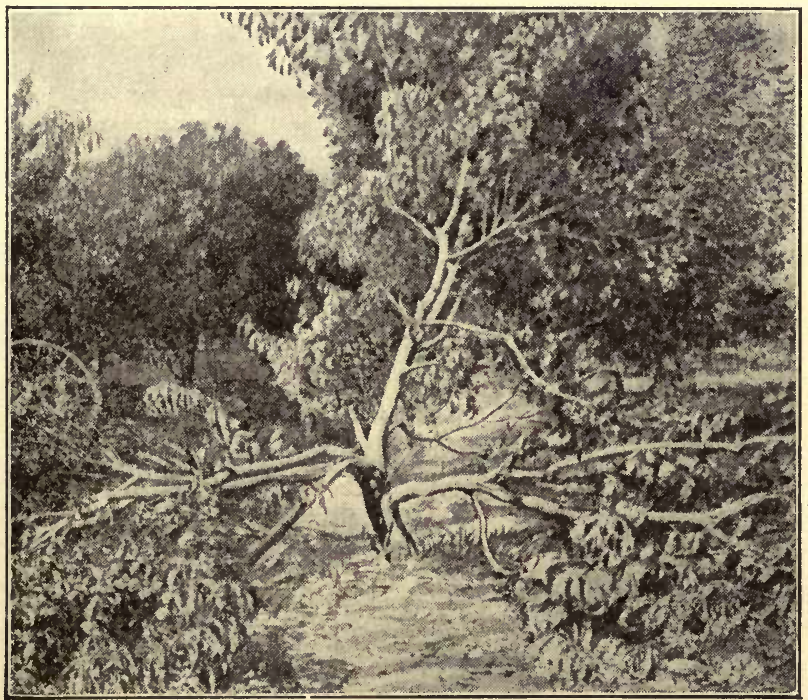

BROKEN DOWN BY OVER-BEARING 


\section{$\mathrm{X}$ \\ INSECT ENEMIES}

IT IS often said that the insect enemies of all crops are constantly multiplying in these latter times and that the modern farmer has a great deal more to contend against than his grandfather used to have. While this view of the case is usually exaggerated, it still has some foundation. At any rate, to grow regular crops of fancy fruit which will grade up to the requirements of the best markets, requires constant vigilance. The fruit grower today must be acquainted with a considerable number of insect enemies, must be able to recognize the work of each at a distance and must be ready to meet these foes in an effective manner.

The most serious enemies of the peach are the San José scale, the peach borer, the peach lecanium, the plum curculio and the fruit bark beetle. Fortunately there are few orchards where all these insects operate at once, yet the orchards which are free from serious attacks by some of these are even more rare.

\section{SAN JOSE SCALE}

Unquestionably the San José scale should be awarded the first place among injurious fruit insects. Its geographical range is almost exactly the same as that of the peach tree. Thousands of peach orchards have been killed out entirely by this enemy; others have had their lives seriously threatened; many crops have been ruined; others have been partly 
damaged. Everywhere the scale is a source of expense and anxiety to the peach grower.

The scale is most easily seen on the fruit, which when attacked is marked with small red circles around the scales. The fruit, however, is not attacked until the tree is already pretty well infested. The fruit grower must learn, therefore, to recognize the presence of the scale on the twigs. Here it may be seen as a rough, grayish, scurfy covering readily recognized after one has become acquainted with it.

The San José scale need not be mistaken for any other scale insect. It is much smaller than the other kinds commonly seen on fruit trees, being rather smaller than a pinhead. It differs also from most other scales in being distinctly circular, whereas most species are oblong or oyster-shaped. It is also black with a dot or pimple in the center, giving it somewhat the appearance of a fungus pustule.

The insects hibernate under these scales and begin their activities about the time the sap starts in the spring. Early in the summer the adult insects emerge and the females produce their young, which resemble small yellowish mites, and which move about on the tree looking up fresh fields and pastures new. As soon as they find suitable territory, they settle down and work their beaks into the bark or the young fruit and proceed to suck the juices of the tree. They begin at the same time to form waxy coverings which rapidly harden, turn dark colored and constitute the protecting scale over them. They are extremely prolific. The progeny of a few scattering San José scale will infest a whole orchard within a year or two.

Fortunately this insect can be successfully held in check by constant and persistent spraying. Experience indicates that the so-called soluble oils and 
the lime-sulphur mixtures are the most effective remedies. Extensive experiments have been made in summer spraying, especially with the lime-sulphur sprays. While a few careful operators have shown excellent results by these methods, it cannot be said that summer spraying has proved a general success against San José scale. Present prac-

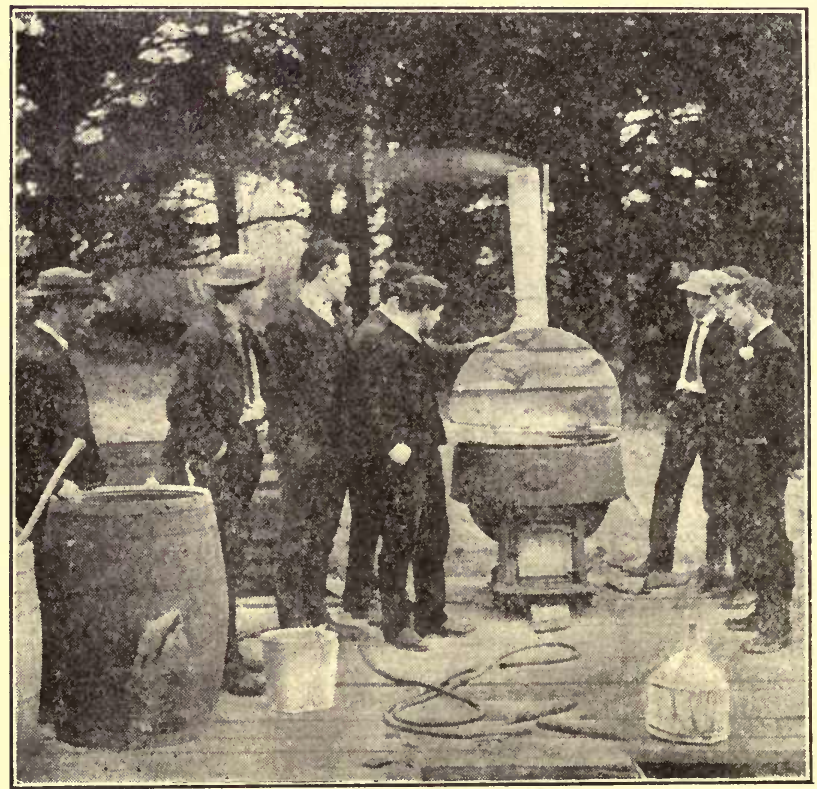

BOILING LIME-SULPHUR

tice puts the chief emphasis on the theory of a thorough spring spraying, which is given about the time the snow goes off the ground and before the buds start into growth. In cases of very severe infestation, it is feasible to spray the orchard heavily 
late in the fall after the leaves have dropped and again in the spring in the usual manner.

Orchards which require a systematic San José scale campaign should first be thoroughly pruned. The tops of the trees should be shortened and old broken branches cut out, reducing the area to be sprayed and facilitating the work of the sprayer. Where a regular annual spraying is given, as it must be in the San José scale districts, it is highly important to keep the trees pruned in this compact form and to keep the heads open and clean.

\section{LIME-SULPHUR WASH}

This spray solution is used chiefly for killing the San José scale, and has been found on the whole the most efficient spray for that purpose. The recipe is as follows:

Fresh stone lime ............... 6 pounds Flowers of sulphur, or sulphur flour..... I5 pounds Water ....................... go gallons

Flowers of sulphur usually cost a little more than the sulphur flour, but should be preferred when the solution is to be cooked over a fire in the kettle. When the solution can be cooked with live steam, which is the better way, the cheaper grades of sulphur are equally available.

Begin by slaking the lime in a small amount of water in a large iron kettle. When the slaking lime generates a considerable amount of heat, sprinkle the sulphur in gradually, thus utilizing the heat of the lime in cooking the sulphur. At this stage, a fire should be made under the kettle and the solution kept up to the boiling point, adding the water a little at a time. Vigorous boiling should be main- 
tained for about an hour, at the end of which time the solution will become a dark orange color and should have very little sediment at the bottom. Whether it shows sediment or not, the solution should be strained through a fine strainer into the spray tank and used while still hot.

There are several forms of ready-made lime-sulphur on the market; some of these are fairly good,

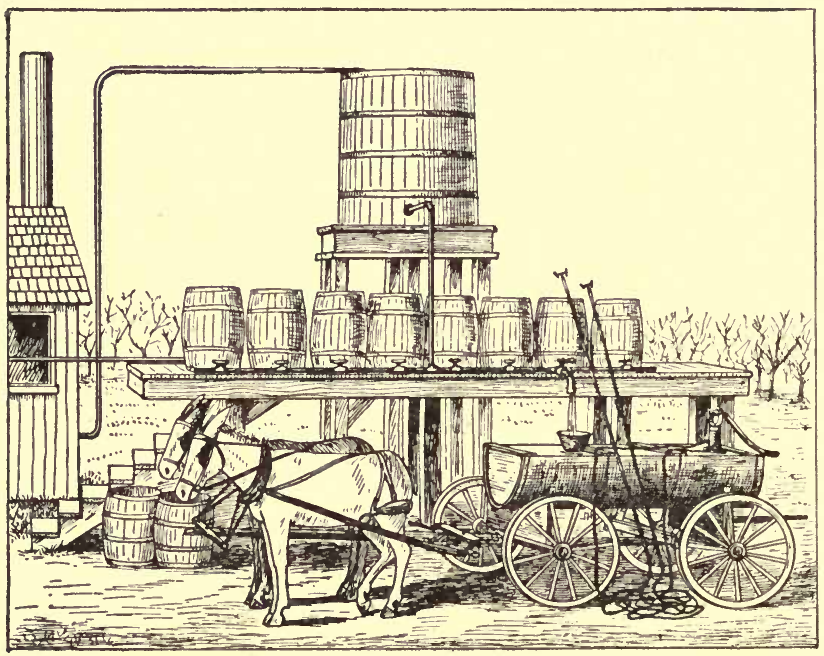

COOKING PLANT FOR LIME-SULPHUR

but none of them has yet been found equal to the freshly made solution described above.

\section{SELF-BOILED LIME-SULPHUR}

Another method of making the lime-sulphur spray produces what is called the self-boiled mixture, which seems to have properties considerably different from the mixture described above. This self- 
boiled mixture seems to be especially valuable as a fungicide, particularly on the peach. It controls the leaf curl, the brown rot, the scab, and, when arsenate of lead is added at the spraying after the blossoming season, the curculio also. The most recent methods of making this mixture, as worked out by Scott and Ayres of the United States Department of Agriculture, are as follows:

The 8-8-50 formula is recommended. .This mixture can best be prepared in rather large quantities - say enough for 200 gallons at a time, making the formula 32 pounds of lime and 32 pounds of sulphur, to be cooked with 8 or Io gallons of water, and then diluted to 200 gallons.

The lime should be placed in a barrel and enough water poured on almost to cover it. As soon as the lime begins to slake the sulphur should be added after first running it through a sieve to break up the lumps. The mixture should be constantly stirred and more water added as needed to form a thick paste at first, and then gradually a thin paste. The lime will supply enough heat to boil the mixture several minutes. As soon as it is well slaked, water should be added to cool the mixture and prevent further cooking. It is then ready to be strained into the spray tank, diluted and applied.

The stage at which cold water should be poured on to stop the cooking varies with different limes. Some limes are so sluggish in slaking that it is difficult to obtain enough heat from them to cook the mixture at all, while other limes become intensely hot on slaking. Care must be taken not to allow the boiling to proceed too far. If the mixture is allowed to remain hot $\mathbf{I} 5$ or 20 minutes after the slaking is completed, the sulphur will go into solution, combining with the lime to form sulphides, which 
are injurious to peach foliage. It is very important, especially with hot lime, to cool the mixture quickly by adding a few buckets of water as soon as the lumps of lime have slaked down. The intense heat, violent boiling, and constant stirring result in a uniform mixture of finely divided sulphur and lime, with only a very small percentage of the sulphur in solution. The mixture should be strained to take out the coarse particles of lime, but the sulphur should be carefully worked through the strainer.

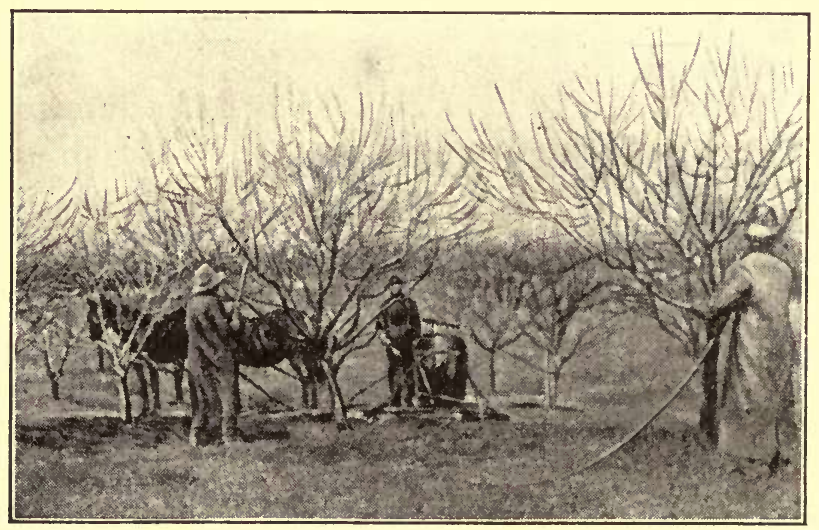

SPRING SPRAYING FOR SCALE

Arsenate of lead used with this mixture should be added at the rate of two pounds to 50 gallons.

\section{SOLUBLE OILS}

Many orchardists prefer to use the soluble oils. These are now extensively offered in the market, mostly under various trade names. They are products of the kerosene industry, the oil being made up to approximately the same specific gravity 
as water and in such a manner that it will mix with water readily under favorable conditions. The usual way of applying is to put these oils into the spray tank with water in the proportion of one gallon of oil to I 5 or I6 gallons of water. The solution is then stirred vigorously by pumping it back into the barrel. It is then ready for immediate use.

This ease of mixing forms a great argument in favor of the soluble oil as compared with the limesulphur sprays. Furthermore, it is much less caustic when it strikes the hands or the face of the operator. This is also an important advantage. One of its most serious defects is that it cannot be seen on the tree as the lime-sulphur mixture can, and it is difficult, therefore, to tell when the tree is fully covered.

A very common practice among peach growers, and one which is on the whole to be recommended, is the use of soluble oil and lime-sulphur in alternate years. When heavy spraying is to be done in cases of severe and neglected infestation, lime-sulphur should be used in the fall and the soluble oil in the spring.

\section{PEACH TREE BORER}

Probably the peach tree borer has caused more profanity than even the San José scale. It is a particularly troublesome and annoying insect and the methods of discouraging its attacks are such as to draw heavily on a fruit grower's religious fortitude. It is much more difficult, as a matter of fact, to overcome the attacks of the peach tree borer than to clean out the San José scale. This insect occurs all over the eastern United States in practically every orchard, and many competent men believe it to be 
responsible for more actual damage than all other peach insects combined. It is the cause of the dying out of many orchards at IO to 15 years of age when they should otherwise live to 20 to 25 years of usefulness.

The larvæ or grubs of this insect live on the tender inner bark of the roots and lower portion of the trunk. The tree is often completely girdled by these

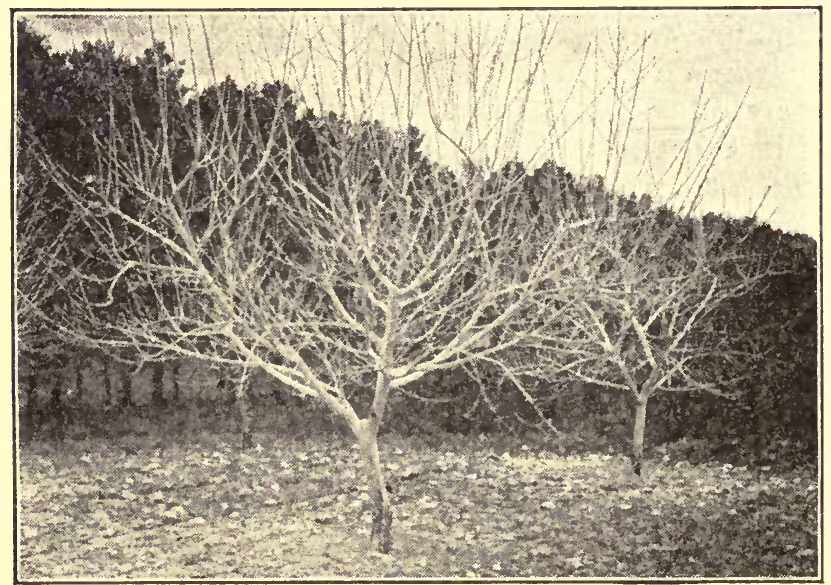

SPRAYED WITH LIME-SULPHUR

borers. In such cases the leaves turn yellow and the tree soon dies. The presence of the insect is shown usually by gummy gelatinous material exuding from the wounds. The eggs are laid in July or August by a pretty black moth, usually on the lower part of the trunk near the ground. The eggs hatch in about ro days and the little borers work in through cracks in the bark. At this time they throw out minute quantities of fine brown dust from the holes and this will give a clue to their presence, providing the in- 
spection is sufficiently careful. They hibernate during the winter and begin to work again during the spring, at which time the exuded gum becomes apparent.

One method of fighting this insect is to wrap the trunk of the tree with stout building paper, the soil being mounded up over the base of this protecting sheet and the top of the paper being tightly tied to the trunk. These protęctors have to be adjusted every fall and removed every summer. This is a troublesome and expensive labor and the method is not altogether efficient as a protection.

A great many different kinds of washes have been tried, including such concoctions as the stewed liver of a black cat killed in the dark of the moon. Indeed, a good many of the remedies recommended are built on this plan and they all seem to be equally effective. They have been generally abandoned by practical peach growers.

The only satisfactory method of fighting this insect is that of removing the grubs with a small sharp knife. The operator goes through the orchard, preferably during November and again in the spring just before the leaves begin to grow. Each tree trunk is minutely examined, and if signs of the borer are found, they are followed up with a knife and the borer dug out. This is.often a tedious and difficult job and considerable damage results to the tree during the operation. However, no equally effective method has yet been discovered.

This work may be facilitated considerably if the soil is mounded up about the trunks of the trees in summer just before the eggs are laid. This has a tendency to make the moth deposit her eggs higher up on the trunk where the borers are easily dug out. The mounds of earth should be drawn away from 
the trees at the time of the first spring cultivation.

At the winter meeting of the Virginia State Horticultural Society in I9I2 the dregs of lime-sulphur wash were highly commended as a preventive of peach borer troubles. The thick dregs were swabbed on the trunk about the time when the adult insects would normally be actively laying eggs. It was claimed that the work was effective and that no injury resulted to the trees. This method seems worth trying experimentally, at least.

\section{THE LECANIUM SCALE}

This insect is very bad in certain parts of the country and in certain parts of particular orchards. It is, however, a local insect and not so well known or generally found as the San José scale or the peach tree borer. Nevertheless, it occasionally becomes so bad as to take all the profit out of a good crop. A sooty, moldy fungus forms on the excretions of the insect. When this appears to a considerable extent on the fruit, it makes the product unmarketable. It occurs most frequently in certain parts of Maryland, southern Pennsylvania and Georgia.

This minute scale hatches about the middle of June. The best time to treat it is when the young are spreading over tree and fruit. At this time it may be sprayed with a solution of whale oil soap, made up in the proportion of one pound of soap to four or five gallons of water. It may also be treated with a 15 per cent solution of kerosene emulsion. Either treatment is difficult and noisome and of limited effect.

\section{THE PLUM CURCULIO}

THE insect becomes very troublesome in certain years, its work being particularly noticeable when 
the crop of fruit is light. This insect occurs everywhere and feeds upon various kinds of fruit, especially stone fruits, although it often attacks apples also. Some energetic peach growers have thought it profitable to maintain an active campaign against this insect, but it seems to be a more common practice to let the curculio take what fruit it will and trust to the June drop or to hand thinning to eliminate the greater portion of the infested fruits.

The adult insect is a small hard beetle with a short snout. This beetle comes nosing around about the time the fruit trees bloom. The female lays her eggs in the young fruit, making a small crescent-shaped puncture in which to place each egg. The eggs hatch in from three to five days and the larvæ bore into the fruit. They usually complete their damage in two or three weeks. By this time the fruit often falls to the ground. The larvæ enter the soil, where they pupate. Here they change again to beetles, emerging two or three weeks later to feed on the ripening fruit.

Good care and clean cultivation in summer tend to reduce the damage of the curculio to some extent. By gathering and destroying fallen fruit a large number of insects are removed from the orchard. The regulation textbook method of fighting the curculio is to jar the trees during the early mornings of May and June and to catch the beetles upon sheets spread under the trees. During the cool mornings the insects are sluggish and easily fall from the tree when it is shaken.

A regular piece of apparatus for this sort of work is made by constructing a canvas umbrella about 12 feet in diameter. This umbrella has an open slit on one side reaching from the circumference to the center. The umbrella is then mounted in an in- 
verted position upon a wheelbarrow or some similar truck so as to have the open slit.at the forward end of the circular catcher. This big canvas is then run under each tree and the tree jarred so as to cause the beetles to fall into it.' The beetles are then easily collected and burned. In some cases this method doubtless pays its way. The energetic fruit grower must be his own judge as to whether he can afford this expense of jarring the entire orchard five to I 5 times during the growth of the crop.

Really the most practical method of meeting the attacks of the curculio is by spraying with arsenical

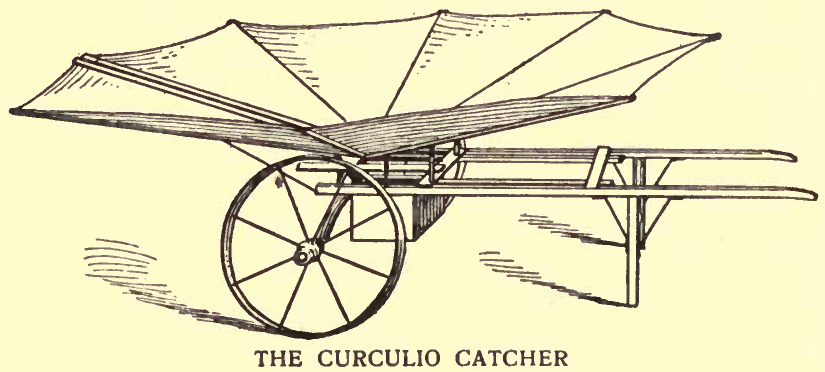

poisons. White arsenic, paris green or arsenate of lead may be applied in the usual manner with the spray pumps. Two or three treatments are required. The first should be given very soon after the blossoms fall, the second treatment two weeks later, and the third treatment, if one is given, two weeks after the second. As paris green is apt to injure peach foliage it is not recommended, though careful applications, especially in combination with lime or well-made Bordeaux mixture, may do no harm. Arsenate of lead is by all odds the safest and best of the arsenical poisons, and is now generally superseding all others in orchard treatment. 
In the large peach sections of the central and the southern states where the best peach growers are adopting the practice of summer spraying with selfboiled lime-sulphur, the poison is added to this solution and applied at the same time. Scott and Quaintance recommend that this combined mixture be made of a strength of eight pounds of lime and eight pounds of sulphur to each 50 gallons of water and the arsenate of lead added at the rate of two pounds to each 50 gallons of the mixture. If the poison is used without the lime-sulphur spray there should be added a certain amount of lime, say two pounds of lime to 50 gallons of water.

The use of the combined poison and lime-sulphur spray is referred to further in the chapter on Plant Diseases, page 140.

\section{FRUIT BARK BEETLE}

The fruit bark beetle and the peach tree bark beetle, two different, but very similar insects, do a good deal of damage, especially in the central states. They bore holes in the tree trunks, making the bark look as though it had been struck by a charge of bird shot. These insects seem to be much worse on orchards which are otherwise in poor condition, and they are generally regarded as hardly worth the attention of the best fruit growers. In other words, general good care and constant attention are depended upon to prevent damage by these insects.

In this connection it is important to remark that general good care goes a long way toward keeping in check all kinds of insect and fungus pests. These cause their greatest damage on neglected orchards. 


\section{XI \\ DISEASES OF TREE AND FRUIT}

Although the peach is fully acclimated to the continent of North America and seems to be perfectly at home here, it is by no means such a sturdy and healthy tree as the apple. It seems to be a shortlived, weak and uncertain tree subject to various accidents and diseases. While an apple orchard is expected to live and thrive during more than a man's natural lifetime, a peach orchard is hardly expected to be profitable for more than 15 or 20 years. This relatively early disappearance of the trees is brought about by various causes, but largely by the insidious attacks of several serious diseases. Most important of these are $(a)$ yellows and its close relative, the rosette, $(b)$ a somewhat similar disease recently discovered and known as "little peach," $(c)$ the brown rot, $(d)$ the scab and $(e)$ the leaf curl.

THE YELLOWS

This is one of the most serious diseases which attacks the peach tree and one of the most difficult to meet, and part of this difficulty lies in the fact that the cause of the disease is still unknown, although many of the best scientists of the world have studied the subject for many years. The following interesting characterization of the disease is made by Prof. L. H. Bailey: "The yellows is a distinct disease. It is not a condition. It attacks peach trees of all ages and in all conditions of vigor, seeming to have a preference for those that are thrifty. It is incurable 
and its termination is always fatal. It is communicable from tree to tree. The means of communication is unknown, but it does not spread through the soil, it probably does not originate in the roots, it is evidently not conveyed from flower to flower, and it is probably not transferred by means of pruning tools. It may be disseminated by buds, even by those from branches that do not yet show signs of the disease. The one unmistakable symptom of yellows is the red-spotted character of the fruit. The flesh is commonly marked by red lines or splashes beneath the spots. These peaches generally ripen prematurely."

Another striking symptom of the disease, one which often first meets the grower's eye, is the tufty growth of weak, young shoots which appear along the sides of the old branches. These crowded shoots are small and yellow with small, narrow leaves. The appearance is wholly abnormal, is never seen on healthy trees and is an unmistakable symptom of yellows.

As soon as the tree is attacked, it begins to show a distinct loss of vigor, the leaves turn yellow and fall prematurely, the fruit is small, poor, tasteless, ripens early and is more fuzzy than the normal fruit. The tree succumbs to the disease the second or third year, depending somewhat on its general physical condition. When the yellows strikes a neglected orchard, it makes short work of it.

There has been a great deal of discussion among fruit growers as to the degree in which yellows is contagious. Some have denied that the disease spreads from tree to tree or from orchard to orchard, others have felt convinced that it spreads seriously throughout any peach-growing section when it is once introduced. In many states there are now laws 
dealing with peach yellows, rosette and "little peach." These laws commonly authorize the destruction of affected trees.

The only practical treatment thus far known is to dig out and burn every affected tree the moment the disease is definitely diagnosed. This means the entire destruction of an orchard in some cases, but the best and most experienced fruit growers consider it far safer to dig out and burn an orchard than to keep one in which a large proportion of the trees are dying of this disease.

A strong difference of opinion exists also as to the practicability of replanting peach trees in land where the yellows has killed an earlier stand of peach trees. Some growers claim that the disease will certainly reappear in the new trees, while other practical men believe that the disease is not retained in the soil at all and that trees planted on such land run no more risk of infection than on virgin soil. Most of the large peach growers who are in the business to stay have made up their minds that an orchard may be abandoned on account of yellows or other diseases, the land cleared thoroughly, cultivated to cereal crops for a few years and put back to peach trees with every prospect of success. A definite rotation of this kind is actually planned and carried out by some of the best men in the business.

Rosette is so nearly like the yellows that it is regarded as being the same disease, manifesting other slightly different symptoms. It is characterized chiefly by the formation of small tufts or rosettes of weak shoots and leaves along the sides of the branches; somewhat resembling the tufts of shoots formed in later stages of the yellows. It comes upon tree and fruit in much the same manner as yellows, 
being incurable and fatal in all cases. The treatment for rosette is precisely the same as for yellows.

\section{“LITTLE PEACH” AND "BIg PEACH"}

Little peach is a disease that has recently appeared in Michigan and is hardly known outside of the Michigan peach belt, though it has been found in a few places in New Jersey and western New York. The characteristic feature is the smallness of the fruit, which instead of expanding with the season's growth remains small, hard and worthless. The trees lose vigor, the leaves are small and weak and the tree dies after two or three years of misery. The cause of this disease is quite as obscure as the cause of the yellows and of the rosette. It is probably of the same general nature. It is equally incurable and almost as promptly fatal. The proper treatment is to dig out and burn the trees as soon as the disease is discovered.

Big peach is a new malady which has appeared in some New Jersey peach orchards. The fruits enlarge enormously, often to twice or three times normal size. Orchardists have so far resorted to cutting and burning, since they have not been able to learn the cause or preventive methods.

\section{LEAF CURL}

This has been one of the most serious diseases in recent years in northern and central latitudes. It has caused serious concern to all peach growers and more active attention has been given to it than to the yellows for the reason that the disease seems to be preventable. It is caused by a definite, wellknown fungus. Proper spraying will check the 
trouble. In fact, the disease may be almost completely eradicated under favorable circumstances.

The disease, characterized by the curling or crumpling of the leaves, usually shows soon after the first foliage has attained its full size. These curled and puckered leaves soon take on a grayish appearance, due to the ripening of the fungus spores. The leaves then soon fall off and the tree is thereby greatly weakened. The fruit also follows the leaves and the trees may be left entirely bare by the first of July. If the disease recurs during two or three successive years the trees will be killed outright.

The spread of this disease is greatly dependent upon weather conditions, cool, wet, muggy weather being especially favorable to it. Usually the disease is not noticed until the damage is nearly done; that is, until the leaves are curled or until they begin to drop. At this time nothing can be done to help the situation for the current year. As the disease is pretty apt to appear in succeeding years, however, adequate arrangements should be made for spraying the following spring.

Any of the standard fungicides, if properly applied, will mitigate the ravages of leaf curl. Strong solutions of Bordeaux mixture are satisfactory if given very early in the season. The application should be made before the opening of the buds in spring and the second application should follow just before the blossoms open. The first application, which is the most important, can well be made with the plain copper sulphate solution, three pounds of copper sulphate in 50 gallons of water.

A few years ago it was noticed that the leaf curl was much less severe on trees treated with the limesulphur spray for the San José scale. Continued experiments have proved that the lime-sulphur mix- 
ture has a very considerable fungicidal effect, and that when thoroughly applied in early spring before the opening of the buds, as is the proper practice in fighting the scale, the leaf curl will be greatly checked. Thorough annual sprayings of this character will practically cut the leaf curl out of the list of dangerous orchard troubles.

\section{BROWN ROT}

The brown rot appears most prominently on the fruit, but attacks also the flowers, buds, twigs and foliage. It is due to a well-known fungus and can usually be prevented by proper spraying.

It is conspicuous on the fruit which it attacks late in the growing season, usually about the period of maturity. It often works on the fruit even after it is picked and sent to market. It shows on the fruit in the form of small brown spots which enlarge rapidly, causing the whole fruit to decay. During warm damp weather the disease is very severe, often destroying an entire crop just when it is ready to pick or when it is already picked and on its way to market. Fruits left on the tree dry and shrivel. Many hang on the tree all winter, while others fall to the ground. The fungus remains dormant in dried fruits as well as in the twigs of the tree, and from these sources the infection spreads the following year.

Spraying with the ordinary remedies will do much to check the ravages of this disease, providing the work is begun early. Sprayings with Bordeaux mixture should be given first before the buds open, second before the blossoms open and third a week after the blossoms fall. Recent experiments seem to show, however, that the weak solutions of self- 
boiled lime-sulphur offer the most satisfactory means of fighting this disease. This spray has been extensively investigated by Scott and Quaintance who find that the fruit rot, the scab and the curculio may all be fought with the same series of sprayings. Their very interesting conclusions with regard to the treatment of these troubles may be quoted in full. They say:

"Most of the peach orchards in the eastern half of the United States should be given the combined treatment for brown-rot, scab and curculio. This is particularly true of the southern orchards, where all these troubles are prevalent. In some of the more northern orchards the curculio is not very troublesome, but as a rule it will probably pay to add the arsenate of lead in at least the first limesulphur application."

"The self-boiled lime-sulphur mixture referred to in the following outlines of treatment should be made of a strength of eight pounds of lime and eight pounds of sulphur to each 50 gallons of water, and the arsenate of lead should be used at the rate of two pounds to each 50 gallons of the mixture or of water. When the poison is used in water there should be added the milk of lime made from slaking two to three pounds of good stone lime. When used in the lime-sulphur mixture additional lime will not be necessary."

"Midseason varieties-The midseason varieties of peaches, such as Reeves, Belle, Early Crawford, E1berta, Late Crawford, Chairs, Fox and Beers Smock should be sprayed as follows: (I) With arsenate of lead alone, about Io days after the petals fall, or at the time the calyxes are shedding, (2) with selfboiled lime-sulphur and arsenate of lead, two weeks later, or four to five weeks after, the petals have been 
shed. (3) With self-boiled lime-sulphur alone, four to five weeks before the fruit ripens."

"Late varieties-The Salway, Heath, Bilyeu, and varieties with similar ripening period should be given the same treatment prescribed for midseason varieties, with an additional treatment of self-boiled lime-sulphur alone, to be applied three or four weeks after the second application."

"Early varieties-The Greensboro, Carman, Hiley, Mountain Rose, and varieties having the same ripening period should receive the first and second applications prescribed for midseason varieties."

"Where the curculio is not particularly bad, as in Connecticut, western New York, and Michigan, the first treatment, which is for this insect alone, may be omitted. Also for numerous orchards throughout the Middle States where the insect, especially in the younger orchards, is not yet very troublesome, orchardists should use their judgment as to whether the first application may be safely omitted. Where peach scab is the chief trouble, the brown-rot and the curculio are of only minor importance, as may be the case in some of the Allegheny Mountain districts, satisfactory results may be had from two applications; namely, the first with self-boiled limesulphur and arsenate of lead four to five weeks after the petals fall, and the second treatment of the above schedule with self-boiled lime-sulphur alone three to four weeks later. These two treatments, if thoroughly applied, will control the scab and the brown-rot, especially of the early and midseason varieties, and will materially reduce curculio injuries. Even one application of the combined spray made about five weeks after the petals fall would pay well, although this is recommended only for conditions where it is not feasible to do more." 
The cost of this treatment will vary from three to Io cents a tree, five cents being a fair average for mediumsized trees under usual labor conditions. A very slight increase in the crop will pay handsomely for this investment.

\section{SCAB}

Taking it the country over, scab stands next to the brown rot as destructive peach fungus. The disease is common throughout all the peach-growing districts, at least to the east of the Rocky Mountains. It is present in nearly all orchards, and especially in wet seasons causes enormous damage. It is more common in the central and southern states than in the northeastern states.

This disease, known also as spot and sometimes as mildew, is caused by a fungus which occurs in the skin of the peach. It produces small, rough, black spots which give the fruit a smutty appearance and which usually cause the skin to crack open in a very unsightly fashion. The fruit is stunted in size and remains hard and tasteless instead of ripening properly. The fungus also attacks the twigs.

Different varieties vary greatly in their susceptibility to the attacks of peach scab. Late varieties usually show the disease worse than early varieties. Those sorts which are commonly grown in the central states-Delaware, Maryland, Pennsylvania, West Virginia-seem to be more subject to damage than the varieties which are popular northward, such as Greensboro, Carman, Champion, etc.

Early sprayings with Bordeaux mixture or other fungicides tend to prevent this disease by killing the spores and preventing early infections. The most practicable treatment, however, seems to be that recommended by Scott and Quaintance and already outlined under the head of brown rot. 


\section{XII}

\section{SPRAYING}

THE practice of spraying is still somewhat new. Many excellent men now living have never seen the work done, and a good many who still have fruit trees think the work unnecessary. Successful fruit growers, however, know it to be indispensable. No time need be spent now arguing in favor of spraying. The San José scale and the peach leaf curl keep up that argument all the while. And their arguments are convincing, irrefutable.

We may observe, however, that spraying will never cure any disease. It is only preventive in its action. Practically the same situation exists with respect to insects; for though the scale can be brought under control after it is pretty well established, the rule is that any fight against insects, to be successful, must be well under way before the insects become established.

\section{SPRAYING MACIIINERY}

A spraying outfit consists of a tank of some sort, a pump, a nozzle or nozzles and connections. As in every technical undertaking it is important that each part be carefully chosen and properly adjusted to all the other parts.

A good tank holding 100 to 200 gallons can be bought of the manufacturers of spray machinery cheaper than it can be made at home. It is suited to use with a power sprayer or with the heavier equipments of hand pumps. For small outfits a bar- 
rel serves best. Any good strong barrel will do, but convenient barrels are sold also by the dealers in machinery.

The pump may be either run by hand or by a gasoline engine. Other types of power have been largely experimented with, such as compressed air, gas, the steam engine, traction from the wagon

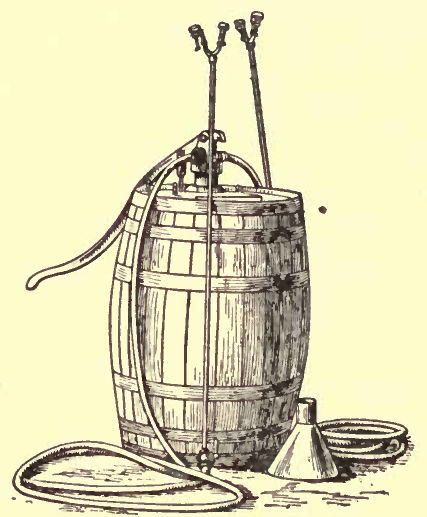

HEAVY HAND PUMP wheel, etc.; but while some of these have proved satisfactory in certain hands, the only generally successful pumps are those here recommended. For 20 acres of orchard or more the gasoline motor is to be recommended. For less than 20 acres hand power is likely to prove most economical. Nozzles are of many kinds, though for all practical discussion they may be reduced to two types; viz., the Vermorel and the Bordeaux types. The general style of these is shown in the accompanying illustrations, pages I48, I50, I52. Nozzles of the improved Vermorel type are generally regarded as best for careful spraying, especially for the spring applications of lime-sulphur. They are also more economical of the solutions used.

The selection of proper hose presents some special difficulties. The corrosive solutions soon spoil almost any rubber hose, and the purchase of a new supply entails constant expense. Some men prefer to buy cheap cotton hose and replace it as fast as it gives out. Others recommend buying the best. 
Small hose, about half an inch in diameter, is better than larger and heavier sizes.

Rods for directing the nozzles are always required. The best rods are of bamboo, and may be bought in various lengths from the purveyors of spray machinery. Four feet is long enough for young trees, but 6 or 8 feet will be required on trees of bearing size.

Every outfit must also include a strainer. The strainer should be large and fitted with copper wire, 20 meshes to the inch.

\section{SPRAY SOLUTIONS}

A great many fungicides and insecticides have been introduced and tested in the last few years. Many of these have good qualities, while a few are practically worthless. For use on peach trees, however, we may settle down pretty comfortably to three sprays; viz., soluble oil, lime-sulphur and Bordeaux mixture. Even the Bordeaux mixture is now largely abandoned by many of the best growers, who have substituted for it the self-boiled lime-sulphur spray.

There are various ways of making up the limesulphur mixture. The proportions of the ingredients vary more or less with different workers. The following formula is fully tested and has been found satisfactory:

\section{I6 pounds unslaked lime, I6 pounds flowers of sulphur, 50 gallons water.}

In small quantities this mixture can be most easily prepared in a large iron kettle, such as is used for cooking food for hogs. To make up the full recipe as given a 50-gallon kettle is necessary. Such an 
equipment is perhaps the cheapest and most convenient arrangement for handling a small orchard, say up to five acres of trees. When an orchard gets to be as large as Io acres it will probably be best to put in some sort of apparatus for cooking with live steam.

The making of the lime-sulphur mixture is begun by slaking the lime in the kettle, using hot water.

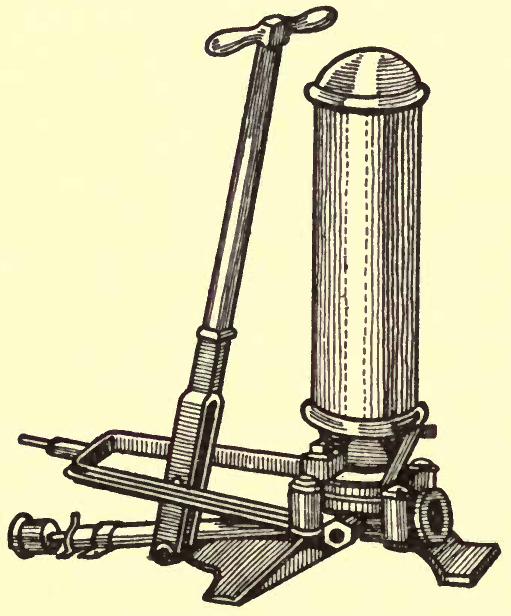

BARREL SPRAY PUMP

The fire under the kettle should be started at this time. As the lime slakes add water slowly. When the slaking is well under way the sulphur should be added. The heat generated by the slaking lime will help to melt it, and this is a help of s o m e importance. At this stage the kettle should contain only IO-I 5 gallons of water. Vigorous and constant stirring of the mixture is necessary during this period, which will occupy about i 5 minutes. When the lime is thoroughly slaked and the sulphur dissolved the rest of the water may be added, preferably hot. The whole is then brought to the boiling point and vigorously boiled for 40 minutes to an hour. Thorough boiling is very important. During this cooking the mixture changes to a dark reddish-orange, very characteristic and easily recognized after once being 
seen. The appearance of this peculiar color is one of the best tests for a well-made mixture.

Some sediment will usually be found in the bottom of the kettle. This is mostly undissolved particles of lime, or unburnt bits of limestone. Any considerable amount of this sediment, however, indicates a poor grade of lime. The solution must be strained before using. It should be strained directly into the sprayer and used hot off the fire. The hotter the solution can be put on the trees the better.

Whenever large quantities of the lime-sulphur mixture are to be used it is best to provide a steam cooking plant. This consists merely of any sort of steam boiler for generating the steam, and a hose for conducting the live steam into the barrels in which the cooking is done. The illustration, page I24, shows the arrangement of the various elements in the scheme. Such an equipment is comparatively inexpensive, and will produce a better grade of limesulphur mixture than can be made in any other way.

Good lime is very important in making up this recipe. Air-slaked lime or half burnt lime should never be used. In any case when the quality of the lime is in doubt the quantity ought to be correspondingly increased. An excess of lime will do no injury, and it is a slight advantage. At least it whitens the trees and helps to show how far the spraying has advanced.

Good clean flowers of sulphur should be used. The so-called "sulphur flour" is a trifle cheaper, but is not so good, particularly when one has to cook the mixture in a kettle. When live steam is used the difference is less important. Whenever possible sulphur should be bought in barrel lots. Barrels hold about 200 pounds. Purchases should always be made by sample. Early in the winter the fruit 
grower should write to leading supply houses and wholesale dealers in drugs and chemicals for samples and prices.

Lime-sulphur is the nastiest, dirtiest and most humanly unpleasant spray ever devised. Perhaps this is one reason why it makes the scales so uncomfortable. Every fruit grower must become inured to the annual hardship of the lime-sulphur campaign, and as far as possible he must try to inure

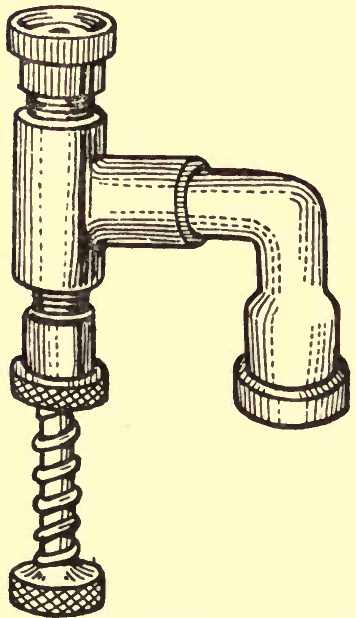

SINGLE "VERMOREL" NOZZLE the hired men to it. Let him remember, though, that it is a vile experience, and let him have some patience, especially with green men. The man who sprays with lime-sulphur for four weeks in the spring is entitled to at least a half day off the Fourth of July. The solution is very hard on the skin, and harder on some men than on others. Care must be taken to prevent the solution falling on the hands and face. The hands ought to be protected with coarse, cheap cotton gloves, which can be thrown away as fast as they wear through. Even the horses or the mules attached to the spray wagon are entitled to the protection of a good blanket. The sulphur spray will injure the harness as well as the horses.

This solution is used chiefly for the early spring campaign against the San José scale; but it has very distinct fungicidal properties and serves to check 
some of the most serious plant diseases, such as fruit rot and leaf curl.

There are now on the market any number of commercial mixtures of ready-made lime-sulphur. Some of these are very good, others very poor. No one should use these mixtures extensively without positive proof of their efficiency, which proof can hardly be secured in any other way than by careful tests in one's own orchard. Only reliable manufacturers should be patronized, and new schemes held in grave suspicion. Good home-made lime-sulphur is better than the best commercial ready-made brands.

\section{SELF-BOILED LIME-SULPHUR}

For summer spraying the lime-sulphur is also useful, but it is used in weaker forms and is usually prepared by the self-boiling process. The most extensive experiments with this spray have been made by Messrs. Scott and Quaintance of the United States Department of Agriculture. Their directions for making it may well be quoted:

"The standard self-boiled lime-sulphur mixture is composed of eight pounds of fresh stone lime and eight pounds of sulphur to 50 gallons of water. In mild cases of brown rot and scab a weaker mixture containing six pounds of each ingredient to 50 gallons of water may be used with satisfactory results. The materials cost so little, however, that one should not economize in this direction where a valuable fruit crop is at stake. Any finely powdered sulphur (flowers, flour, or "commercial ground" sulphur) may be used in the preparation of the mixture.

"In order to secure the best action from the lime, the mixture should be prepared in rather large quantities, at least enough for 200 gallons of spray, using 
32 pounds of lime and 32 pounds of sulphur. The lime should be placed in a barrel and enough water (about six gallons) poured on almost to cover it. As soon as the lime begins to slake the sulphur should be added, after first running it through a sieve to break up the lumps, if any are present. The mixture should be constantly stirred and more water (three or four gallons) added as needed to form at first a thick paste and then gradually a thin paste.

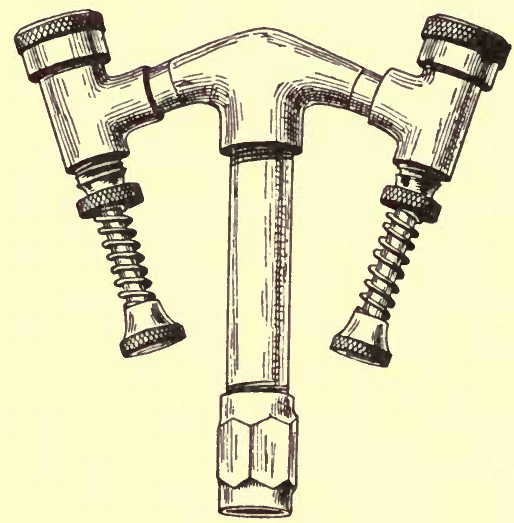

DOUBLE “VERMOREL" NOZZLE The lime will supply enough heat to boil the mixture several minutes. As soon as it is well slaked water should be added to cool the mixture and prevent further cooking. It is then ready to be strained into the spray tank, diluted and applied.

"The stage at which cold water should be poured on to stop the cooking varies with different limes. Some limes are so sluggish in slaking that it is difficult to obtain enough heat from them to cook the mixture at all, while other limes become intensely hot on slaking, and care must be taken not to allow the boiling to proceed too far. If the mixture is allowed to remain hot for 15 or 20 minutes after the slaking is completed, the sulphur gradually goes into solution, combining with the lime to form sulphides, which are injurious to peach foliage. It is there- 
fore very important, especially with hot lime, to cool the mixture quickly by adding a few buckets of water as soon as the lumps of lime have slaked down. The intense heat, violent boiling, and constant stirring result in a uniform mixture of finely divided sulphur and lime, with only a very small percentage of the sulphur in solution. It should be strained to take out the coarse particles of lime, but the sulphur should be carefully worked through the strainer."

In the use of this mixture it is often desirable to add some insecticide, which should always be arsenate of lead. Messrs. Scott and Quaintance, already quoted, give the following suggestions regarding the use of the arsenate of lead with the self-boiled lime-sulphur: "Arsenate of lead is to be found on the market both as a powder and as a putty-like paste, which latter must be worked free in water before it is added to the lime-sulphur mixture. The paste form of the poison is largely used at the rate of about two pounds to each 50 gallons of the limesulphur wash and is added, after it has been well worked free in water, to the lime-sulphur spray previously prepared. As there are numerous brands of arsenate of lead upon the market, the grower should be careful to purchase from reliable firms. A decided change in color will result when the arsenate of lead is added to the lime-sulphur mixture, due to certain chemical changes which, in the experience of the writers, do not injuriously affect the fungicidal and insecticidal properties of the spray or result in injury to the foliage.

"In large spraying operations it will be more convenient to prepare in advance a stock mixture of arsenate of lead, as follows: Place roo pounds of arsenate of lead in a barrel, with sufficient water to 
work into a thin paste, diluting finally with water to exactly 25 gallons. When thoroughly stirred, each gallon of the stock solution will thus contain four pounds of arsenate of lead, the amount necessary for Ioo gallons of spray. In smaller spraying operations the proper quantity of arsenate of lead may be weighed out as needed, and thinned with water. In all cases the arsenate of lead solution should be strained before or as it is poured into the spray tank. The necessary care should be exercised to keep the poison out of the reach of domestic and other animals."

\section{SOLUBLE OILS}

In the universal campaign against the San José scale a considerable figure is cut by the soluble oils.

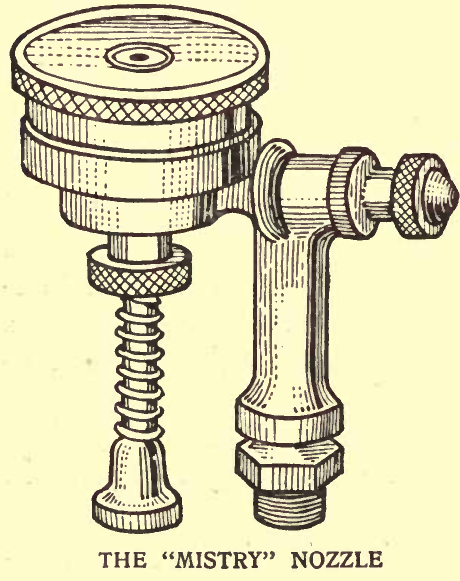
These are simply various preparations of coal oil made up to a specific gravity practically equal to the specific gravity of water and in a form that they will readily mix with water. The usual method of using consists simply of mixing the oils with the water in the spray tank. This is so very much easier than making lime-sulphur mixture, and their use is attended with so much less annoyance, that many growers prefer them. They are not generally so 
effective, and are harder to put it on thoroughly, especially due to the fact that they leave no trace on the tree, and it is hard to tell when a tree has been fully covered. They have no fungicidal properties as the lime-sulphur has.

A common practice, and one to be indorsed, is to put on a spray of soluble oils in late fall or early winter for the treatment of very light infestations of scale and when fungus diseases are not feared. This will mean principally the treatment of young orchards of one or two years' growth. Or the soluble oils may be used for a fall spray on badly infested orchards when they can be followed with a thorough spring spraying with the regulation limesulphur. This double dose is not too much for bad cases of San José scale, and serves as the best general method of bringing them promptly under control.

\section{BORDEAUX MIXTURE}

While Bordeaux mixture is the best known of all fungicides, and often of value in peach growing, it has less use here than in apple culture. The changes in the formula have been very few and of a minor nature, showing that Bordeaux mixture is as nearly perfect as such things can be. The mixture is made in various strengths for various purposes, but probably the best formula for spraying dormant peach trees is the standard mixture, as follows:
4 pounds copper sulphate (blue vitriol),
4 pounds lime,
50 gallons water.

To make up the mixture first dissolve the copper sulphate. This process can be very much hastened 
by using hot water. The usual method, however, is to put the copper sulphate into a gunny sack and hang it on a fork handle in the top of a barrel or a tub, so it will just barely be immersed in the water. As fast as it dissolves it sinks toward the bottom of the vessel. If only 50 gallons (say one barrel) of mixture are to be made it is well to dissolve the copper sulphate in 25 gallons of water.

The next step is to slake the lime. This should be done by adding a little water at a time, just enough to keep the lime slaking, but not enough to dissipate the heat generated in the process. When the slaking is finished more water can be added, making the lime into a thick cream. It can then be diluted so as to make 25 gallons or half a barrel of solution. If necessary, it should be strained. With good lime, however, the straining can be omitted.

The two solutions are now ready-the copper sulphate in one tub or barrel and the lime in another. To make the mixture, dip or pour the copper sulphate into the lime, or else pour both solutions at once into a third barrel. In either case the mixture must be stirred vigorously during the pouring. Under no circumstances should the process be reversed and the lime poured into the copper sulphate. This little detail, which is of no obvious importance whatever, really makes the difference between a good and a very bad mixture which may ruin the foliage on every tree it touches.

When a big campaign of spraying is on and much bordeaux has to be made, the best plan is to make up stock solutions. To do this dissolve say 40 pounds of copper sulphate in 40 gallons of hot water, and set it aside for use. Then in a suitable box slake 40 pounds of lime, and add enough water to make 40 gallons of this solution also. With care these 
solutions will keep for some time; if they stand for several weeks they become considerably concentrated through evaporation of the water.

To use these stock solutions in making up a barrel of bordeaux for spraying take four gallons of the copper sulphate solution and dilute it to approximately 25 gallons. Then take four gallons of the lime solution and dilute it in another barrel, making approximately 25 gallons. Then pour the copper sulphate solution into the lime solution as before directed, stirring thoroughly.

No matter how the Bordeaux mixture is made it should be strained before using. To do this put it through cheesecloth as it goes into the spray tank.

In making up large quantities of Bordeaux a great amount of labor can be saved by a convenient arrangement of barrels or tanks. The usual way is to build a platform, preferably in two stories, say 6 and I 2 feet high. The stock solutions are made up in tubs, barrels or tanks on the upper platform. They are also ladled out and diluted on this upper stage. They are then allowed to run together into a trough conducting them to a barrel on the lower platform. They mix as they run together into the trough, and this mixture should be vigorously stirred in the barrel during the operation. The mixture thus completed is drawn off by gravity into this spray tank, passing through the cheesecloth strainer on its way.

This staging must be made high enough so that the completed mixture will run down into the mounted spray tank. There must be arranged a convenient water supply, sending water easily up to the top platform. This staging can be used in making and handling other sprays, though it is especially adapted to the manufacture of Bordeaux.

A word needs to be said about the chemicals used. 
Copper sulphate is seldom adulterated, though sometimes it is not so clean as it ought to be. The granulated form costs about one-half cent more a pound than the lumps, and is easier to dissolve. If the amount of work to be done will justify it the copper sulphate should be bought by the barrel. A barrel contains in the neighborhood of 200 pounds and costs from $63 / 4$ to $7 \mathrm{~T} / 2$ cents a pound at present, with a tendency for the price to go higher.

The proper selection of lime is more important. The lime must be of good quality, well burned and not air slaked. The fine lime sometimes preferred by masons should not be used. Lumps are better.

Always use lime enough. The quantity recommended in the formula already given will be sufficient, if good lime is used; but in case of doubt more lime can be used. It is customary in books and bulletins to recommend the so-called ferro-cyanide test, but in actual practice it is better to rely on good lime. The idea of this ferro-cyanide test is to determine whether the lime has completely neutralized the copper sulphate. A solution of potassium ferro-cyanide (yellow prussiate of potash) is made by dissolving say one ounce of the ferro-cyanide in six ounces of water. A few drops of this solution may be dropped into the Bordeaux mixture to be tested, when, if the copper sulphate has not been neutralized, it will instantly give a deep brownishred color. If the mixture is properly neutralized no color will appear. This test is very accurate and reliable, provided the Bordeaux is evenly mixed; but it is too much bother for practical use in the field.

Bordeaux mixture is nowadays seldom used on peach trees when in foliage; but in case it is to be applied to the leaves it should be made considerably 
weaker than the standard formula already given. The following recipe may be used:

$$
\begin{aligned}
& 2 \text { pounds copper sulphate, } \\
& 4 \text { pounds lime, } \\
& 50 \text { gallons water. }
\end{aligned}
$$

THE SPRAYING CAMPAIGN

In order to make spraying effective it is always necessary to organize a vigorous campaign. A

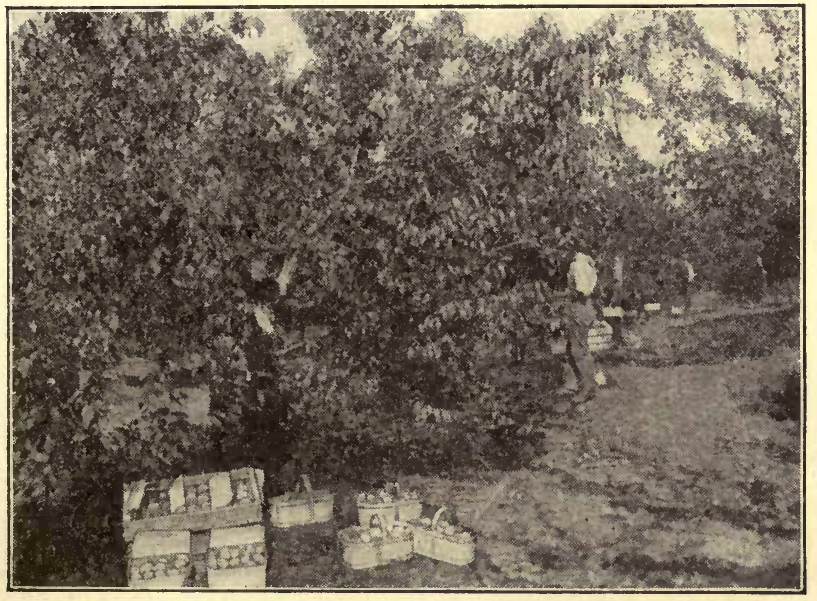

THE PEACH HARVEST IN A SMALL ORCHARD

definite program of operations must be laid off, every item based on careful study and on all available experience, and this program must be steadily followed.

This program can be somewhat definitely stated for the care of peach orchards. In its broad outlines it is as follows: 
I. Fall or winter treatment with soluble oil on young trees with light infestation of scale, or on old orchards with severe infestation. (See page I 52.)

2. Spring treatment with lime-sulphur for San José scale, leaf curl and monilia. (See page I45.) Bordeaux mixture is sometimes used for this spring treatment when scale is not present.

3. Summer treatments with self-boiled limesulphur for peach scab and monilia; or with lime-sulphur plus arsenate of lead for curculio. (See page 149.)

\section{GENERAL SUGGESTIONS}

There are many things to look after in spraying. One must be ever on the alert, and must be well informed as to the purposes and methods of his practice. The following specific suggestions are based on long experience, and should always be borne in mind:

I. Have a definite knowledge of the life and habits of the insect or the fungus to be fought. Be sure to understand in particular the vulnerable points, the points at which the foe is to be attacked, and the way it is to be circumvented. Spraying with paris green to kill San José scale is as useless as voting for the American Express Company in order to introduce parcel post.

2. Spray thoroughly. Sloppy, slovenly work is bad enough anywhere, but carelessness in spraying defeats the whole object of the work about as fully and promptly as anything can.

3. Spray annually. It is like taking a bath every summer whether a man needs it or not. The chances are he will need it. Spraying is a sort of an insurance. One cannot wait till insects are devouring his 
trees or disease has taken hold of the crop, and then start his spraying. He has to get there first.

4. Be prepared early. This is good advice with all sorts of farm work, but in spraying, where a delay of even a day or two may spell ruin to the crop, nothing should be put off, nothing overlooked, nothing taken for granted. Every bit of apparatus and all needed chemicals should be inventoried and the list scrupulously checked before spraying time comes round.

5. Spray early. If the work is allowed to lag and come along two weeks or a month late, it is likely to be much less effective or wholly worthless.

6. Do not spray while the trees are in bloom. It is never necessary, it is even dangerous to the blossoms, and it is always dangerous to bees.

7. Solutions of sulphur or copper sulphate are hard on tin or galvanized iron. They should always be stored in wooden, earthen or glass vessels. Pump cylinders should be of brass for use with Bordeaux mixture, but for lime-sulphur should be of iron.

8. Several of the spray chemicals, as arsenate of lead, are deadly poison. They should be treated as such. They should always be fully labeled, marked "POISON," and kept well out of reach of children, preferably under lock and key. 


\section{XIII}

\section{MARKETING THE CROP}

The peach is one of the most difficult of the tree fruits to market properly. It is perishable and very delicate. The crop must be handled rapidly and at the same time very carefully. For this marketing large quantities of labor are required. These necessary laborers must be employed for a short time only, so there is not much opportunity to organize and train them for the difficult work they have to perform. The shortness of the harvest season and the fact that peach harvest cannot be relied upon even every year also increase the difficulty.

\section{PICKING}

It requires considerable experience to judge ac-

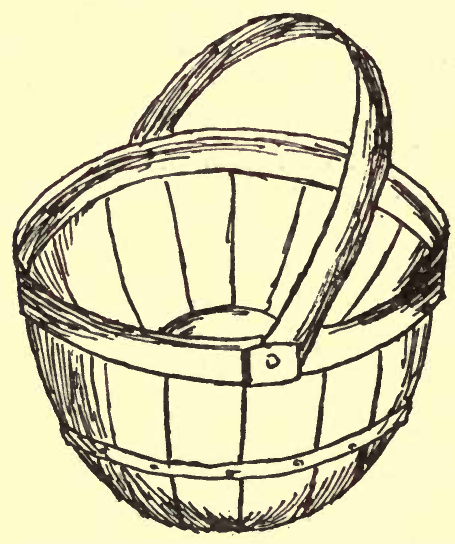

HALF-BARREL PICKING BASKET curately the time when a peach is ready to pick. The maturity will depend a good deal on the market for which the fruit is destined. If to be used at home it will be allowed to ripen on the tree, and of course, under these circumstances it will attain a finish and a quality which it cannot have under any other conditions. The 
fruit which has to be handled in the open market can never be allowed to become thoroughly soft and ripe. The man who meets the market must have a pretty definite idea of how many days must elapse between picking and consumption of the fruit, and allowance must be made for this at picking time. The picker tells whether a peach is ready to pick or not by feeling it with his hands, or by observing the color of the fruit.

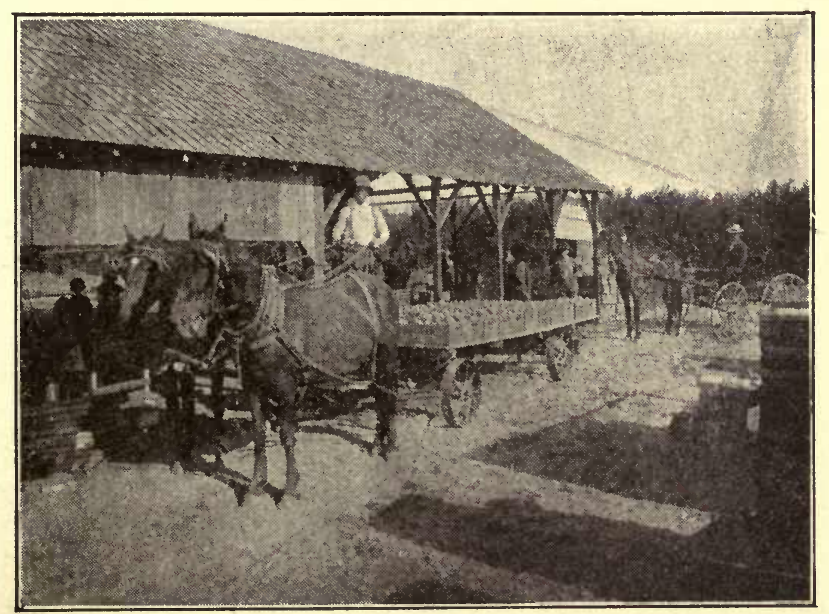

HAULING TO THE PACKING SHED

When a considerable amount of fruit has to be handled, the organization of the picking gang becomes a serious problem. The men have to be found hurriedly, and there is not sufficient time to train them as they ought to be trained for their difficult task. In the South, where negro labor is abundant, it is widely employed and is generally found to be satisfactory. In districts where Italian 
labor is available it is also found to be very satisfactory. Near manufacturing centers women and girls can usually be employed, and when the proper ones are found, they make very good pickers. In most districts, however, the picking gang is miscellaneous and nondescript in the extreme. In general the workers receive their wages by the day. These wages will vary with the locality, running from 75 cents to $\$ 2$ a day or even more. In most large orchard enterprises pickers are paid by the basket. Where half-bushel baskets are used for picking the wages are from two to five cents a basket.

\section{SORTING}

As soon as the fruit is picked it must be carried to the packing house. For this purpose nothing is better than the regulation fruit wagon as made by several manufacturers. This wagon has good springs, and broad flat bed on which the fruit baskets are piled.

A convenient packing house centrally located is of great importance in handling a peach crop. Its arrangement is a problem upon which the fruit grower can well spend considerable thought and some money. A small packing house should be arranged to receive the fruit at one side; to handle it, sort it and pack it near the center of the house; and pass it out to wagons or cars on the opposite side. A large packing house should be arranged to receive the fruit from two sides if not three, to have it sorted in two ranges of sorting tables and delivered to a center aisle. The fruit should then be inspected and passed along the center aisle to the end of the house from which it is handed directly into the cars. 
The actual work of sorting requires considerable skill and experience. Women and girls have been found especially useful at this task. Some men make good fruit packers; others are useless.

Mechanical graders and sorters have been put upon the market from time to time and have been carefully tested, but so far as the writer knows no machine of any sort has ever proved satisfactory.

\section{PACKAGES}

One of the most important problems in handling the peach crop is the selection of proper packages. Those most commonly used are the quart berry basket, the four-quart till basket, the two-and-ahalf-quart bale basket, the climax basket of various sizes, the Georgia carrier, the Jersey basket and the bushel basket.

The quart basket precisely as made up for handling strawberries, is sometimes used in s e 11 ing peaches, especially in the retail market. It is not a good package, however, and

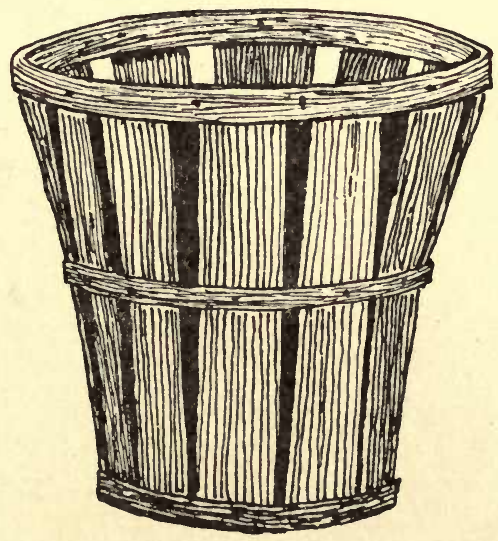

THE JERSEY BASKET should never be recommended. It is used only for second grade peaches, which properly ought to be sold in larger quantities. Where really good peaches are to be sold on fruit stands at retail they should be sold by 
the piece or the dozen. Nevertheless the quart basket is cheap and convenient and will doubtless continue to be used.

The four-quart till basket as used in the Georgia carrier is also frequently used without the carrier as a retail package. Four quarts is a convenient amount to be handled in a retail market. Many retail dealers make a practice of sorting up fruit from larger packages into the four-quart basket and passing them out to their customers in this form.

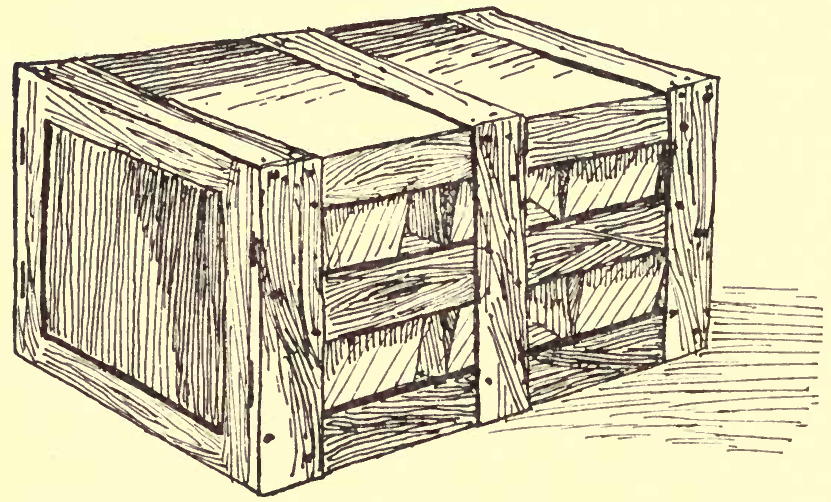

THE GEORGIA CARRIER

As a rule the package is not so convenient for the fruit grower on account of the difficulty of handling into the market without the crate. It really requires the crate to transport it.

The two-and-a-half-quart bale basket is not much used, but deserves more attention. It has the form of the Jersey peach basket, but has also a small wire bale. It has proved to be very convenient in retail markets. It is attractive to the customer and cheap for the fruit producer. It seems strange that so 
good a basket should not have received more wide attention.

The climax basket is one of the most convenient packages of all to handle and this, no doubt, has accounted somewhat for its wide popularity. It is also one of the first baskets known in the peach trade, and so has had a certain prestige on account of its age. Climax baskets are made in various sizes, mostly one-fifth, one-sixth, one-eighth, one-tenth bushel sizes. They seem to be much more popular

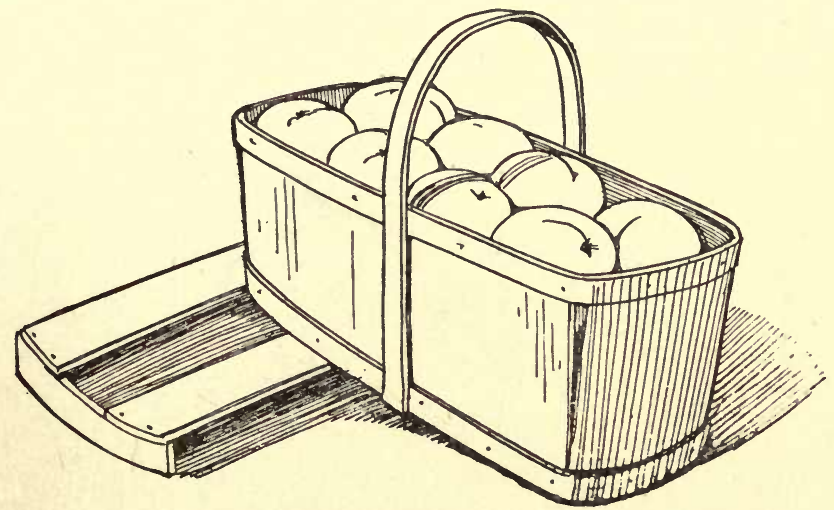

THE CLIMAX BASKET

in Michigan than elsewhere, although the markets centering about Chicago use them rather freely. They are much better adapted for local markets than for long shipments.

The package par excellence for long shipments is the Georgia crate or peach carrier. This crate holds six four-quart till baskets or 24 quarts of peaches. No other basket has been found which stands shipment so well and delivers its fruit in such good condition at the end of long journeys. This package 
has the additional advantage that the fruit may be sold out in four-quart parcels, the amount which seems to be especially attractive to most consumers.

The next most important basket in the market is the Jersey basket, made in the form of a truncated cone. This basket is cheap and easily handled. The quantity of fruit which it carries is satisfactory to

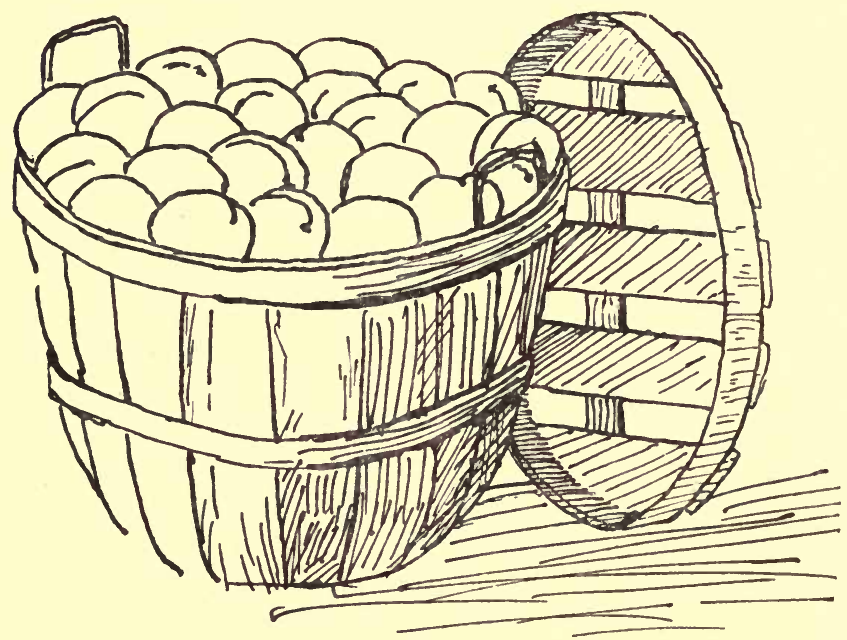

THE BUSHEL BASKET

most consumers, so the package may be handled directly from the orchard to the consumer without being re-sorted in any way. These Jersey peach baskets have been made in various sizes all the way from two quarts to two bushels, but the correct and popular size is the I6-quart or half-bushel basket. In a good many states this size has been legalized, and in some all other sizes have been ruled out by law. 
The bushel basket would seem to be the last thing in the world in which to handle peaches, but it has been found very satisfactory in certain northern markets, particularly in Michigan and western New York, where a good deal of fruit is shipped, even to considerable distances, in this package. The basket is made with staves and not braided and is supplied with a substantial wooden cover which tends to protect the fruit from damage in shipment.

Recently the California, Oregon and Colorado shippers have been sending fancy peaches to the eastern markets in a special box, measuring $5 \times$ II I $1 / 2$ $x$ I $81 / 2$ inches inside. The ends are made of $3 / 4$-inch stuff, and bottoms and sides of $3 / 8$-inch pine. The fruit is nearly always paper wrapped, carefully graded and packed. It may be shipped and handled long distances in this package without damage. The package, however, is a trifle expensive and should be used only for very fancy trade.

All of these packages are what are known as the gift packages, that is, they are used up by the consumer and are never returned to the shipper. In fact, the returnable fruit packages have now almost wholly gone out of use in the United States and Canada.

\section{TRANSPORTATION}

The railroad service cuts a big figure in the handling of large peach crops. Closely linked with the railroad transportation is the refrigerator car service. Of course, every manager of a peach orchard must find transportation for his crop; and where the refrigerator service has to be depended upon, he must make the necessary arrangements for this also; but these are general questions upon 
which profitable advice can hardly be given in a brief book on peach growing.

\section{SELLING METHODS}

Aside from direct retail selling in home markets, which will be discussed later, there are two principal methods of selling fruit crops. The most com-

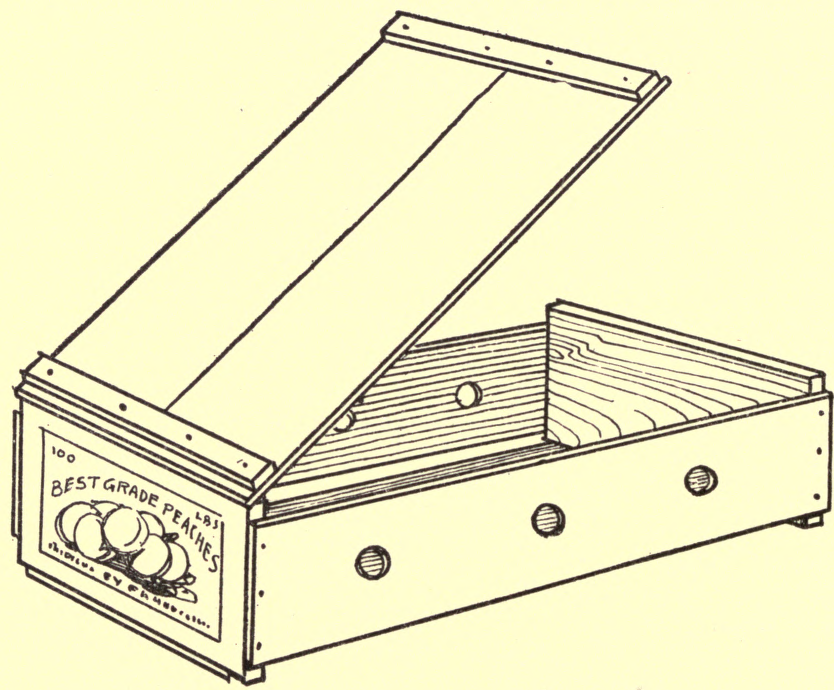

mon method is by consignment to commission men. The problem of the commission man has been discussed with great fervor in fruit growers' meetings from time immemorial. The commission man has been damned for nearly everything that ever happened in the peach orchard, including the work of the borers and the damage by the neighbor's cows, yet in a good many cases it has seemed as though 
he deserved all the blame that could possibly be laid upon him. At any rate he has sometimes done his best to earn all the condemnation that could be offered him. Large growers, however, are apt to fare better at the hands of the commission man than small ones. At the present time the tendency is to regard the commission man as a necessary evil, and the fruit grower deals with him if he cannot do better.*

A better way of selling whenever it can be adopted is that of turning the peaches over to buyers who pay cash at the railroad station. Such buyers appear in considerable numbers at harvest time in the large fruit districts. Unless they prove to be a crowd of sharpers, or there is some other defect in the marketing organization, they offer the best opportunity for disposing of the crop. Of course, the grower need not jump at the conclusion that it is always better to sell for cash in hand at railway stations. These men who buy in this way have to take some chances, and necessarily they must leave a margin between the price which they pay on the ground and that which the fruit may be expected to bring in the city markets. Very often the shrewd fruit grower can make good money for himself by passing over the cash bidder at the railway station and consigning his fruit to some commission man in the city. He must be his own judge on this point, and must remember that some risks have to be run. He cannot win in every instance. There is some gambling in the peach business, and the man who gambles must be prepared to lose occasionally.

* For a full discussion of commission dealing and of selling methods in general, see Waugh's "Fruit Harvesting, Storing, Marketing." 


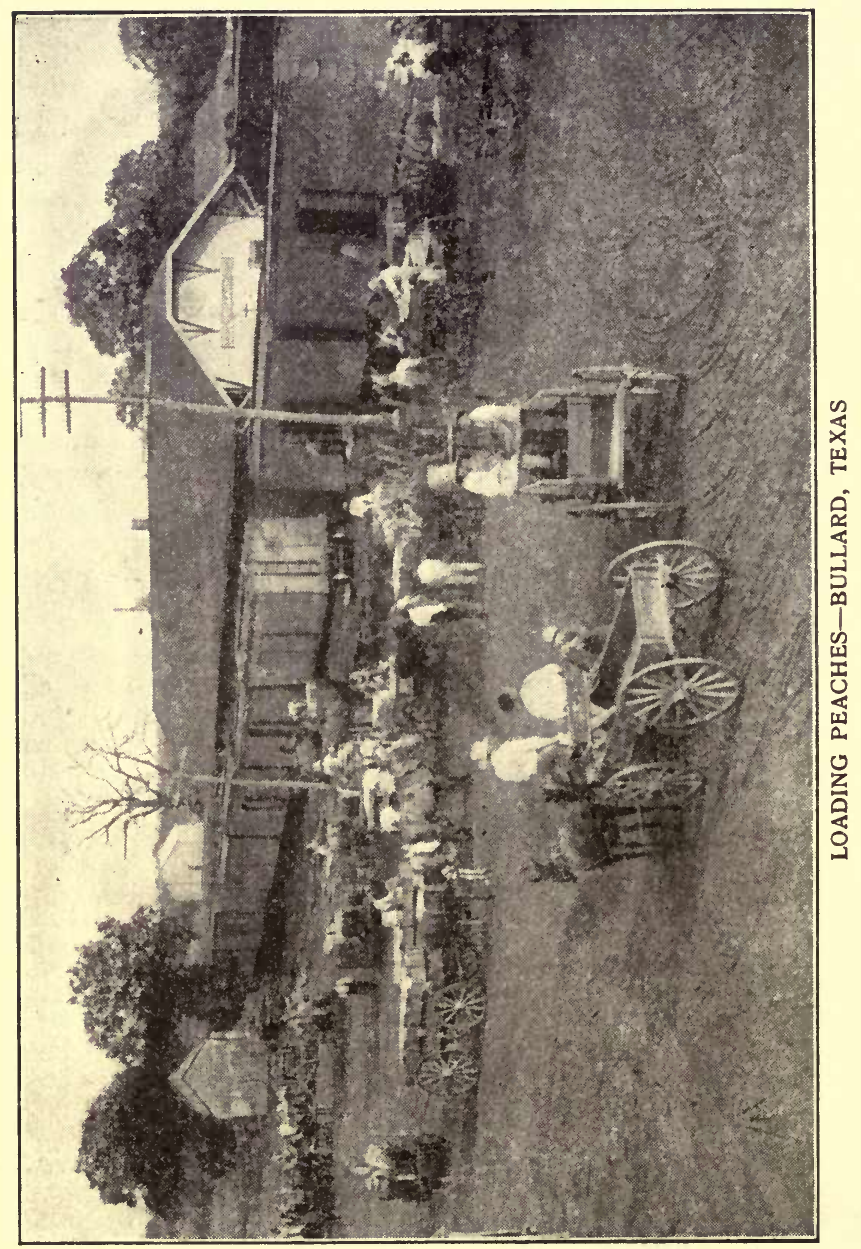


Doubtless the best method of all for handling large peach crops is through the organization of cooperative selling associations. These have now been formed in all of the best peach districts, as well as in many other fruit-growing regions. Some of the best of these are in the state of Colorado. The description as given in the "Cyclopedia of American Agriculture" by Mr. James B. Morman is worth quoting:

"There are two methods of packing and grading fruit, as practiced by the Colorado associations.

"(I) The association does the packing. In this case the growers deliver the fruit direct from the trees to the packing houses. Here the assocation's packers sort, grade, and pack the fruit into boxes or crates, the culls being returned to the grower. The grower's number, which is given to him at the beginning of the season, is marked on each package with the grade of the fruit. When loaded into cars a strict account is kept of the number of boxes, varieties, and grades of each grower's fruit. In this way the price for each box of fruit in any car is easily determined.

"(2) The growers do the packing. This occurs when there is a large amount of fruit to be handled. When the growers do the packing the association hires an inspector whose duty it is to inspect every load as it is delivered. This he does by opening the boxes-on the side in the case of apples. If the pack is satisfactory, not more than two boxes are usually opened. If, on inspection, the pack is found unsatisfactory, the entire load must either be placed in a lower grade or the whole repacked. In this case, likewise, each one's fruit is designated by number. Most of the associations have now adopted the latter method as the more satisfactory, for the rea- 


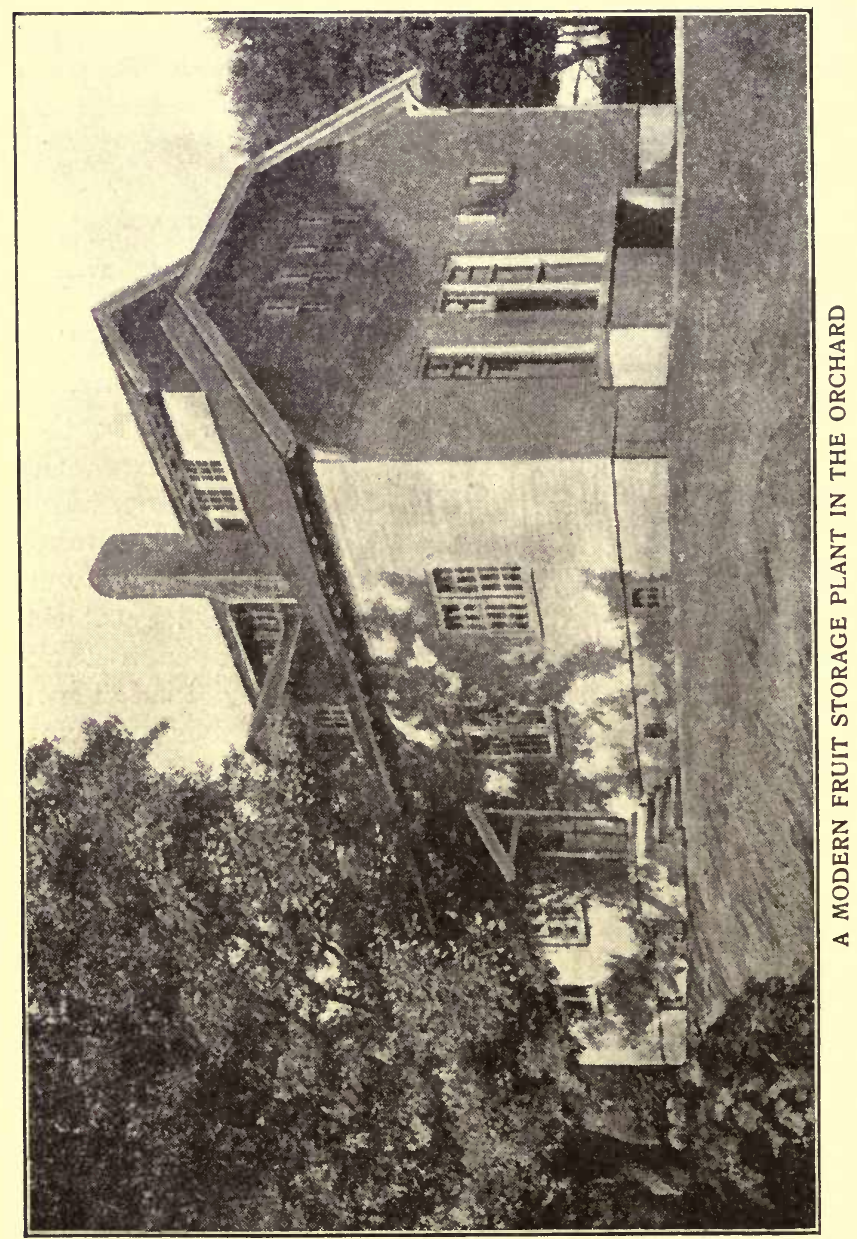


son that when a grower does his own packing he has a respect for the judgment of the inspector. To repack a load of fruit is found to be rather expensive, as is also the placing of fruit in a lower grade. One experience is usually sufficient. Notwithstanding so much care, poorly packed fruit sometimes finds its way into the market.

"The association charges a commission on all sales to defray expenses. This is usually five per cent, and when the packing is done by the association, an additional charge is made to cover the cost of box and labor of packing. The surplus, if any remains, is distributed as premiums.

"The system of selling has been somewhat changed during the past few years. Formerly all fruit was consigned to commission men, but on account of dissatisfaction with the returns made by the consignees as to the condition of certain shipments of fruit made by the associations, the plan of selling f. o. b. is largely practiced, consignments are made only to well-known firms, and much of this fruit is sold at auction.

"Even with this arrangement difficulties sometimes occur, so the custom of the associations sending agents to the most important distributing points has arisen. It is the duty of the agent to inspect all cars that come into his territory, as near the destination as possible, and thus protect the association from dishonest buyers, and adjust differences that arise when fruit actually reaches the buyer in poor condition. This is the system practiced when fruit is sent by freight in carload lots.

"Shipments by express are made only to nearby points. In such cases the growers receive exactly what the fruit brings, less the express charges and the association's commission. This practice is con- 


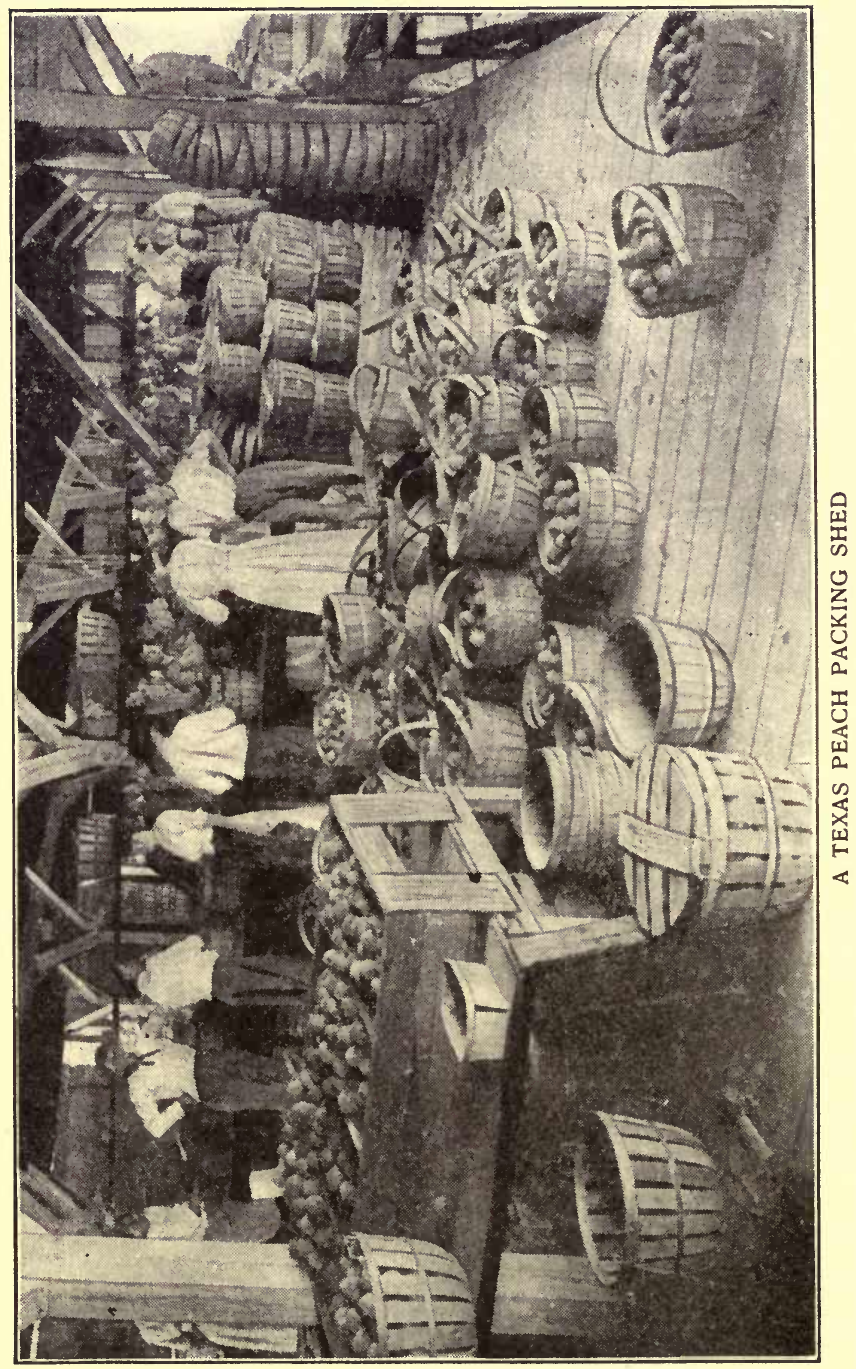


fined largely to early fruits, but the business by express is exceedingly limited on account of high express rates."

\section{THE HOME MARKET}

Thus far we have spoken only of wholesale selling in large and relatively distant markets. This is the way in which a large proportion of the peach crop is handled, but the best of the markets after all are those which are near home, and this is peculiarly true in handling the peach crop. True, considerable quantities of peaches are sold in home markets every year, but this amount ought to be greatly increased.

Mr. J. H. Hale, well known throughout the United States as one of the most extensive operators in large peach orchards, has recently been quoted as saying, that "while commercial peach orcharding on a large scale is undoubtedly being overdone in some sections of our country, one branch of the business has been sadly neglected-the little home markets that dot this great country of ours by the tens of thousands. Everyone loves a luscious peach, and nearly all who own land can grow peaches if they will. While I would be glad to see from one to a dozen peach trees in every garden, I fully realize that that happy day is yet a long way off. Therefore there is a great money-making opening for commercial peach growing in a small way in and around every center of population.

"The little home market orchard may have 50, 100,200 or 500 trees, depending on surrounding population, and should be planted with varieties suitable to the climate, covering early and late ripening kinds. One has little idea how many peaches can be sold to neighbors until they try it. I know of many peach orchardists who annually sell $\$ 500$ to $\$ 1,000$ 
worth of peaches to farmers within easy driving distance of the orchard, and this direct sale is nearly all profit. There are no freight or express charges to pay, no commissions on sale and no waste of any kind. When peaches fully mature on the trees they turn out more bushels of better quality and sell at top prices. Customers are satisfied and sales steadily increase. It is a great business opening too long neglected." This statement by Mr. Hale will be emphatically indorsed by everyone who understands the conditions throughout the country.

The great objection which has to be overcome here is that which lies against peddling. A great many farmers have a fierce prejudice against anything of this sort, and would rather work by the day cleaning out somebody else's horse stables than to peddle fruit. On the other hand, a good many men feel the folly of such an attitude and have brought themselves to the wisdom of supplying good fruit to their friends and neighbors in country and in town and making a good profit out of it for themselves.

The fruit is hauled from the orchard direct to the consumer and is sold either by the peck or the bushel or in suitable baskets. The I6-quart Jersey basket is by all odds the best package for handling fruit in this way, although a few scattering peaches could be handled from climax baskets or from the two-and-a-half-quart bale basket already described. It is worth while to consider also the use of paper boxes or cartons for this home market. These could be used especially for various fancy fruits. Already packages of this kind have been adopted by many growers of fancy apples and have been found satisfactory in meeting the retail trade. They are equally well adapted to the handling of fancy peaches. 
In this connection a word ought to be said regarding the value of advertising. Many of the large fruit-selling associations have adopted definite advertising plans and have found it possible to expand their business largely by the use of numerous advertising methods. Even the man catering to a small home retail trade can use various methods of

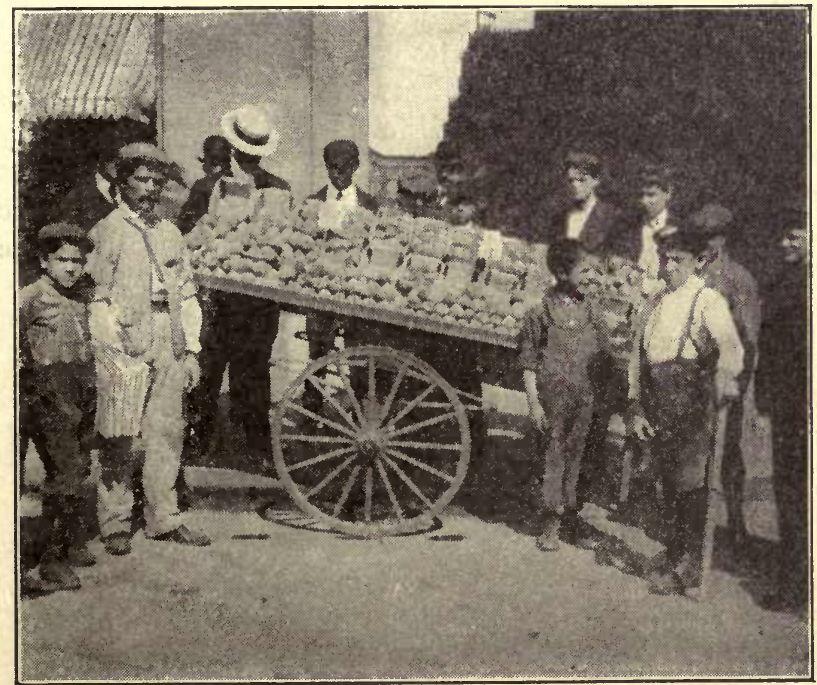

THE ULTIMATE RETAIL MARKET

advertising to advantage. The local newspaper will be his friend and should be liberally patronized in an advertising way. The farmer should not be satisfied simply to please the editor by a present of a peck of peaches, for which he gets a two-line notice in the news column, but should put in a good reading advertisement weekly. This should call attention to the good qualities of his peach crop, to his 
methods of delivery and should make a special point of describing the good methods of using peaches.

Of course, the largest amount of fruit is used in the way of canning, but there are many other ways of cooking and serving peaches which can be advantageously advertised. Every little thing of this kind which serves to call attention to the crop or to offer new methods of consumption will add to the trade. The handling of a peach crop is always a difficult matter, and the man who succeeds at it must keep his eyes and wits about him and must use all the refinements of modern business. He must be strictly on the job day and night from the time the first Greensboros ripen until the last Late Crawfords are gone and the money is all collected and safely in the bank. 


\section{XIV \\ THE FAMILY ORCHARD}

THE business of peach growing has been so highly specialized of late years that the production of peaches for home use has been almost forgotten. It has gone so largely into the hands of the big growers-men and companies with hundreds of thousands of trees-that the plain farmer who keeps a dozen trees is ashamed to mention the fact. This is a great pity, for the home-grower of peaches is just as good a man as the specialist with a thousand acres, and there are a good many more of him.

Then, again, the peach is one of the finest fruits for the home garden. It is easily grown. Over a large territory it is a sure and abundant cropper. It comes early into bearing. The best varieties are easily obtainable, and mistakes in variety selection are much harder to make than among apples, plums or pears, where the beginner stands an enormous chance of going wrong. The home-makers, suburbanites and amateur horticulturists everywhere, ought to be encouraged to plant more peaches.

I do not refer here to the general farmer who grows a few peaches to sell about town off his milk wagon or along with his Plymouth Rock eggs. That man also is to be encouraged. For the present let us consider the needs of the man with the family orchard, who wants peaches for his own home use and who never expects to sell a bushel to anybody.

Of course, such a man must forego some of the refinements of modern specialized peach growing. He cannot do all the things that the big growers do. 
Yet some of these omissions he can make good in other ways, by intensive culture and personal care. He cannot pick and choose a climate especially adapted to peach growing. He has to live and grow peaches where his home is. But he can choose an elevated spot with good air drainage instead of planting his peaches and other fruit trees in a low, frosty pocket. He cannot have the widest choice of soils, but he can use the best he has, preferring a warm, light, well-drained side hill to a heavy clay bottom. He cannot have a power sprayer, but he can do just as good work with a hand pump, and he can watch his few trees more closely to see what their particular needs are. He cannot have a pickers' strike at harvest time, and he is quite likely to be satisfied without it.

The maker of a family orchard should begin by selecting a favorable site, reasonably convenient to the dwelling house. It should be on high land, with a good slope. The soil should be coarse, perhaps gravelly, but rich in plant food, without being silty, clayey or heavy. It should be well drained; and if the drainage is not perfect enough, tile should be put in to make it so. The area should also be capable of thorough cultivation. The home acre should be a garden rather than an orchard; but a good orchard requires that perfect tillage proverbially characteristic of a garden rather than that general neglect represented in many so-called orchards. The various systems of neglect, known as seeding down, mulching, etc., widely practiced in apple orchards, are wholly unsuited to the management of peach trees and particularly bad in a family fruit garden. After the best bit of land about the farm has been selected it must be put in the pink of condition and kept so. 
If the would-be peach grower is a suburbanite with a half-acre or less of land at his disposal, he has naturally no choice at all, but must use that soil he has. If his soil is too unpropitious, he had better give up peach growing altogether; but ordinarily by tile drainage, deep working, adding vegetable matter and by other approved methods of soil improvement, he can make a promising start.

In the family fruit garden peaches will be grown along with other fruits. The spacing and arrangement will therefore be a compromise calculated to meet the needs of all sorts. A good plan is to adopt the square rod as a unit. Standard apple trees can then be set two rods apart with fillers between, consisting of dwarf apples, peach trees, plums or whatever may be required. Peaches in a block by themselves following this unit would stand at one rod$161 / 2$ feet-apart each way. If space is extra valuable and care is correspondingly good, bush fruits such as currants and gooseberries can be grown in these smaller spaces, at least for the first few years.

The farmer who puts out peaches for family use, and with whom land is not a serious matter, should be urged to "get a plenty while he's gittin'." He is apt to shy at 50 cents a tree asked by the tree peddler; and not being used to tree planting an order for a dozen trees looks bigger to him than a thousand looks to a real fruit grower. But peach trees can be had for much less than 50 cents apiece, and two dozen trees are not too many for the smallest farm family. I should want a hundred; but perhaps this is the judgment of a man inured to fruit growing, and perhaps I couldn't eat so many peaches anyway.

Spring planting will be safest for beginners. But the novice should observe with particular care the 
practice good peach growers follow in cutting back their nursery trees at time of setting out. In suburban gardens I often see peach trees spoiled by being planted without heading back. The experienced planter cuts off all the side shoots and cuts the main stem back to a straight stub 6 to 20 inches long. Roughly stated, the better peach man he is the shorter he heads them back.

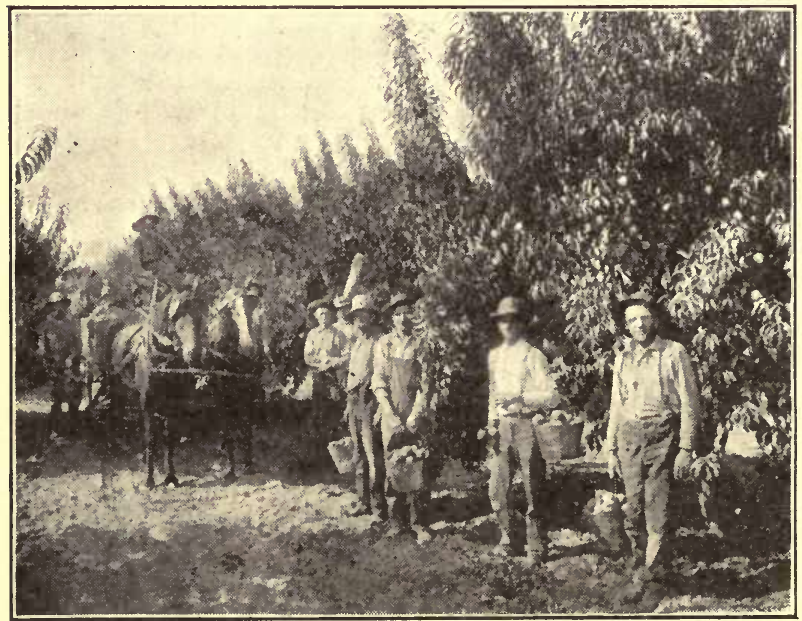

PICKING TIME

The novice need not undertake any fancy system of pruning or shaping the heads of his trees, and quite the less so seeing that the experts themselves do not agree on these points. However, he can keep his trees headed low, can keep the centers open, preferably by June pruning, and can cut out dead or broken branches. So much is safe; any more is not strictly necessary.

Along with good tillage the trees should be given 
a fair supply of plant food. Nitrogenous barnyard manures are not particularly good for fruit trees, except to keep up the supply of vegetable matter when that is being depleted, and they are more prejudicial to the health of the peach tree than to any other species of fruit. Supposing the soil to have plenty of humus or vegetable matter, mineral fertilizers should be given to the peach trees. Of these potash is the most important, and after that phosphoric acid. The potash can be given in the form of wood ashes, but more economically in the form of muriate of potash. The phosphoric acid can best be applied in the form of basic slag meal (Thomas phosphate powder).

Young trees and such as show sparse yellow foliage should have a limited amount of nitrogen. On moderately good soil a young peach tree ought to thrive on a ration consisting of one ounce of nitrate of soda, one pound of slag meal and one pound of muriate. A five-year-old tree bearing a good crop of fruit should have two ounces of nitrate of soda, three pounds of basic slag and three pounds of muriate. In any case these plant foods should be sowed under the trees, but not too near the trunks, say in a zone from $I$ to 8 feet in radius; and should be raked or harrowed into the surface of the soil.

Some cover crop should always be sown in the family orchard. In the southern states this ought to be cowpeas; in the middle states it ought to be crimson clover; in the northern states it ought to be mammoth clover or winter vetch. Winter vetch seed is so expensive as almost to preclude its use in commercial orchards, but need not be seriously considered in the family garden.

The family orchard will properly contain a wide selection of varieties-some early, some late; some 
yellow, some white; some free, some cling; some for eating and some for canning. A larger number of varieties may be wisely planted than in a commercial orchard; and in their selection one should pay more attention to fine quality and less to hardiness, health and productiveness.

The case may be summed up in a sentence by saying that good peaches and plenty of them can be grown by anyone who is physically and morally capable of garden work of any sort, all that is required being reasonably good garden conditions, reasonably sound horticultural instincts and reasonably decent care. 


\section{XV}

\section{BOTANICAL AND POMOLOGICAL STATUS}

THE peach is one of the newest of cultivated fruits, much newer to garden culture than the apple and the pear, at least so far as European civilization is concerned. All the evidence goes to show that the peach originated in China (although the old opinion used to be that it came from Persia); and Chinese civilization is so much older than that of Europe that no one can tell how long it has lasted. The peach and many of the allied fruits have been grown and cultivated in a rough sort of way by the Chinese people for centuries immemorial. The peach eventually made its way to western Europe by the Persian route, having been grown and highly esteemed in India and Persia before it was carried to Greece and Italy. In these latter countries, it made its appearance shortly after the beginning of the Christian era. The fact that it was received directly from Persia is commemorated in the Latin name (Prunus persica, or Amygdalus persica), and gave rise to the original impression of a Persian nativity.

The species to which the peach belongs has been variously referred to the genus Prunus, of which the plum is the type, and more doubtfully to other genera. All of this has no. interest whatever for the practical grower of peaches and has very little botanical significance. The question rests merely upon the scientific definitions of these closely related genera. 


\section{NECTARINE}

The nectarines should always be considered with the peaches because they are very closely related. In fact, nectarines not infrequently grow on the same trees with peaches. Several authentic cases have been known where nectarines have originated directly by bud variation upon the branches of peach trees. Yet in some botanies the nectarine has been given a separate scientific name, being held to be a separate species. Such arrangement is of doubtful validity. The nectarine does not come sufficiently true from seed to maintain the definite and fixed characters which should be attributed to a separate species. About the only recognized distinction between the nectarine and the peach is that the former has a perfectly smooth skin like the plum, whereas all varieties of peaches have some sort of tomentum, or "fuzz," on the surface of the fruit.

\section{NEAR RELATIVES}

The nearest botanical relatives of the peach are the small dwarf Chinese species, Prunus davidii, which is rarely grown as an ornamental in this country, but which has no apparent horticultural importance, and the Simon plum, Prunus simonii, which has been planted to some extent in this country as a commercial plum, and which has been used extensively, especially in California, in hybridizing with Japanese plums.

\section{CLASSFFICATION OF PEACHES}

Systematic study of varieties of peaches in this country is of recent origin. Apparently, Prof. R. H. 
Price made the first important contribution to the subject in his Texas Experiment Station Bulletin 39, published in 1896 . In this he proposes to divide the cultivated peaches into several natural groups. These groups he characterizes fully, and into them he distributes a majority of the varieties then known in Texas. All the more recent classifications have been founded on this one, and are like it in some degree. In his "Cyclopedia of American Horticulture” (iii., I227), published in I90I, Prof. L. H. Bailey gives a natural classification for peaches very closely modeled on the Price classification. The present writer, in turn, has outlined a natural classification of peaches,* which, with a few changes of names and descriptive terms, follows the same outline. It seems best, under the circumstances, to give only one of these outlines here, and doubtless the latest one can be properly offered. This divides the cultivated varieties into five natural groups, named and characterized as follows:

I. Persian Group (or typical peaches)-These are round, more or less pointed, marked with an indistinct suture ; flesh yellow or white, and characteristically soft and juicy; pits roundish or elliptical, pointed, deeply corrugated, mostly clinging to the flesh or only partially free. This group includes all the commonest old-fashioned varieties, such as the Crawfords, Oldmixon, Alexander, Amsden, Salway, Chair Choice, etc.

2. Chinese Cling Group-Trees broad-headed, open, spreading or even drooping, usually very vigorous, hardy, and prolific ; foliage large, flat, almondlike, dark green, retaining its color late in the fall, when it changes to a grayish-green tint; glands

*Waugh, "Systematic Pomology," p 175. 
reniform in the pure type; flowers very large, light pink in the pure type, but smaller and darker colored in some of the mixed descendants; fruit large, often enormously so, generally long oval and compressed, creamy white, with a delicate blush in the pure type, but white or yellow in the mixed descendants; skin very delicate and thin in the pure type, with a delicate marbled or stippled appearance, but firmer in many of the recent varieties; flesh fine grained, soft, juicy, melting in the pure type, but firmer in mixed descendants; stone somewhat flat, with medium corrugations, adhesion various; season variable, but early varieties predominating. Chinese Cling is the type of this group; but Belle of Georgia, Waddell, and Hiley are, perhaps, the best known commercial types. Elberta, best known of all, belongs to this group, but its characters do not conform nicely to those of the pure type.

3. Honey Group-Fruit long and irregular in form, with a deep suture, and usually with a long, pointed apex; pits long, corrugated, and sharply pointed. Tree not hardy, suitable for planting only in the extreme southern states, along the Gulf of Mexico. The variety, Honey, is the one commonly grown.

4. Columbia Group-Mostly large trees (Columbia itself being an exception to this rule); fruit late, firm, often streaked and mottled; pits small, oval, pointed. The variety Columbia, taken as the type, has been long known in the United States, but has never been cultivated on an extensive scale. Other varieties are Cabler, La Reine, Lula, Texas, and Victoria.

5. Peen-to Group-Tree large and vigorous, willowy, with long, slender branches; leaves long and narrow; fruit much flattened endwise. (Though 
this is the most striking characteristic of the variety Peen-to itself, the seedlings raised from this variety seldom show this peculiar form.) Skin white and mottled with red, much as in the Chinese Cling group, flavor sweet but peculiar; stone flattened endwise like the fruit. This is said to be a distinctly southern type, ranging farther south than any of the other peaches. Until very recently it was supposed to be too tender to be grown outside of Florida; but in 1902 the variety was discovered growing thriftly and fruiting nicely on the grounds of the Massachusetts Agricultural College, Amherst, Mass. The variety is said to grow in China as far north as Tien-Tsin. These things suggest that the Peen-to group may have a northern range much beyond that now assigned to it.

The peaches are unusually easy of classification on purely arbitrary lines, and such classifications have accordingly been in most general use. The one which we may take as representative of them all, and which is, at the same time, one of the best yet devised, is the classification of John J. Thomas. This arrangement was used in the various editions of "The American Fruit Culturist." The "Synopsis of Arrangement" follows, a few varieties being named in each group by way of illustration. These varieties are named and classified here exactly as given in Thomas' book. Many varieties of recent introduction might, perhaps, be used better by way of illustration; but this would require not only a thorough study of the varieties in question, but perhaps also some readjustment of the scheme of classification.

I. Freestones, or melters; flesh not clinging to the stone.

1. White flesh, or nearly white. 
(a) Glandless leaves, which are deeply and sharply serrate-Tillotson, Red Rareripe.

(b) Leaves crenate, with globose glands-Belle-

grade, George IV, Hale Early, Troth.

(c) Leaves with reniform glands-Brevoort, Morris White.

2. Flesh deep yellow.

(a) Leaves crenate, globose glands-Barnard, Crawford Early, Crawford Late.

(b) Leaves with reniform glands-Bergen.

II. Clingstones, or Pavies. Flesh adhering to the stone.

1. Flesh pale or light colored.

(a) Leaves serrate, without glands-Newington.

(b) Leaves crenate, glands globose-Oldmixon Cling.

(c) Leaves with reniform glands-Heath.

2. Flesh deep yellow.

(a) Leaves serrate, without glands-Orange Clingstone.

(b) Leaves with reniform glands-Lemon Cling, Tippecanoe.

3. Flesh purplish crimson.

(a) Glands reniform-Blood Cling. 


\section{XV}

\section{CHOOSING VARIETIES}

The American list of varieties of peaches harmonizes with the whole American business of peach culture. That is, it is larger and more liberal than the list of varieties offered in any other country where peaches are known. Furthermore, it is distinctly American. So far as I can recall there is not a single well-known variety in cultivation in America at the present day which did not originate on this continent. In the entire list of about 200 varieties recommended by the American Pomological Society, six are of European and one of Chinese origin. Of the six European sorts, Rivers (Early Rivers) is probably the only one which could be found in any current nursery catalog. The Chinese variety, Chinese Cling, is best known as the parent of many of our promising modern varieties such as Greensboro, Carman and Champion. The situation in this respect is very different from that which we find in the apple list or plum list. In the apple orchard or the plum orchard we find growing many important varieties of European or Asiatic origin.

This excessive preponderance of American varieties in our peach list shows that this fruit has been very fully acclimatized on this continent. To all intents and purposes it is an American fruit. The mere fact that its distant parentage traces back to Asia hardly counts. Very few of us who grow peaches can trace our parentage back very far without ceasing to be Americans. 
This constant introduction of American varieties still goes on. New sorts are coming out continually. A remarkably large number of those which have been introduced during the last decade give promise of permanent value. As these new and better varieties come into culture, the older and less valuable sorts diminish in popularity, disappear from the nursery catalogs and finally join forever the ranks of the has-beens. In that excellent standard fruit book, "Barry's Fruit Garden," in the edition of 1883 , out of 80 varieties described, 25 or nearly one-third are of foreign origin; and a large number of varieties named, both foreign and American, are now unknown and could not be discovered with a pomological search warrant anywhere in America. The list of varieties for profitable market orchards given in the book referred to ("Barry's Fruit Garden," page 4IO), shows in a very striking way how rapid has been the progress in the adoption of new varieties. The list is as follows:

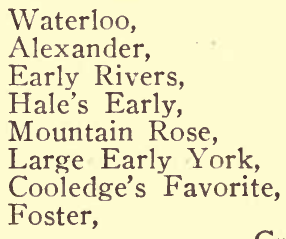

Crawford's Early,
Jacques' Rareripe, Morris White, Reeves' Favorite, Oldmixon Free, Crawford's Late, Red Cheek Melocoton, Stump the World, Smock.

This list does not contain a single variety now regarded as a leading market sort. It does contain several varieties now generally accepted as of secondary importance. It also contains a few sorts now entirely discarded.

The most striking event in the history of peach varieties in America was the introduction of the Chinese Cling. This variety and the seedlings from 
it began to be known in a very small way during the '7os, but not until the introduction of Elberta, Carman, Champion and Belle of Georgia during the '9os did the commercial value of this group dawn upon the peach-growing and peach-consuming public. There was considerable conservatism shown at first in adopting these varieties, particularly on account of the white flesh of the leading sorts. There had been (and to some extent still is) a prejudice against white-fleshed peaches. Ignorant buyers fancy that the yellow-fleshed sorts are richer. At any rate they look better to the eye, and a large section of the fruit-buying public still makes its purchases on eye-judgment.

These varieties, however, had such important good qualities, both in tree and fruit, that they rapidly made their way and are now regarded as the most important of our market sorts. The fruit is found to be of definitely superior quality, and this fact is slowly wearing its way into the consciousness of consumers. The fruit is beautiful indeed, for though it is not yellow, it usually ripens with a beautiful red blush, which makes it fully as attractive to the unprejudiced eye as any yellow peach.

The Elberta which, though somewhat off the regular type, still represents a yellow form of the Chinese Cling group, meets the demand for a variety with yellow flesh and skin, and at the same time maintains very important commercial qualities of enormous value. The Elberta has easily become the leading market peach of North America. It takes the same rank among peaches that Ben Davis takes among apples, except that it is better in quality and actually serviceable over a wider range of territory.

At the present time there are opportunities still open for improvement. New varieties are needed to 
fill gaps in the present list or to supply qualities which do not exist now in proper combinations. Varieties resembling Champion and Carman, but with better shipping quality, would be extremely desirable. Additional yellow-fleshed sorts of the Elberta type would be acceptable, and there is very practical need of good yellow market varieties coming earlier than Elberta, and especially of one or two yellow market varieties coming later than Elberta. It is to be hoped and expected that ambitious American pomologists will extend our peach lists still further and that the complementary discarding of old varieties will go on as of old.

The Elberta is far and away the most popular peach in America. Though the plantings of this variety have been materially cut down during the last few years, it is still probably true that there are as many trees of this variety now being set as of all other varieties in the list. Furthermore, this prominence of the Elberta extends over the entire peach-growing region from New Hampshire to Texas.

Next to Elberta the white flesh varieties of the Chinese Cling group seem to be most popular and profitable. The order of their popularity seems to be: Champion, Carman, Belle of Georgia, Waddell and Greensboro. One important quality which has recommended these varieties to commercial growers, especially in the northern states, is the relative hardiness of their buds. They certainly will stand colder winter weather than most other varieties, and appear to be able to withstand more severe spring frosts also.

So far nothing has been said about the Crawfords. A few years ago Early Crawford and Late Crawford were considered to be the leading varieties, 
both for home use and for market. They are still much planted, especially the Early Crawford. Late Crawford is used to some extent by planters, especially in New Jersey and Maryland. Their unquestionable high quality makes these varieties favorites of the best customers. Housewives who are in the habit of canning fancy peaches for home use still insist on Crawfords, and rightly object when Elbertas are offered as a substitute. On account of this demand from discriminating customers, many of whom are willing to pay a higher price for what they want, the Crawfords are still grown by some of the best peach men.

Other varieties of secondary commercial importance which are still planted and which we could not afford to discard are Oldmixon Free, a white peach of the highest quality; Reeves, a good yellow sort, which has a considerable vogue in Delaware and Maryland; Mountain Rose, which is still considerably planted, although in most cases it might be practicably supplanted by Greensboro and Carman; Salway, an old-fashioned sort still considerably grown in New York, Michigan and Canada; Smock, also frequently grown in New York and Michigan, especially for home use; Fox, a good white peach from New Jersey, which many growers still fancy; Foster, a yellow peach of particularly fine quality suitable for the home garden.

If a list should be made on the basis of quality with a view to providing the home garden with those sorts which are the very best and which can be produced only by devoted amateurs, this list will certainly contain : Foster, Early Crawford, Late Crawford, Champion, Oldmixon. To this list each individual would be at liberty to add particular varieties of his own preference or such as might be 
especially adapted to his locality. It is always important to make a selection of this sort in putting out varieties for home use.

Along the northern limit of peach-growing varieties have to be selected largely with reference to their hardiness. This has given cause from the beginning for a demand for particularly hardy kinds. The Triumph was largely propagated a few years ago on account of its hardiness, but in quality it has proved to be so thoroughly inferior that it has been discarded. Fitzgerald is a newer and perhaps better sort which has been widely disseminated on account

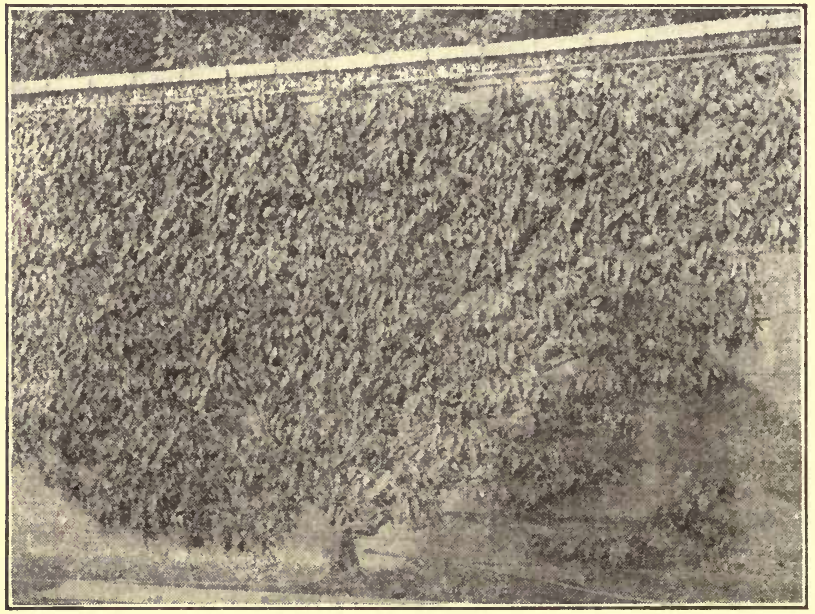

PEACH GROWN AGAINST A WALL

of its hardiness and which enjoys considerable favor, especially in Ontario. In the Canadian fruit-growing section the Yellow St. John is also a distinct favorite. In selecting varieties for hardiness, the Chinese Cling type already referred to should never 
be forgotten. Although Greensboro, Carman, Champion, Waddell and Belle of Georgia may be a trifle less hardy than Fitzgerald and Triumph, they are still distinctly superior in this respect to such sorts as Early Crawford and Oldmixon.

In making up an effective list for orchard planting certain principles may well be borne in mind. The rules of choice will be very different in making up a family orchard from what they will be in making up a commercial orchard, and perhaps it is best to state these rules, therefore, in simple antithetical form.

\section{RULES FOR CHOOSING VARIETIES}

Commercial Orchards.

Use as few varieties as possible.

Give only second thought to quality.

Choose varieties which ship well.

Choose varieties which ripen in succession.

Choose only hardy and healthy sorts.

Plant no novelties nor curiosities.
Home Orchards.

Select several or many varieties.

Choose family favorites.

Give first attention to quality. Provide succession of varieties.

Do not discard a good variety on account of defects in tree or shy bearing.

Test promising novelties and get some curiosities such as nectarines. 


\section{XVII}

\section{VARIETY CATALOG}

Acampo-A California introduction; early, yellow, handsome. Albright-Medium size, round, white skin, cling, good quality. late; use, dessert and market; originated in North Carolina.

Alexander-Small, round, red and white skin, creamy white flesh, semi-cling, poor quality, very early ; use, dessert and market; originated in Illinois; formerly much planted on account of its earliness, but now commercially obsolete. Allen October-Medium size, round, red and yellow skin, red and yellow flesh, freestone, poor quality, late; use, dessert and market; originated in Missouri.

Alton-Closely resembles Minnie, and thought by some to be identical with that variety. A large white peach, with red cheek, earlier than Carman.

Amelia-Medium size, round; red and white skin, white flesh, freestone, good quality, early; use, dessert and market; originated in North Carolina.

Ameliaberta-Medium size, yellow skin, yellow flesh, freestone; originated in Georgia.

Angel-Medium size, round, red and white skin, green white flesh, freestone, good quality, early; use, dessert and market; originated in Florida.

Arp or Arp's Beauty-A yellow market variety said to be liked in Oregon and Washington.

Augbert-Originated in Texas (?); round, large, yellow red, freestone, good quality.

Bailey (Friday Seedling)-Originated in Iowa; freestone, good quality.

Banner-Originated in Ontario; round, large, yellow red, freestone, very good quality, early.

Barnard (Early Barnard)-Originated in Illinois; round, medium large, red yellow, freestone, very good quality, medium early.

Beers Smock-Medium size, oval, red and yellow skin, red and yellow flesh, freestone, poor quality, late; use, dessert and market; originated in New Jersey.

Belle (Belle of Georgia)-Originated in Georgia; round oblate, medium large, white red, freestone, very good quality; dessert, kitchen and market use; mid-season or a little later. A fine market peach of the hardy Chinese Cling type. 
Bequett Cling-Medium size, green white and red skin, clingstone, good quality, medium early; use, market and kitchen; originated in Texas.

Bequett Free-Medium size, green white and red skin; freestone, good quality, medium early; market; originated in Texas.

Bergen Yellow-Large, round, red and yellow skin, yellow flesh, freestone, very good quality, medium season; use, dessert.

Bidwell Early-Small, oval, red and white skin, green white flesh, clingstone, medium quality, very early; use, dessert and kitchen; originated in Florida.

Bidwell Late-Small, oval, red and white skin, green white flesh, clingstone, good quality, late; use, dessert and kitchen; originated in Florida.

Bilyeu-Medium size, round, green white skin, white flesh, freestone, medium quality, very late; use, dessert, kitchen and market; originated in Maryland, where it is still a favorite variety.

Bishop Early-Medium size, round, white skin, freestone, good quality, medium late; use, market; originated in California.

Blood Cling-Large, round oval, yellow skin, red and yellow flesh, clingstone, medium quality, very late; kitchen use; a favorite curiosity and fancied by many for pickling.

Blood Free-Large, round oval, yellow skin, red and yellow flesh, freestone, very late; kitchen use; originated in America; medium quality.

Bokhara-Introduced by the late Professor Budd from Turkestan, but not valuable aside from its superior hardiness.

Brandywine-Large, yellow green red skin, freestone, medium quality, medium early; market use; originated in Delaware.

Brett (Mrs. Brett) -Originated in New York; round, medium size, white red, freestone, good quality, very late.

Brigdon (Garfield)-Medium size, round oval, red and yellow skin, red and yellow flesh, freestone, good quality, season medium; dessert and market use; originated in New York.

Briggs (Briggs' May)-Originated in Massachusetts, round, very large, white red, freestone, very good, early medium season.

Cable (Cable's Late)-Originated in Ohio, round, very large, yellow red, freestone, very good, medium late.

Cabler Indian-Large, round, red skin, red flesh, clingstone, poor quality, season medium; kitchen use; originated in Texas, and suited to extreme southern planting.

California (California Cling)-Originated in California; round, large, yellow red, clingstone. 
Carman-Originated in Texas; round, large, white, good, early; one of the finest sorts for home use or market.

Carpenter (Carpenter Cling)-Oblong, medium size, creamy white blushed, clingstone, good quality.

Chairs Choice-Medium size, round, red and yellow skin, red and yellow flesh, freestone, medium quality, medium season; kitchen and market use; originated in Maryland. A good canning variety and a good shipper.

Champion-Medium size, round, creamy, red skin, white flesh, freestone, good quality, medium early; dessert and market use; originated in Illinois; a first-class sort of the Chinese Cling type.

Charlotte (Early Charlotte)-Originated in Europe; oval, large, green white red, freestone, very good quality, early medium season.

Chili, Hill's-Medium size, oval compressed, red and yellow skin, red and yellow flesh, freestone, medium quality, medium early; market use; originated in New York; widely planted.

Chilow-A cling of the Lemon Cling type.

Chinese Cling-Very large, round compressed, creamy, white, red skin, clingstone, very good quality, medium season, kitchen and market use; originated in America, from Chinese seed and the parent of more important commercial varieties.

Chinese Free-Round, large, white red, freestone, good quality, medium season.

Climax (Horn's Hybrid)-Originated in Florida, round oval, medium size, yellow red; freestone, good quality, early.

Coleman-Compressed, small, creamy white blushed, freestone, good, medium early.

Columbia-Medium size, round, white skin, yellow flesh, medium quality, freestone, medium late; market use; originated in Georgia.

Conkling (Conklin)-Round, medium large, yellow creamy red, freestone, good, medium season.

Connett Southern Early-Large, oblate, white skin, semiclingstone, good quality, medium season; market use; originated in North Carolina.

Countess-Originated in Florida, round, large, white red, freestone, good, medium season.

Cox Cling-Medium size, round, green white skin, green flesh, clingstone, good quality; dessert and market use; originated in Texas.

Crosby-Medium size, round, red and yellow skin, yellow flesh, freestone, good quality, medium season, market use; originated in Massachusetts; formerly a great favorite, but now waning in popularity. 
Delaware (Delaware Rareripe)-Originated in Delaware (?) ; round, medium size, creamy white blushed, freestone, good, medium early.

Deming (Deming's September)-Oblate, large, yellow red, clingstone, medium season.

Dewey (Admiral Dewey)-Originated in Georgia; medium size, yellow, freestone, good, early.

Early Barnard-Medium size, round, red and yellow skin, yellow flesh, medium quality, medium season; market use; originated in Illinois.

Early China-Medium size, oval, white skin, white flesh, freestone, good quality, very early; dessert and market use; originated in Texas.

Early Crawford-Large round oval, yellow red skin, yellow flesh, freestone, very good quality, medium season; dessert and market use; originated in New Jersey.

Early Michigan (Husted No. 15)-Originated in Michigan (?) ; round, medium size, green white blushed, semiclingstone, good.

Early Toledo-Medium size, round, white red skin, white flesh, early; dessert and market use; originated in Ohio; freestone.

Early York-Medium size, round oval, white red skin, white flesh, freestone, very good quality, early; dessert and market use; originated in England.

Eaton-Medium size, round, yellow red skin, yellow flesh, clingstone, medium quality, medium season; dessert and market use; originated in North Carolina.

Ede (Captain Ede)-Originated in Illinois; round oval, medium size, yellow red, freestone, medium season.

Edgemont Beauty-Yellow, with red cheek, somewhat like Late Crawford.

Elberta-Large, round compressed, yellow red skin, yellow flesh, freestone, good quality, medium late; market use; originated in Georgia. Easily the leading variety for market.

Emma-Large, round compressed, yellow red skin, freestone, very good quality, medium late; market use; originated in Georgia.

Emperor-Originated in New Jersey; large, yellow red, freestone.

Engle (Engle's Mammoth)-Originated in Michigan (?); round, large, yellow red, freestone, very good, medium late.

Everbearing-Originated in Georgia; oblong, large, creamy white, freestone, good.

Eureka-Recommended by Stark Brothers' Nurserles.

Excelsior (Prince's Excelsior)-Originated in New York; round oblate, large, yellow, freestone, good, late. 
Family Favorite-Medium size, round oblate, green white skin, green flesh, semi-clingstone, good quality, early; dessert and market use; originated in Texas.

Fitzgerald-Medium size, oval, red yellow skin, yellow red flesh, freestone, very good quality, medium early; dessert and market use; originated in Canada; very hardy.

Florida (Florida Crawford)-Originated in Florida, oval compressed, late, yellow, freestone, good, medium season.

Florida Gem-Originated in Florida, round, medium size, white, freestone, good quality, early.

Forrester-Large, round, yellow red skin, very good quality, medium season; dessert and market use; originated in Georgia.

Foster-Very large, round, yellow red skin, yellow flesh, freestone, best quality, medium season; dessert and market use; originating in Massachusetts, remarkable for high quality and worth planting for home use.

Fox-Medium size, round, white skin, creamy white flesh, freestone, good quality, late; market use; originated in New Jersey, and heavily planted in that section.

Frances-Originated in Ohio; round oval, large, yellow red, freestone, medium early.

Galveston-Small, round oblate, yellow green skin, yellow green flesh, clingstone, late; dessert use; originated in Texas, medium quality.

George IV-Originated in New York; round, large, white red, freestone, very good; dessert use; medium season; an old-time favorite.

Globe-Large, round oval, yellow red skin, yellow flesh, freestone, good quality, medium season; market use; originated in Pennsylvania.

Golden Cling-Large, oval compressed, yellow red skin, yellow flesh, clingstone, good quality, late; kitchen and market use; originated in California.

Gold Drop (Golden Drop)-Originated in Michigan (?), round oval, medium size, yellow red, freestone, very good.

Governor Hogg-Originated in Texas (?), round, large, creamy white, semi-clingstone, good quality.

Greensboro-Medium size, round, red skin, white flesh, semiclingstone, good quality, early; market use; originated in North Carolina; one of the very best early varieties, tree hardy, prolific and an early bearer.

Hale-Small, round, green white red skin, green white flesh, semi-clingstone, medium quality, early; market use; originated in Ohio.

Hall (Early Yellow Hall)-Originated in Maine; round, large, yellow red, good, early. 
Heath Cling-Large, round oval, white red skin, white flesh, cling, best quality, very late; kitchen and market use; originated in Maryland.

Heath Free (Freestone Heath) -Originated in Massachusetts; oblong, large, green white, freestone, good, medium late.

Henrietta-Medium size, round oblate, yellow red skin, yellow red flesh, clingstone, medium quality, late; market and kitchen use ; originated in District of Columbia.

Hiley (Early Belle)-Originated in Georgia; round, large, creamy white red, freestone, early.

Honey-Small, oval, creamy skin, white red flesh, freestone, very good quality; dessert and kitchen use; originated in New York, but more suitable for southern growing.

Hynes Surprise-Small, round, red skin, creamy flesh, semiclingstone; medium quality, late; dessert and market use; originated in Kentucky.

Illinois-Described as a fine white market peach.

Imperial (White Imperial)-Originated in New York; round, very large, white yellow red, freestone, very good, early.

Ingold, Lady-Medium size, round, yellow red skin, yellow red flesh, freestone, good quality, medium early; dessert and market use; originated in North Carolina.

Iron Mountain-Originated in New Jersey; round oblong, large, yellow green, semi-clingstone, good.

Japan Dwarf (Japan Dwarf Blood)-Originated in Japan; round, medium size, yellow red, very good, very early.

Jacques (Jacques' Rareripe)-Originated in Massachusetts, round, compressed, large, yellow red, freestone, good, medium late.

$\mathrm{J}$. $\mathrm{H}$. Hale is a new peach originated by the man whose name it bears. It is a yellow fruit of the Elberta type, probably a seedling of that variety, larger and probably better, about the same season; smooth and very attractive. The originator and introducer claims great things for this variety.

Kalamazoo-Medium size, oval, red yellow skin, yellow red flesh, freestone, very good quality, medium early ; dessert, market and kitchen use; originated in Michigan, and largely planted there.

Kerr, Jessie-Medium size, oval, white red skin, white flesh, medium quality, very early; market use; originated in Maryland.

Keyport-Medium size round oval, white red skin, white flesh, freestone, poor quality, late; market use; originated in America.

Klondike-Originated in Pennsylvania; large, white yellow, good, late.

Krummel, or Krummel's October-Described in glowing terms by Stark Bros. Late, yellow, freestone. 
Lagrange-Originated in New Jersey; round oblate, greenyellow red, large, freestone, very good, late.

Large York-Medium size, round, white red skin, white flesh, freestone, good quality, early; dessert and market use; originated in England.

Late Admirable-Large, round oval, green red skin, white flesh, freestone, very good quality, medium season; dessert use; originated in France.

Late Crawford-Large, round, yellow red skin, yellow flesh, freestone, very good quality, late; dessert and market use; originated in New Jersey; a fine old favorite and widely accepted as the standard of quality.

Late Rareripe-Medium size, round oval, yellow red skin, white flesh, freestone, very good quality, medium season; dessert and market use; originated in America.

Lee, General-Large, round oblate, green skin, green flesh, clingstone, good quality, early; market use; originated in America.

Lemon Cling-Large, round oval, yellow red skin, yellow flesh, clingstone, very good quality, medium season; dessert and market use; originated in South Carolina. Extensively used by the California canneries.

Lemon Free-Large, oblate, yellow skin, yellow flesh, freestone, very good quality, late; dessert and market use; originated in Ohio.

Levy (Henrietta, Levy's Late)-Originated in District of Columbia; round, late, yellow, clingstone, very good; market and kitchen use; very late.

Lewis-Medium size, round, red white skin, creamy flesh, freestone, good quality, late; dessert, kitchen and market use; originated in Michigan.

Louise-Medium size, round, red skin, white flesh, freestone, good quality, early; dessert and market use; originated in England.

Louisiana-Round, large, white, freestone.

Lolo, Miss-Medium size, round, red white skin, creamy flesh, freestone, good quality, early; dessert and market use; originated in Texas.

Lone Tree-Originated in Iowa; medium small, yellow, freestone, very good, medium late.

Longhurst-Originated in Canada; oval, medium large, yellow, freestone, good.

Lorentz-Originated in South Carolina; round, medium large, yellow, freestone, good.

Lovell-Medium size, round compressed, yellow red skin, yellow flesh, freestone, good quality, late; kitchen and market use ; originated in California.

Lovett (Lovett's White)-Originated in California; very large, yellow red, clingstone. 
McDevitt (McDevitt Cling)-California; oblate compressed, very large, yellow red, clingstone, very good; kitchen and market use; medium season.

McIntosh-Round, large, creamy white, semi-cling, very good, medium early.

McKevitt-California; white, clingstone.

Mamie Ross-Medium size, round oblate, white skin, yellow flesh, clingstone, good quality, early; dessert and market use; originated in Texas.

Maggie (Maggie Burt)-Texas; oval, large, wnite, clingstone, good, very early.

Mary Choice-Large, round, yellow red skin, yelıow red flesh, freestone, very good quality, late; market use; originated in Maryland.

Mathews (Mathews' Beauty) - Round, large, yellow, freestone, good.

Mayflower-A very early, bright red, promising new variety. May Lee-An early cling variety.

Miller (Miller Cling) - Very large, yellow, clingstone.

Morris White-Medium size, oval, creamy white skin, white flesh, freestone, medium quality, medium season; kitchen and market.

Mountain Rose-Medium size, round, white red skin, white flesh, very good quality, freestone, medium early; originated in New Jersey; dessert and market use.

Muir-Large, yellow skin, yellow flesh, freestone, very good quality, medium season; dessert, kitchen and market use; originated in California.

New Prolific-Round oval, large, yellow, freestone, very good.

Niagara-Originated in New York; large, freestone, very good, medium early.

Nichols (Nichols' Orange)-Originated in California (?) ; large, yellow, clingstone.

Oldmixon Cling-Medium size, round oval, creamy skin, white flesh, clingstone, good quality, medium season; kitchen and market use.

Oldmixon Free-Medium size, round oval, creamy skin, white flesh, freestone, very good quality, medium season; dessert and market use; a fine variety and a great favorite in its neighborhood.

Onderdonk-Medium size, oval, white skin, white flesh, freestone, guod quality, medium season; dessert and market use; originated in Texas.

Orange Cling-Medium size, round, yellow skin, yellow flesh, clingstone, medium quality, medium season; kitchen and market use.

Orman-Originated in Texas (?).

Ovieda-Originated in Florida (?) ; compressed, medium size, green white blushed, freestone, very good, medium early. 
Pallas-Medium size, oval, white skin, white flesh, freestone, early; dessert and market use; originated in Georgia.

Parham-Small, round, yellow white skin, white red flesh, freestone, medium quality, late; market and kitchen use;

Parks (Parks' Late Cling) - Originated in Illinois; round oblate, very large, creamy yellow red, clingstone, good, very late.

Peen-to-Small, form very oblate, white skin, white flesh, clingstone, good quality, early; dessert use. This is a Chinese type of which several forms are known in America. It is suited to southern climates, particularly Florida, though it has been fruited as far north as Massachusetts.

Peninsula-Large, oblate, yellow skin, yellow flesh, freestone, good quality, medium late; market use; originated in Maryland.

Phillips Cling-Medium size, oblate compressed, yellow skin, yellow flesh, clingstone, good quality, medium late; dessert and market use; originated in California.

Picquet-Medium size, round, yellow red skin, yellow flesh, freestone, medium quality, late; dessert use; originated in Georgia.

Prize-Medium size, oblate, yellow skin, yellow red flesh, freestone, good quality, late; market use.

Ray-Originated in Mississippi; round, medium size, creamy white red, early medium season; a very good market variety.

Red Bird-A very early cling variety recommended for Central States.

Red Cheek Melocoton-Medium size, round oval, yellow red skin, yellow flesh, freestone, medium quality, medium season; dessert and market use.

Red River-Originated in Texas; round, medium large, creamy white, semi-clingstone, good quality, early.

Reeves Favorite-Large, round oval, yellow red skin, yellow flesh, freestone, good quality, medium season; market use; originated in New Jersey; widely planted.

Richmond-Large, round, yellow red skin, yellow flesh, freestone, medium quality, medium season; market use; originated in New Jersey.

Rivers-Medium size, round compressed, creamy white skin, white flesh, freestone, good quality, early; dessert and market use; originated in England.

Robert-Originated in Delaware (?) ; round, medium, yellow, freestone, very good.

Royal George-Small, round, white red skin, white flesh. freestone, best quality, medium season; dessert use. 
Russell-Medium size, round, white red skin, white flesh, freestone, good quality, early; dessert, kitchen and market use; originated in Nebraska.

Salway-Medium size, round oval, yellow red skin, yellow flesh, freestone, medium quality, late; market use; originated in England.

Sellers (Sellers Golden Cling)-Originated in California; very large, yellow, cling, late.

Slappey-Round, medium size, yellow, freestone, very good, early.

Smock-Medium size, oval, yellow red skin, yellow flesh, freestone, medium quality, late; market use; originated in New Jersey.

Sneed-Medium size, oval, green white skin, white flesh, clingstone, poor quality, very early; market use; originated in Tennessee. This variety was formerly much planted as a first-early market sort, but has been very properly abandoned by progressive growers.

Snow-Medium size, round, white skin, white flesh, freestone, medium quality, medium season; dessert and market use.

Stevens Rareripe-Medium size, round oval, creamy white skin, white flesh, freestone, good quality, medium late; market use; originated in New Jersey.

Stinson (Stinson's October, Stinson's Late)-Originated in Mississippi (?); round oval, large, creamy white red, clingstone, good, late.

St. John (Yellow St. John)-Medium size, round, yellow red skin, yellow flesh, freestone, good quality, early; market use; originated in America. A great favorite in the Ontario peach district.

Stonewall Jackson-Medium size, round oblate, green yellow skin, green flesh, clingstone, medium quality, early; kitchen and market use; originated in Texas.

Strawberry-Small, oval, red skin, white flesh, freestone, good quality, early medium; dessert and market use; originated in New Jersey.

Stump-Large, round oval, white red skin, white flesh, freestone, medium quality, medium late, market use; originated in New York.

Suber-Originated in Florida (?); round, medium size, creamy white red, clingstone, good, early.

Success-Originated in Texas; round, large, yellow, freestone, good.

Susquehanna-Very large, round, yellow red skin, yellow flesh, freestone, best quality, medium season; dessert and kitchen use; originated in Pennsylvania.

Taber-Originated in Florida (?); round medium size, creamy white blushed, clingstone, good, medium season. 
Tarbell-Originated in Massachusetts; round, very large, yellow red, freestone, very good, medium late.

Taylor-Originated in District of Columbia; round, large, yellow, clingstone, very good.

Texas-Small, round oblate, yellow green skin, green flesh, semi-clingstone, poor quality, late; dessert use; originated in Texas.

Thompson (Mrs. Thompson's Golden Free)-Originated in Florida; yellow, freestone.

Thurber-Medium size, round oval, white red skin, white flesh, freestone, good quality, early; dessert use; originated in Georgia.

Tillotson-Small, round, white red skin, white flesh, freestone, good quality, early; dessert use; originated in New York.

Tippecanoe-Large, round, yellow red skin, yellow flesh, clingstone, medium quality, late; dessert and market use; originated in Pennsylvania.

Toledo (Early Toledo)-Originated in Ohio (?); round, large, yellow white, freestone, good, early.

Triumph-Small, round, yellow red skin, yellow red flesh, semi-clingstone, poor quality, early; market use; originated in Georgia. Tree and bud very hardy, prolific, but fruit is small and very poor in quality. The variety is hardly worth growing except in the coldest regions.

Troth-Small, round, white green red skin, white red flesh, freestone, poor quality, medium early; market use; originated in New Jersey.

Tuskena-Large, oblate compressed, yellow skin, yellow red flesh, clingstone, good quality, early; dessert, kitchen and market use; originated in the South.

Victor-Round, medium size, creamy white, semi-clingstone, good, early.

Victoria (Early Victoria)-Originated in England; round, medium size, yellow red, freestone, very good, early.

Waddell-Oblong, medium large, creamy white, freestone, good. A first-class midseason market peach of the Chinese cling group.

Wager-Small, oval, yellow skin, yellow flesh, freestone, poor quality, medium season; market use; originated in New York.

Waldo-Small, oval, white skin, white flesh, freestone, medium quality, early; dessert and market use; originated in Florida.

Walker, Free-Large, oblate, white red skin, white red flesh, freestone, good quality, late; dessert and market use; originated in Delaware. 
Ward Late-Medium size, round oval, white red skin, white flesh, freestone, good quality, very late; dessert and kitchen use.

Washington-An old variety, which some growers recommend for the family orchard.

Waterloo-Small, round, white red skin, green white flesh, semi-clingstone, poor quality, very early; dessert and market use; originated in New York.

Wheatland-Very large, round, yellow red skin, yellow flesh, freestone, medium quality, medium season; dessert and market use; originated in New York.

Wonderful-Originated in New Jersey; round, large, yellow red, freestone, late.

Yazoo (Yazoo Cling) - Originated in Mississippi; clingstone.

Yellow Rareripe-Medium size, red skin, yellow red flesh, freestone, good quality, medium season; dessert and market use. 


\section{XVIII}

\section{THE NECTARINE}

Though well known in Europe and a decided favorite in England, the nectarine is a stranger in America. It is practically unknown here. Probably not one fruit grower in a hundred has ever seen a nectarine. It is very hard to account for this strange neglect of a good fruit.

The nectarine is simply a smooth-skinned peacha peach without the fuzz. This definition itself would imply that it was a good thing. The fuzz on the peach certainly has no culinary value; we may even doubt its having any commercial value. The fruit being otherwise the same as the peach, the nectarine would seem to have a decided advantage over this splendid and well-known fruit. Neglect of the nectarine in America seems to arise largely from the fact that varieties adapted to American conditions have not been introduced. For the most part the varieties which are listed in the fruit books have originated in England and are not adapted to our section any more than European varieties of peaches are. Could we have nectarines of the quality of the Early Crawford peach or of the Foster or Champion, they certainly would find many friends in this country.

The nectarine used to be regarded by botanists as a separate species, but it is now known definitely to be the same as the ordinary peach, with the exceptions already described. Nectarines have frequently originated from peach seeds, and conversely peaches have originated from nectarine seeds. The 
most convincing evidence, however, of their identity lies in the fact, well authenticated in several cases, that nectarines originate by bud variation from peach trees. Furthermore, these nectarine trees sometimes revert to the peach character by bud sporting.

This interchangeability of peach and nectarine shows their identity and indicates definitely the fact that they are to be propagated, cultivated and managed in all ways alike. At $\mathrm{th}$ is time it will be unnecessary, therefore, to give any special directions for the propagation or cultivation of the nectarine. We may simply reiterate the statement that what we need in this country are some good va rie tie s adapted to Ameri c a n conditions. We may hope for something of this kind in the future. Several new varieties of very fine quality have recently been introduced in Eng-

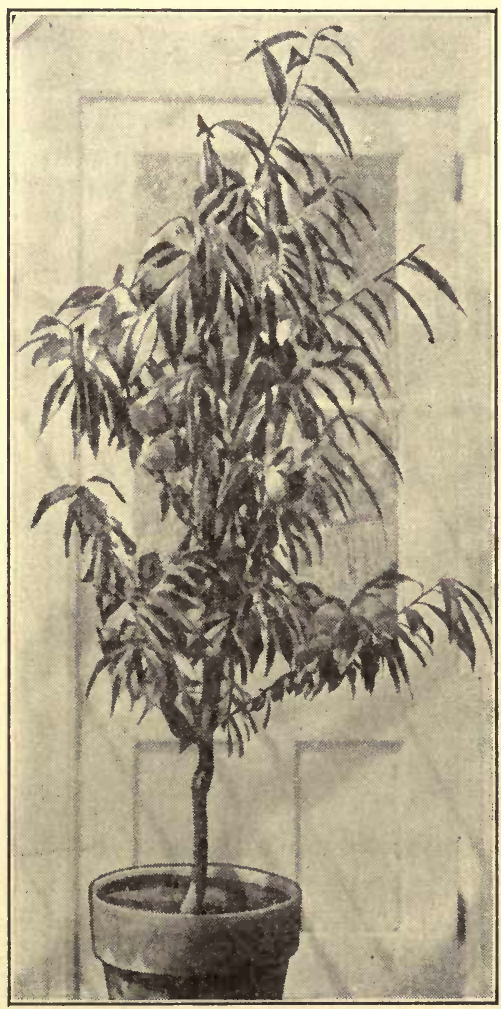

NECTARINE GROWN UNDER GLASS 
land, and it is impossible to see why similar advances cannot be made in this country.

In England the nectarine is largely grown under glass, for which use it is often preferred to the peach. Its comparative popularity in that country may be indicated roughly by the fact that Robert Hogg in his Fruit Manual, edition of 1875 , named and described 35 varieties of nectarine exclusive of synonyms. These were classified into 12 different groups. On the other hand a careful search through the current catalogs of American nursery firms has found only one which offered any nectarines whatever. W. \& T. Smith, of Geneva, N. Y., include three varieties, named and described in their catalog as follows :

Early Violet, medium size, yellowish green, with a purple cheek, flesh pale green, highly flavored, last of August.

Elrudge, medium size, pale green covered with dark red, flesh greenish white, melting, very juicy with a rich, high flavor, beginning of September, freestone.

Gawny, medium size, pale orange, dark cheek, flesh orange, melting, rich, the very best early variety, ripening the first of August.

Professor Wickson in the Cyclopedia of American Horticulture, states that the nectarine is grown in California almost exclusively for drying and canning, and even for these uses is of but minor importance. As compared with peaches, for canning, the output of nectarines is only about one-eighth of one per cent of that of the peach, and for drying only about one per cent of that of the peach. The varieties grown for both canning and drying are the white nectarines, because they do not color the syrup in canning and because when sulphured they make a beautiful translucent amber color. 


\section{XIX \\ UTILIZING THE FRUIT}

The peach is pre-eminently a fruit to be eaten fresh and raw. The ripe, juicy, luscious peach in the hand is worth two in the compote. Great quantities of the fruit meet their final market in this form. It is the ambition of honest American fruit growers to produce peaches so cheaply that any honest, industrious workingman may give his family a good filling up every year. Peaches can be and should be eaten fresh in large quantities by everyone.

Then come peaches and cream! The words have become the universal synonym for everything rich and luscious to the palate. Good thick cream, and plenty of it, at peach time will make any peach grower's family completely happy. There is a common prejudice in favor of the yellow varieties for this sort of consumption. This prejudice has no fair foundation, aside from the fact that yellow fruit looks better on white china than white fruit does. Yellow varieties like Late Crawford or Foster are, of course, unsurpassable; but the best white varieties such as Carman, Champion or Oldmixon, are just as good to the taste. Perhaps the housewives of the future will arrange to serve them on yellow saucers, or even on red ones, in order to help out the color scheme, seeing that is all that now stands in their way.

\section{CANNING}

Next to the raw, fresh peach the canned fruit is the most acceptable; and probably one-half the en- 
tire American peach crop annually finds its way into cans. Doubtless everybody knows how to do the trick, but for fear someone may look into this book expecting suggestions for canning, I will insert the recipe and directions given by Mrs. Maria Parloa, as follows :

\section{8 quarts of peaches, \\ 1 quart of sugar, \\ 3 quarts of water.}

Put the sugar and water together and stir over the fire until the sugar is dissolved. When the syrup boils skim it. Draw the kettle back where the syrup will keep hot but not boil.

Pare the peaches,* cut in halves, and remove the stones, unless you prefer to can the fruit whole.

Put a layer of the prepared fruit into the preserving kettle and cover with some of the hot syrup. When the fruit begins to boil, skim carefully. Boil gently for ten minutes, then put in the jars and seal. If the fruit is not fully ripe it may require a little longer time to cook. It should be so tender that it may be pierced easily with a silver fork. It is best to put only one layer of fruit in the preserving kettle. While this is cooking the fruit for the next batch may be pared.

It is most important that the jars, covers, and rubber rings be in perfect condition. Examine each jar and cover to se? that there is no defect in it. Use only fresh rubber rings, for if the rubber is not soft and elastic the sealing will not be perfect. Each year numbers of jars of fruit are lost because of the false economy in using an old ring that has lost its softness and elasticity. Having the jars, covers, and rings in perfect condition, the next thing is to wash and sterilize them.

Have two pans partially filled with cold water. Put some jars in one, laying them on their sides, and some covers in the other. Place the pans on the stove where the water will heat to the boiling point. The water should boil 10 or 15 minutes. Have on the stove a shallow milk pan in which there is about 2 inches of boiling water. Sterilize the cups, spoons, and funnel, if you use one, by immersing in boiling water for a few minutes.

\footnotetext{
*Some cooks insist upon silver knives for paring, because they claim that steel knives injure the fruit. If the fruit is fully ripe, and if it is scalded before paring, this dictum may be disregarded. For scalding, the water should be in considerable quantity and boiling hard ("galloping," the cooks call it), and only a small number of peaches should be immersed at a time. A frying basket is an excellent utensil to use. From 30 to $90 \mathrm{sec}-$ onds' d:p is enough. The skin will peel off in great sheets, thus reducing labor.
} 
When ready to put the prepared fruit in the jars slip a broad skimmer under a jar and lift it and drain free of water. Set the jar in the shallow milk pan and fill to overflowing with the boiling fruit. Slip a silver-plated knife or the handle of a spoon around the inside of the jar, that the fruit and the juice may be packed solidly. Wipe the rim of the jar, dip the rubber ring, in boiling water and put it smoothly on the jar, then put on the cover and fasten. Place the jar on a board and out of the draft of cold air. The work of filling and sealing must be done rapidly, and the fruit must be boiling hot when it is put into the jars. If screw covers are used, it will be necessary to tighten them after the glass has cooled

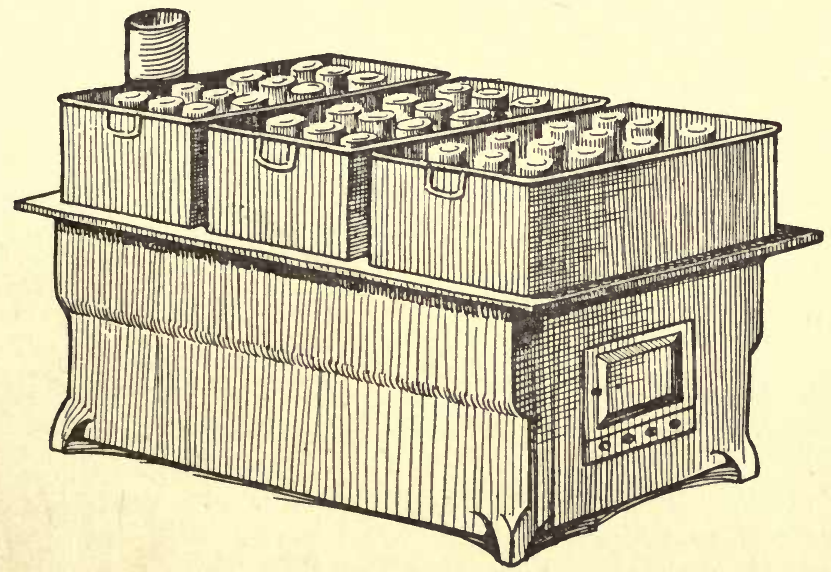

SMALL CANNING OUTFIT

and contracted. When the fruit is cold wipe the jars with a wet cloth. Paste on the labels, if any, and put the jars on shelves in a cool, dark closet.

In canning, any proportion of sugar may be used, or fruit may be canned without the addition of any sugar. However, that which is designed to be served as a sauce should have the sugar cooked with it. Fruit intended for cooking purposes need not have the sugar added to it.

Large growers of peaches everywhere have experimented seriously with various methods for disposing of waste peaches or of taking up any excess in times of glut when it may easily happen that for 
several days at a time a reasonable profit cannot be realized by shipping even good grades of fruit. Canning always seems to be one of the most promising methods of utilizing such peaches, and many growers have therefore established their private canneries, some on a large scale, some in a smaller way.

The net result of many years of experience the country over seems to show that such private canneries are not always a success, and that they are most likely to be of use to owners of small or medium-sized orchards. The extensive growers can usually arrange to turn their surplus over to some established canning factory; and on the other hand the relatively large canning plants which they would require for their own use and the large personnel which they would be obliged to organize hurriedly in case of need, make too big and complicated an undertaking to carry. The writer knows of one large orchard in which a fully equipped cannery was installed at an expense of several thousand dollars. It was used one year during a glut; but owing to inexperienced management and untrained operatives, no profit was realized. During the six years next succeeding, the peach crop moved to market properly without any glut, and the cannery was not called into requisition. When the time came again that the plant might have been used, it was altogether worthlessthe woodwork had rotted down and the ironwork rusted out. Practically it was a total loss. This experience is not universal, of course, but it seems to be fairly typical.

On the other hand, the small grower who has no very well-established shipping market, but who depends largely on peddling his peaches to his neighbors, is sure to find some year that peaches are 
plentiful and his neighbors all have enough. Thus he is left with a big crop on his hands. Then, with a good canning outfit, he and his family, the hired man and the hired girl can put up the bulk of the crop in good tin cans, turning them off during the winter and converting a dead loss into a clean and handsome profit.

Such home canning outfits are obtainable on the market at all prices from $\$ 5$ up to several hundred. A good farm outfit, capable of putting up 3,000 cans a day or more, can be bought for $\$ 100$. It is easily set up and easily operated by anyone who has reasonable mechanical ingenuity and who is capable of any good clean piece of work at any other job. The full directions for installing and operating these outfits are supplied by the manufacturers, so that further details need not be given here.

\section{THE CANNING INDUSTRY}

The practice of canning fruit for winter use is peculiar to America. In many countries it is hardly known, and nowhere is it practiced to the same extent, or anywhere near it, as in the United States and Canada. The peach is the prime favorite for canning, whether in the home kitchen or in the biggest canning factories. It is the easiest to handle, it keeps the best and it comes out in the winter in the most acceptable quality. For all these reasons it is put up in enormous quantities. Gould and Fletcher have compiled statistics to show somewhat of the extent of this industry, and these figures are given herewith as showing the amounts of peaches put up in 1904 by the commercial canning factories. The amount put up in home kitchens cannot be estimated, but it may be roughly guessed at 50 per cent of the amount canned in factories. 
Quantity and Value of Peaches Packed in Various States.

\begin{tabular}{|c|c|c|c|}
\hline \multirow{2}{*}{ State. } & \multicolumn{2}{|c|}{ Canning season of 1904} & \multirow{2}{*}{$\begin{array}{l}\text { Value, } \\
\text { season of } \\
1899 .\end{array}$} \\
\hline & Cases.* & Value. & \\
\hline 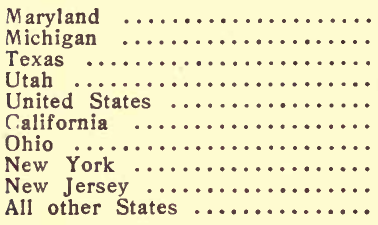 & $\begin{array}{r}69,269 \\
30,086 \\
17,845 \\
1,302,715 \\
744,715 \\
352,244 \\
12,762 \\
10,060 \\
9,767 \\
57,128\end{array}$ & $\begin{array}{r}179,838 \\
52,989 \\
43,868 \\
\$ 3,894,272 \\
2,640,524 \\
753,003 \\
35,134 \\
39,399 \\
19,370 \\
130,147\end{array}$ & $\begin{array}{r}102,504 \\
60,775 \\
3,362 \\
\$ 4,283,165 \\
3,103,775 \\
758,919 \\
10,940 \\
72,591 \\
2,500 \\
167,799\end{array}$ \\
\hline
\end{tabular}

*A case is generally understood to hold 24 cans.

In the statistics for 1904 "all other states" includes Alabama, Arkansas, Delaware, Illinois, Indiana, Mississippi, Missouri, Nebraska, North Carolina, Oregon, Pennsylvania, South Carolina, Virginia, and West Virginia, together with small lots in still other states not named, amounting to 14,576 cases, valued at $\$ 36,452$.

\section{PEACHES FOR VINEGAR}

Waste peaches, those too poor or too ripe for shipping or canning, or those partially decayed, may be utilized by pressing out the juice and fermenting it for vinegar or brandy. The United States bureau of chemistry, reporting on this matter, shows that peaches contain sufficient fermentable sugar for use as vinegar stock, and that they can be successfully handled by machinery already in use for making apple cider and vinegar. Other points of interest are as follows: First, but little variation was found in the composition of the same variety of peaches when obtained from different localities. Second, the peach juices analyzed were found to be rich in 
sugar, but were about one per cent lower in sugar than average apple juices. They were considerably richer than apples in sucrose and in acid. Third, it was found that the use of pure culture yeasts was not necessary to insure rapid alcoholic fermentation. Fourth, the ciders prepared from peaches were considerably poorer in alcohol than apple ciders on account of the fact that peaches contain less total sugars than apples. Fifth, the presence of brown rot was found not to interfere with the alcoholic fermentation of the ground peaches, but a large proportion of the sugars was wasted by allowing the fruit to rot before fermenting. Sixth, wellflavored vinegars were produced by the use of a small quick-process generator. These vinegars were of acceptable quality, though turbid, and did not possess the distinctive peach flavor.

\section{PEACH WINE}

The following directions for making peach wine are taken from a French cookbook:

Press the juice from the fruit and use five gallons of water to every bushel of fruit; in other words, dilute the juice pretty freely. To each gallon of juice add two pounds of sugar. Put this mixture in an open cask or a stone jar. Allow it to ferment, skimming off the scum which rises. When no more scum appears, draw off the liquor, preferably with a siphon, so as not to disturb the sediment, placing it in a keg, which should be laid on its side in a moderately cool cellar. A second fermentation, slower than the first, will now follow, during which time the keg should be kept nearly but not quite closed and perfectly full. A small quantity of the juice should be kept at hand in a separate vessel for this purpose. This slow fermentation will last for three to six months, and its completion may be easily judged by the fact that no more gas is given off. The cask may then be tightly bunged up, or the wine drawn off into clean bottles and tightly corked. Further aging in wood or glass improves the appearance and the flavor. 


\section{PEACH BUTTER}

This is one of the good old-fashioned farm products. As made at the factories it is usually called peach marmalade, and that is also what the modern college-educated housewife usually calls hers. Genuine peach butter, however, is something which ought not to be allowed to go out of remembrance, and so we would better include a good working recipe recently given by Mrs. Fred Telford in the "Country Gentleman," as follows:

Peach butter can be made from peaches that are ovcrripe; that is, from peaches that are not decayed, but that are too ripe to put upon the market. First-class peach butter usually retails at about 75 cents a gallon, and since but little sugar need be added in its manufacture there is a very good profit in it for the producer when peaches are cheap. It also makes an excellent spread for children's school lunches as well as a good dish for the table.

Wash the peaches thoroughly, cut out all decayed spots, peel and remove the stones. Place them in a preserving kettle and add enough water to prevent them from burning. Boil the peaches slowly, stirring them constantly, until they are well cooked down and smooth. Then add a little cinnamon and about a cupful of sugar for each quart of butter. The taste of people varies, so that a little more or less sugar may be required. Continue the slow cooking and constant stirring until the entire mass is free from lumps and as smooth as it can be made by stirring. While the butter is still boiling hot, put it in glass cans and seal it immediately, using new rubbers and perfect covers.

It is true that butters of this sort keep if placed in unsealed jars, but they are almost sure to mold. The mold does not entirely spoil the butter for use as food, but it makes any sort of food unattractive, and in addition lessens the food value. These mold filaments soon penetrate the entire contents of a quart can; and while they are usually invisible, unless a microscope is used to detect them, they soon produce flavors noticeable to the discriminating taste. If the butter is kept in an unsealed jar, melted paraffin should be poured over the top.

The labor of constant stirring may be partly eliminated in the following manner: Stew the prepared peaches until they become soft and then run them through a colander. Add the same proportion of sugar as for the stirring method, and 
stir it into the butter until it is thoroughly dissolved and mixed. Place the butter in a stone crock, set it in a moderately hot oven, and stir it about every 15 minutes. This method produces just as smooth a butter, lessens the labor and the danger of burning, and eliminates burns on the arms and hands from the spattering of the hot butter.

\section{PEACH MARMALADE}

Those who prefer to make peach marmalade may safely follow Mrs. Rorer's recipe which is as follows:

Rub the peaches, but do not pare them. Cut them in halves, remove the stones, and to every pound of peaches allow a half-pound of sugar. Put the peaches in a porcelainlined kettle, add sufficient water to cover the bottom of the kettle; cover, and heat slowly to boiling point; then stir and mash the peaches until fine, add the sugar and three or four of the peach pits or kernels (to every quart of marmalade) blanched and pounded to a paste. Boil and stir continually for 15 minutes, then stand over a more moderate fire, and cook slowly 20 minutes longer. Stir occasionally, that it may not scorch. Put away in stone jars.

\section{PEACH JELLY}

Peaches are not supposed to make jelly, but the following directions ought to work, as they are given on the eminent authority of Mrs. Rorer, being taken from her celebrated cookbook:

"Pare, stone, and slice the peaches, put them in a stone jar, and to each half-peck of peaches allow one cup of water. Crack a dozen of the kernels and throw them in with the peaches. Stand the jar in a kettle of boiling water, cover closely, and boil for one hour, stirring until the fruit is well broken, then turn into a flannel jelly-bag, and hang up to drip. To every pound of this juice allow the juice of one lemon and one pound of granulated sugar. Put the juice into a porcelain-lined kettle, and bring it quickly to a boil; add the sugar, stir until the sugar is dissolved, then boil rapidly and continuously until it jellies, skimming the scum as it comes to the surface; 20 minutes is usually sufficient, but sometimes I have boiled it $\mathbf{3 5}$ minutes before it would jelly properly. 
"It is wise to commence testing after 15 minutes' boiling. To do this, take out one teaspoonful of the boiling jelly, pour it into the bottom of a saucer, and stand it in a cold place for a moment; then scrape it one side with a spoon-if jellied, the surface will be partly solid; if not, boil a few minutes longer, and try again. As soon as it jellies, roll the tumblers quickly in boiling water, then fill them with the boiling liquid. Stand aside until cold and firm (about 24 hours). Then, if you have jelly-tumblers, put on the lids; if not, cover with two thicknesses of tissue paper, and paste the edges of the paper down over the edges of the tumblers. Then moisten the top of the paper with a sponge dipped in cold water. This moistening stretches the paper, so that when it dries again it shrinks and forms a covering as tight and smooth as bladder skin.

"I do not recommend jelly being covered with brandied paper, as in my hands it has never been satisfactory. The jelly, in cooling, forms its own air-proof covering, and if the top of the tumbler be well secured, it is all that is necessary. Keep in a cool, dark place."

\section{PRESERVED PEACHES}

Peaches make splendid preserves. Mrs. Lincoln's Cook Book tells how to do it thus:

"Pare the peaches; or remove the skins by plunging the peaches into boiling lye (two gallons of water and one pint of wood ashes). When the skins will slip easily, take the peaches out with a skimmer and plunge them into cold water; rinse in several waters, and there will be no taste of the lye. Weigh, and add three-fourths of a pound of sugar to each pound of fruit. Halve them, and use some of the pits, or leave them whole-as you please. The stones improve the flavor. Make a syrup by adding as little water as possible to the sugar-about one cupful to each pound of sugar. When it boils, skim till clear, then add the peaches, and cook until transparent."

\section{GREEN PEACH PRESERVES}

The writer has not tried it, but he has often heard of making preserves of green peaches, and he therefore thinks it safe to introduce the directions given in a French cookbook. It is said that the fruit can 
be used when quite green, even the fruit taken at thinning time when two-thirds grown (it really ought to be thinned sooner) being said to make perfectly edible and even delectable preserves.

Green peaches, 5 pounds;

Sugar, 1 pound for every pound of juice ;

Water enough to cover fruit.

Preparations: First, take off the stems, place the peaches in a kettle, pour over enough water to cover well, and boil until the peaches are tender. Second, empty the kettle on a sieve, placing a dish under it to receive the juice. Third, weigh the juice, pour in the kettle, add as many pounds of sugar as you have pounds of juice, and let boil while skimming until the syrup is cooked to the degree called the great thread, which you try as follows: Dip the hand into cold water and dip the skimmer in the syrup, touch it with thumb and forefinger, and instantaneously open it. If the preserves are cooked enough a thread of sugar will be obtained. Fourth, during the time that the syrup is cooking arrange the peaches in jars, and when the syrup is ready, pour it over the fruit, let cool, and seal tightly.

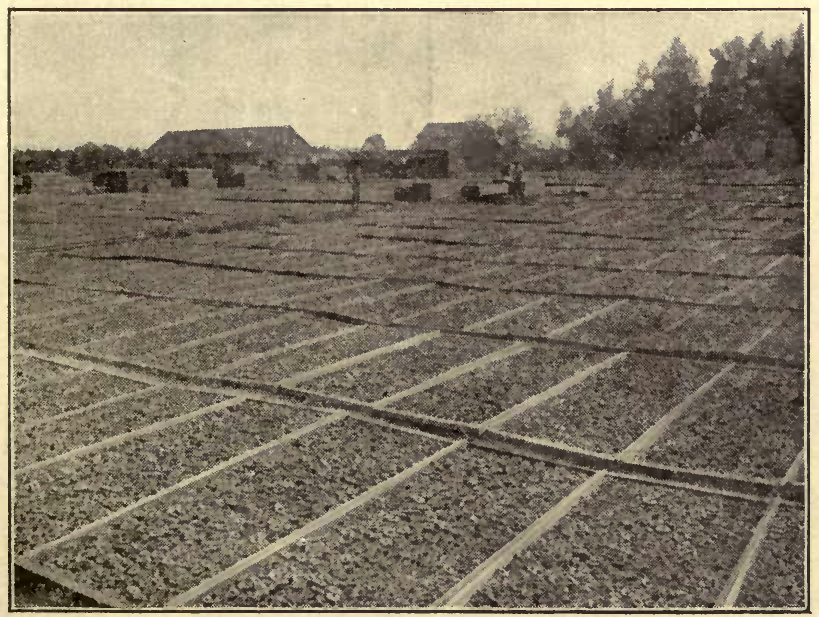

DRYING PEACHES-CALIFORNIA 


\section{SWEET PICKLED PEACHES}

Here we have a favorite farm home product which ought to be put up every year. Clingstone varieties are to be preferred, and those with red flesh are particularly recherche (which is a French word meaning greatly sought for). Mrs. Farmer's Boston Cooking-School Cook Book is authority for the recipe.

1/2 peck peaches,

2 pounds brown sugar,
1 pint vinegar,

1 ounce stick cinnamon, cloves.

Boil sugar, vinegar, and cinnamon 20 minutes. Dip peaches quickly in hot water, then rub off the fur with a towel. Stick each peach with four cloves. Put into syrup, and cook until soft.

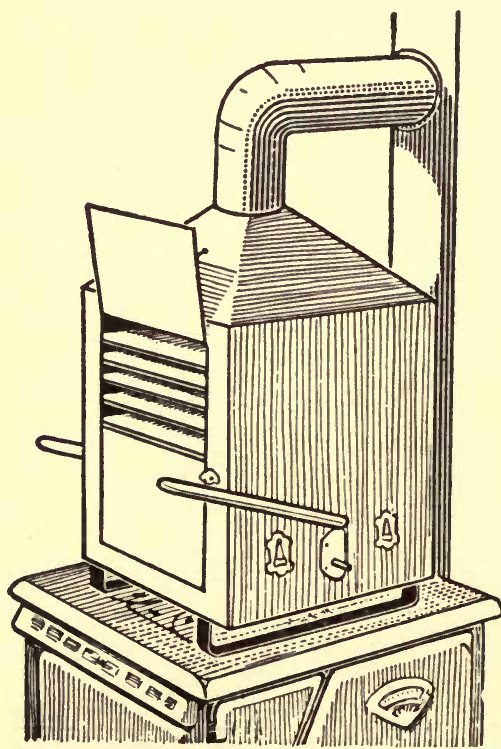

HOME DRYER
DRIED PEACHES

Dried peaches are a staple article of commerce, though they are by no means plentiful nor cheap. The fact that they cost so much of the grocer leads many people to suppose that the surplus crop can easily be worked up in the drier at a profit, but this has not been the experience of most of the men who have tried it in the eastern states. The com- 
mercial drying of peaches is an industry confined almost wholly to California, where the drying is done largely under the sun in the open air. It hardly seems practicable here to enter into a discussion of the methods used in that work.

In the eastern states peaches when dried are usually put through one of the regular fruit evaporators. These may be bought in various sizes, some designed to be operated on top of a kitchen stove, and others fitted with furnaces of their own. The commercial fruit evaporators, of course, are even more ambitious than these, and consist of houses or kilns built especially for the work. Anyone who wishes to try the ready-made driers of any size can get full and reliable directions for operating from the manufacturers; and anyone who wants to build a regular drying factory had better consult the evaporation engineers.

Peaches may be home dried with excellent results. The freestone varieties are best for this purpose. Mrs. Fred Telford gives the following directions:

Peel the peaches, remove the stones, and spread the fruit upon drying frames that have previously been covered with clean wrapping paper. Place the frames in the direct sunshine and cover the peaches with mosquito bar or wire netting. Place the frames far enough from the street or the road to prevent dust from falling on the fruit. Each day place the frames under cover just before sundown. Turn the peaches several times during the first day of exposure. After they have dried for some days the contents of several frames may be placed together on one frame. Peaches may be dried without peeling, but the product is not so well flavored or tender when it is cooked in the winter. Nor do the unpeeled dried peaches sell so well as the peeled fruit. After the peaches have become thoroughly dry they should be kept in a cool, dry place, in something that will prevent all insects from reaching them. A thick paper sack, such as corn meal or pancake flour comes in, is excellent for this purpose. 


\section{SHORT CAKE}

One of the good old-fashioned home cookery luxuries which is never remotely imitated in the restaurants is the peach shortcake. Now, the wrong way to make a shortcake is to prepare as a basis a sponge cake or some other sweetened substratum of the same general sort. This is what they do in cheap hotels. The right way, and the way they practice on good farms, is to make a batch of dough just as though there were to be biscuits for supper. Sometimes it is made a little shorter, but this is hardly desirable. This dough is baked in square or round baking tins, which ought to be big and generous.

There should be at least two of these tins of cake baked, and better three. They should be fully baked but with only a very slight browning. When done they are removed to a big platter, and between the layers of unsweetened cake are spread liberal strata of very ripe sweet peaches, peeled, stoned and sliced thin. The fruit stratum is always heavily sweetened with sugar, and may be touched up a bit with nutmeg or other spices if desired. Some rural gourmets dress their portions with thick yellow cream; other more delicate persons say their stomachs will not stand the treatment. For shortcomings of this sort we recommend i2 active hours a day picking, packing and shipping peaches to market.

\section{PEACH PIE}

Peach pie is probably the best known way of cooking peaches. Here is a good New England recipe, from the land where they know what pie is:

Remove skins from peaches. This may be done easily after allowing peaches to stand in boiling water one minute. Cut 
in eighths, cook until soft with enough water to prevent burning; sweeten to taste. Cool, and fill crust previously baked. Cover with whipped cream, sweetened and flavored.

\section{PEACH COBBLER}

In the country where peaches are cheap as air, and where home consumption is the main feature of the peach market, the people who really know what the peaches are good for make the fruit harvest memorable with a peach cobbler. Apparently this is not an aristocratic piece of cookery. The present writer has searched all the most approved cookbooks in vain for directions or even for a mention of peach cobbler. But it is too good a thing to be overlooked, so in the absence of any cookbook recipe the author will tell how he has himself made a peach cobbler which met with liberal indorsement from hungry children, who ought to know about such matters.

A peach cobbler is simply a peach pie on a large and liberal scale. Instead of being built up in a Ioinch pie tin, it is baked in the biggest dripping pan the house affords-one which will barely go into the oven. A heavy crust is provided, made shorter than biscuit dough, but not so short as the usual pie crust. Some cooks put in a lower crust for the foundation of the peach cobbler, while others prefer to do without the lower crust. The writer follows the former practice. Good peaches, ripe but not soft, of some rich-flavored variety, are chosen, pared, pitted and sliced. The cobbler is filled fairly full of these sliced peaches, which are then freely dressed with sugar, also with nutmeg and any other spices which the cook's taste may fancy; the top crust is put on, some ventilating holes made as in ordinary pie designing, and the thing shoved carefully into a moderate oven. It is baked till the crust is done. Every- 
body gets a piece on his plate about as big as a package of corn-flakes; and a good many folks pour Jersey cream over theirs. Doesn't that make your mouth water? Try it.

\section{PEACH FRITTERS}

Two medium-sized sour peaches, powdered sugar, batter.

Batter: 1 1-3 cups flour, 2 teaspoons baking powder, $1 / 4$ teaspoon salt, 2-3 cup milk, 1 egg. Mix and sift dry ingredients, add milk gradually, and egg well beaten.

Pare peaches, cut in eighths, slice eighths, and stir into batter. Drop by spoonfuls and fry in deep fat. Drain on brown paper, and sprinkle with powdered sugar. Serve hot on a folded napkin.

\section{PEACH DUMPLINGS}

1 quart of flour,

2 heaping teaspoonfuls of baking powder,

1 large tablespoonful of butter or lard,

1 teaspoonful of salt, $\mathrm{r} / 2$ pint of milk.

Pare the peaches, but do not take out the stones. Put the pot over the fire with just enough water to half cover the dumplings; or if you are going to steam them, which is much the better way, have the steamer over the pot, which should be half full of boiling water. Now put the flour into a bowl, and rub into it the butter or lard, then add the salt and bakingpowder. Mix well, and moisten with the milk, using more or less, as the flour requires to make a soft dough; that is, a dough that will roll out nicely without being sticky. Take the dough out on a baking board, roll it out about a half-inch in thickness. Now cut out the dumplings or the covering for the peaches with a large round cutter, about the size of a common saucer; put one peach in the center of each piece, add a little sugar, and carefully work the dough over the peach.

If you boil them, tie each one in a floured cloth, or put them into netted dumpling bags, plunge them immediately into the boiling water, and boil 30 minutes. If you steam them, place them on a dinner plate a little smaller than the steamer, stand the plate in the steamer and steam 40 minutes. Serve on the plate on which they were steamed. Serve hot, with hard sauce or sweetened cream.-From Mrs. Rorer's Cook Book. 
BAKED PEACHES

Mrs. Farmer gives directions as follows for baking peaches:

Peel, cut in halves, and remove stones from six peaches. Place in a shallow granite pan. Fill each cavity with one teaspoon sugar, one-half teaspoon butter, few drops lemon jucce, and a slight grating of nutmeg. Cook 20 minutes, and serve on circular pieces of buttered or dry toast.

\section{BRANDIED PEACHES}

There are a great many good people in this world, and some of them temperate to a fault, who fancy the flavor of brandied peaches. This is one of the standard methods of preparing this fruit, and need not be allowed to go out of use, though perhaps some other name might be chosen more acceptable to the W. C. T. U. The directions following are from Mrs. Rorer's Cook Book:

"Take large white or yellow freestone peaches. (They must not be too ripe.) Scald them with boiling water; cover, and let stand until the water becomes cold. Repeat this scalding, then take them out, lay them on a soft cloth, cover them over with another cloth, and let them remain until perfectly dry. Now put them in stone jars, and cover with brandy. Tie paper over the tops of the jars, and let them remain in this way one week. Then make a syrup, allowing one pound of granulated sugar and a half-pint of water to each pound of peaches. Boil, and skim the syrup, then put in the peaches, and simmer until tender. Then take the peaches out, drain, and put them in glass jars. Stand the syrup aside to cool. When cold, mix equal quantities of this syrup and the brandy in which you had the peaches. Pour this over the peaches, and seal.

\section{PEACH BAVARIAN CREAM}

1 jint can or nine fresh $1 / 2$ box gelatine, peaches,

1 pint of cream.

$1 / 2$ pint of cold water,

Cover the gelatine with the water and let soak a half hour. Press the peaches through a colander; if fresh, first stew and 
sweeten them. Stir the gelatine over boiling water until dissolved. Whip the cream. Add the gelatine to the peaches, mix, and turn into a tin basin; stand the basin in a pan of cracked ice, or snow, and stir constantly until the mixture begins to thicken; then add the whipped cream, stir carefully until thoroughly mixed; turn into a mold and stand aside to harden. Serve with whipped cream heaped around the base. -Mrs. Rorer's Cook Book.

\section{PEACH TAPIOCA}

1 can peaches,

$1 / 4$ cup powdered sugar,

1 cup tapioca,
Boiling water,

$1 / 2$ cup sugar,

$1 / 2$ teaspoonful salt.

Drain peaches, sprinkle with powdered sugar, and let stand one hour; soak tapioca one hour in cold water to cover; to peach syrup add enough boiling water to make three cups; heat to boiling point, add tapioca drained from cold water, sugar, and salt; then cook in a double boiler until transparent. Line a mold or a pudding dish with peaches cut in quarters, fill with tapioca, and bake in moderate oven 30 minutes; cool slightly, turn on a dish, and serve with cream sauce.-Miss Farmer's Boston Cooking School Cook Book.

\section{PEACH LAYER CAKE}

Cake.
$1 / 2$ pound of butter,
5 eggs,
6 ounces of flour,
$1 / 4$ teaspoonful of mace, 1 teaspoonful of baking powder.
$1 / 2$ pound of sugar,
2 ounces of corn starch,
1 teaspoonful of vanilla,
2 tablespoonfuls of sherry,

Beat the butter to a cream; add the sugar gradually, beating all the while, then add the yolks of the eggs, then the wellbeaten whites, then the flour, cornstarch and baking powder; beat well; add the flavorings, mix well. Grease three deep jelly tins, pour in the cake, and bake in a moderately quick oven 15 minutes. When done, remove carefully from the pans, and stand the cakes on a towel for a few minutes to cool.

Pare the peaches, cut them in thin slices. Beat the whites of two eggs lightly, add, gradually, four tablespoonfuls of powdered sugar, and then beat vigorously until stiff enough to stand alone. Put a layer of this over the top of one cake, then a layer of sliced peaches, stand another cake on top of 
this. Put the remainder of the white filling over the top of this cake, then another layer of peaches. Now place the remaining cake on top of this, press down lightly, dust the top over with powdered sugar, and it is ready for use.-Mrs. Rorer's Cook Book.

\section{PEACH AND CANTALOUPE COCKTAIL}

Cut the ends off Gem, Jenny Lind, Rocky Ford or any good musk melon; remove the seeds; fill with cubes of peaches nice and ripe, adding other fruit if desired, such as bits of pineapple, orange, apple, etc.; cover with French dressing made with lemon juice; add a dash of nutmeg and a teaspoonful of fine currant jelly to each melon; serve very cold in crushed ice. In prohibition states these melons sometimes get a big spoonful of sherry each just before coming to the table.

\section{PEACH SHERBET}

At the soda fountain one often encounters peaches and near peaches, sometimes as dressings for college ices, sometimes in other forms. Peach ice cream as usually prepared is not a howling success, but peach sherbet can be made so as to satisfy the criticism of the best palate:

Let best peaches, say Waddell or Late Crawford, ripen thoroughly on the tree. They should be just as soft as good peaches can get without spoiling. Peel and stone a peck of these fruits, handling very carefully. Put them into an ice cream freezer with about one-third their weight of sugar and nothing else. Stir them thoroughly while freezing. Here you have a most delectable dessert. It should not be frozen too stiff, though tastes vary at this point, and everyone should please his own.

\section{PEACH MERINGUE}

Pare and stew one dozen peaches, and press through a colander to remove the stones. Line two deep pie dishes with plain paste; sweeten the peaches to taste; fill the dishes even full, and bake in a quick oven 25 minutes. Then beat the whites of six eggs and six tablespoonfuls of powdered sugar to a stiff froth, add a teaspoonful of vanilla. Cover the pies with this meringue about three-quarters of an inch thick, and 
put back in the oven until a nice brown.-Mrs. Rorer's Cook Book.

\section{PEACH SPONGE}

$1 / 2$ box of gelatine.

1 pound of peaches,

3 eggs,
1 pound of sugar,

Grated rind of one and juice of two lemons.

$1 / 2$ pint of boiling water,

Boil the sugar and water until clear, take the scum from the surface. Pare the peaches, and slice them into this syrup. Stew until tender. Cover the gelatine with cold water and let it soak while the peaches are stewing; add the gelatine to the peaches when they are done, then press the whole through a sieve, add the rind and the juice of the lemons, and stir until cold and slightly thickened. Beat the whites of the eggs to a stiff froth, stir them into the peaches and beat until cold and thick, then pour into a mold to harden. Make a vanilla sauce from the yolks of the eggs. Serve the sponge in a dessert dish, with the sauce poured around it.-Mrs. Rorer's Cook Book.

\section{JELLIED PEACHES}

Soak two ounces of gelatine in a cup of cold water. Boil a cup and a half each of sugar and cider, and the rind of one lemon, for 10 minutes; pour the syrup over the gelatine. Put a layer of sliced peaches and blanched almonds in the mold; fill with the syrup; chill; garnish with whipped cream.-Consolidated Library of Modern Cooking \& Household Recipes.

\section{PEACH CANAPES}

Saute circular pieces of sponge cake in butter until delicately browned. Drain canned peaches, sprinkle with powdered sugar, few drops lemon juice, and slight grating nutmeg. Melt one tablespoon butter, add peaches, and when heated, serve on cake--Miss Farmer's Boston Cooking School Cook Book.

\section{ICED PEACHES}

Any good peaches may be easily iced by dipping first in the beaten white of an egg, then in sugar finely pulverized, and again in egg, and so on until you have the icing of the desired thickness. Peaches should be pared and cut in halves, and treated in this way. 


\section{HISTORICAL SKETCH}

Scientific opinion now leans to the belief that the peach is native to southern China. In former times it was supposed to have originated in Persia. The oldest names which we know signify this Persian origin. But Persia was probably only a way-station in the spread of the peach from China to Europe and thence to North America.

Although at the time of the first settlements in America the peach was not nearly so well known nor so highly regarded as it is today, plantings were made on this continent at a very early date. It is hardly worth while to review the records of these early plantings here; but the general trend of peach culture, its rapid spread, and the unexpected manner in which this fruit made itself at home in America can be judged from the following transcript from a famous fruit book published in Philadelphia in 1803 . This was the American edition of Forsyth's "Culture and Management of Fruit Trees," in which it was said:

"Peaches are in some variety, and ripen to great perfection in the middle and the southern states; as with but a little attention they would in the more northern states of America. It is a fruit that is so natural to the country of these states, that they are applied as food to hogs, also in making brandy, and for culinary purposes. They are in succession, one sort coming after another, from July to November. In some of the states, kilns are erected for drying 
and curing apples, pears, peaches, and other fruits in great quantities; where pies are made into mountains of crust, thick, essential, and cheap; and given to hirelings, as an agreeable food for all laboring people in the country, and which needs but little or no sugar. The dried fruit is packed in casks for family use ; and is sometimes exported as merchandize. They are generally divided into clear-stone and cling-stone peaches. The cling-stone sorts are, in France, called pavies. In a list of thirty-nine choice sorts of peaches, given by Mr. Forsyth, only six are received by the French as pavies or clingstones; and, it seems, in France and England the clear-stone sort is preferred at their tables.

"But of all peaches, perhaps of all fruits, there is none equal in flavor to the American Heath Peach, a cling-stone. It is large, weighing near a pound in common: with but a moderate attention, the editor believes, they would very generally weigh a full pound. It is backward in ripening northward of the Susquehanna; and is one of the last sort that ripens; many weigh a full pound. Peachley's form of a vinery would perfect the ripening, and secure the fruit from thieves.

"Within the states of America, clear-stone peaches are preferred for food to hogs, and for making brandy; perhaps also to be eaten in country families, with milk; but the cling-stone sorts are preferred when of a good sort, well ripened, to be eaten as fruit undressed.

"It is a common fault, after having planted out an orchard of peach trees, to leave the trees to shift for themselves and travel down with old time, with scarcely any culture or attention; and the trees are taken from the nursery, where they had become full grown, crowded and stunted, so as to be now unfit 
for giving good fruit when transplanted: and they are left to themselves, without any training or pruning; and heading-down is scarcely thought of, if known : in consequence, the fruit they yield is mean, and the orchard in the end is given up."

The remarkable manner in which the peach became naturalized here is shown further by the fact that the botanical explorer, Nuttall, found the species growing wild as early as 1812 and as far west as Arkansas. For years beyond memory it has been one of the common wild trees all through the southern Appalachian mountains, these trees having been for many years the source of the commercial "wild" seed so much liked by the nurserymen.

The development of peach orchards in the modern manner began about 1820 , though a large proportion of the early plantations were of seedling trees. Extensive plantings of budded trees were not made until about I870. From this period to about 1890 many good orchards were established, particularly in Michigan, New York, New Jersey, Delaware and Maryland.

Later the introduction of the Honey type of peaches, and of the Peen-to, direct from China, as well as of the Spanish race (see page I88), gave a new impetus to peach culture in the South and extended the plantings over large new areas. From I890 to I900 there came into prominence another new and distinct type of peaches, the Chinese Cling race, brought direct from China. These new varieties, mostly from seedlings originating in this country, were found to possess qualities of great value adapting them to commercial cultivation over the entire North American peach belt. The introduction of the Elberta, in particular, gave a genuine boom to the peach-growing industry. Large, new 
areas were developed, notably in Georgia and Texas, but in many other states also.

In spite of the extraordinary plantings made between the years I895 and 1905, the actual bearing area has recently declined. In 1900 there were, in round numbers, $100,000,000$ peach trees in the United States. In I9Io the number had fallen to $94,500,000$. There were, however, 42,266,000 trees growing and not yet of bearing age; but the short-lived character of the peach tree, and the ravages of San José scale and general neglect are amply shown in these figures. At the present time it would appear that new plantings just about balance the annual losses. 


\section{INDEX}

Acme Harrow

Age of Trees..............

Altitude $\ldots . \ldots \ldots \ldots \ldots \ldots . . . .$.

Barry, $P$. quoted...............

Basic Slag ..................

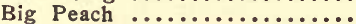

Blake, M. A., quoted..........

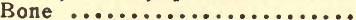

Bordeaux Mixture ..............

Bordeaux Mixture, Dilute .....

Botanical Status .............

Brandied Peaches .............

British Columbia Peach Grow-

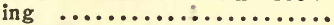

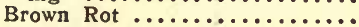

Buckwheat ...................

Bud Killing ..................

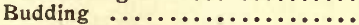

Bushel Basket ................

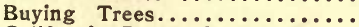

California Peach Growing......

Canada Peach Growing.........

Canning .....................

Canning Industry..$\ldots \ldots \ldots \ldots$.

Canning Outfits ...............

Chinese Cling Group...........

Choosing Varieties ............

Classification of Peaches......

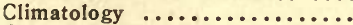

Climax Basket ................

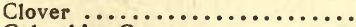

Columbia Group ..............

Connecticut Peach Growing......

Co-operative Selling ............

Cover Crop, Purposes ..........

Cover Crops ............... Cover Crops, Disadvantages....

Cowpeas ...................

Curculio ......................

Curculio Catcher ..............

Deer Damage ..............

Delaware Peach Growing.......

Derivation of Peach...........

Disc Harrow ................

Diseases $\ldots \ldots \ldots \ldots \ldots \ldots$.

Distances for Planting...........

Dried Peaches ...............

Dumplings .................

Dwarf Stocks .................

Elberta $\ldots \ldots \ldots \ldots \ldots \ldots \ldots$.

Elements of Plant Food........

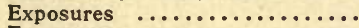

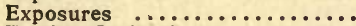

Family Orchard .............
Page

96
72
53

42

192

96

137

100

97

153

157

185

229

2

139

90

16

47

167

16

10

213

217

215

187

191

186

12

165

89

188

5

171

82

82

86

87

130

131

77

185

71

134

60

224

228

49

193

93

32

39

179
Fertilizer Practice ........... 9 99

Fertilizers..$\ldots \ldots \ldots \ldots \ldots \ldots \ldots .9 .69$

Florida Peach Growing........ 2

Florida Peach Growing....... 6

Forming the Head ......... 110

Formulas for Fertilizers...... 100

Frame Work of Trees......... 111

Freezing Trees ............ 13

Fritters $\ldots \ldots \ldots \ldots \ldots \ldots \ldots \ldots, 228$

Frost Warning ........... 30

Fruit Bark Beetle ............ 133

General Management .......... 67

Georgia Peach Carrier.......... 165

Georgia Peach Growing ........ Geography of Peach Growing..

Grades of Trees ..............

Ground Production ............

Hale, J. H., quoted.......... 175

Handling Trees ............ 64

Hardy Varieties ............ 196

Heading In $\ldots \ldots \ldots \ldots \ldots \ldots, 113$

Heading the Tree............. 107

Heating Orchards .......... 25

Historical Sketch ............ 233

Home Garden ............. 179

Home Market ............. 175

Honey Group $. . . \ldots \ldots \ldots \ldots \ldots \ldots, 188$

Hose $. . . \ldots \ldots \ldots \ldots \ldots \ldots . .144$

How to Get Trees............ 43

Improvement of Varieties ..... 193

Inoculation of Soil ......... 85

Insect Enemies ............. 120

lowa Peach Growing ...........

lowa Peach Growing ............

Jelly $\ldots \ldots \ldots \ldots \ldots \ldots \ldots, 221$

Jersey Basket .............. 166

June Buds ................ 49

June Drop..$\ldots \ldots \ldots \ldots \ldots \ldots \ldots .7 \%$

Kainit ............... 98

Kansas and Nebraska Peaches.. 9

Kentucky Peach Growing...... 7

Killing of Blossom Buds...... 16

Laying Down Trees........... 19

Laying off the Orchard........ 63

Leaf Curl .............. 137

Leavens, Geo. D., quoted...... 102

Lecanium Scale ............ 130

Lime .................... 98

Lime-Sulphur Mixture ....... 145

Lime-Sulphur Wash .......... 123

Little Peach ............... 137

Local Markets ............. 11

Local Nurseries ............ 52

Local Peach Culture.......... 3

Low Heads ............... 108 
Macomber Method ......... Page

Macoun, J. C., quoted............ 24

Maine Peach Growing..........

Management ..................

Marketing $. . . \ldots \ldots \ldots \ldots . . . .$.

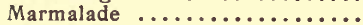

Maryland Peach Growing.......

Massachusetts Peach Growing..

Methods of Selling ..........

Michigan Peach Growing.......

Missouri Peach Growing.......

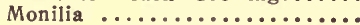

Morman, Jas. B., quoted......

Muriate of Potash.............

Natural Seed .................

Nectarine ...................

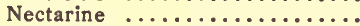

New Hampshire Peach Growing.

New Jersey Peach Growing.....

New York Peach Growing......

New York Peach Growing......

Nitrate of Potash.............

Nitrate of Soda...............

Nitrogen $\quad . . \ldots \ldots \ldots \ldots \ldots$.

Nitrogen from the Air.........

North Carolina Peach Growing.

Northern Limit-Peach Culture.

Nozzles ...................

Nursery Inspection ............

Ohio Peach Growing..........

Orchard Enemies ..............

Orchard Heaters ..............

Orchard Planting ...............

Orchard Rotation ............

Oregon Peach Growing.........

Packages ..................

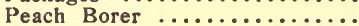

Peach Butter ................

Peach Cobbler ...............

Peach Trees for Fillers........

Peen-to Group ..............

Pennsylvania Peach Growing...

Persian Group ...............

Personal Equation .............

Phosphoric Acid ............

Picking $\ldots \ldots \ldots \ldots \ldots \ldots \ldots$.

Pickled Peaches ...............

Planting Operations ...........

Planting Out ................

Pomological Status .............

Potash ....................

Preserved Peaches ...........

Propagation $. . . \ldots \ldots \ldots \ldots \ldots . . . .$.

Pruning...$\ldots \ldots \ldots \ldots \ldots \ldots$.

Pruning Tools $\ldots \ldots \ldots \ldots \ldots \ldots$

Quality of Varieties.............

Quantity of Seed Per Acre.......

Rabbits ....................

Rape...$\ldots \ldots \ldots \ldots \ldots$.

Reclamation of Old Orchards...

Relatives ....................

Rosette ....................

Rotation of Fruit Plantations..
20
Rotation Page

Rotation Table ............ 80

Rye as Cover Crop............ 91

San Jose Scale ............. 120

Scab $\ldots \ldots \ldots \ldots \ldots \ldots \ldots \ldots \ldots{ } 142$

Scott and Ayres, quoted ....... 125

Scott and Quaintance, quoted ... 133

Scott and Quaintance, quoted .. 140

Scott and Quaintance, quoted .. 149

Seed for Propagation......... 44

Self-boiled Lime-Sulphur ....... 124

Self-boiled Lime-Sulphur ...... 149

Short Cake ............... 226

Smoothing Harrow ............ 72

Smudging ................. 25

Soil Effects $\ldots \ldots \ldots \ldots \ldots \ldots \ldots \ldots, 13$

Soils $\ldots \ldots \ldots \ldots \ldots \ldots \ldots \ldots \ldots, \quad 32$

Soils and Exposures, Summary. 41

Soils, Local Character ....... 35

Soils, Physical Character .... 39

Soluble Oils .............. 126

Soluble Oils $\ldots \ldots \ldots \ldots \ldots \ldots \ldots{ }^{152}$

Solutions for Spraying......... 145

Sorting $\ldots \ldots \ldots \ldots \ldots \ldots \ldots{ }^{1} 162$

Southern Limit-Peach Culture. 14

Soy Beans .............. 89

Special Pruning Problems..... 116

Spray Pumps ............... 144

Spray Tanks $. . \ldots \ldots \ldots \ldots \ldots \ldots \ldots . .143$

Spraying $\ldots \ldots \ldots \ldots \ldots \ldots \ldots \ldots \ldots \ldots \ldots$

Spraying Campaign .......... 157

Spraying Machinery ......... 143

Spring Frosts .............. 17

Spring Frosts $\ldots \ldots \ldots \ldots \ldots \ldots \ldots, 22$

Spring-Tooth Harrow ........ 72

Sulphate of Potash.......... 97

Summer Pruning ............ 114

Tankage ................. 96

Thinning the Fruit .......... 73

Thomas, John J., quoted....... 189

Tillage .................. 67

Tillage Purposes ........... 70

Tillage Tools .............. 71

Time of Planting .......... 59

Tree-Jack ................. 64

Utilizing the Fruit .......... 213

Variety Catalog .............. 198

Variety, Rules for Choosing .... 197

Variety Selection ............ 191

Vetches .................. 90

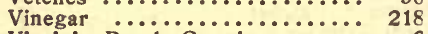

Virginia Peach Growing....... ${ }^{6}$

Weeds as Cover Crop............. 91

Whitewashing $\ldots \ldots \ldots \ldots \ldots \ldots .22$

Whitman, J. C., quoted....... 23

Wild Peach Trees............ 45

Wilder, H. J., quoted......... 34

Wind and Ice.............. 116

Wine from Peaches............ 219

Winter Freezing ............ 17

Winter Freezing $\ldots \ldots \ldots \ldots \ldots \ldots, 116$

Winter Protection..$\ldots \ldots \ldots \ldots .17$

Yellows $. . \ldots \ldots \ldots \ldots \ldots \ldots \ldots . . .134$ 




$\begin{array}{ll}\operatorname{lo}_{0} & a \\ \text { her }\end{array}$

\section{YB 47638}

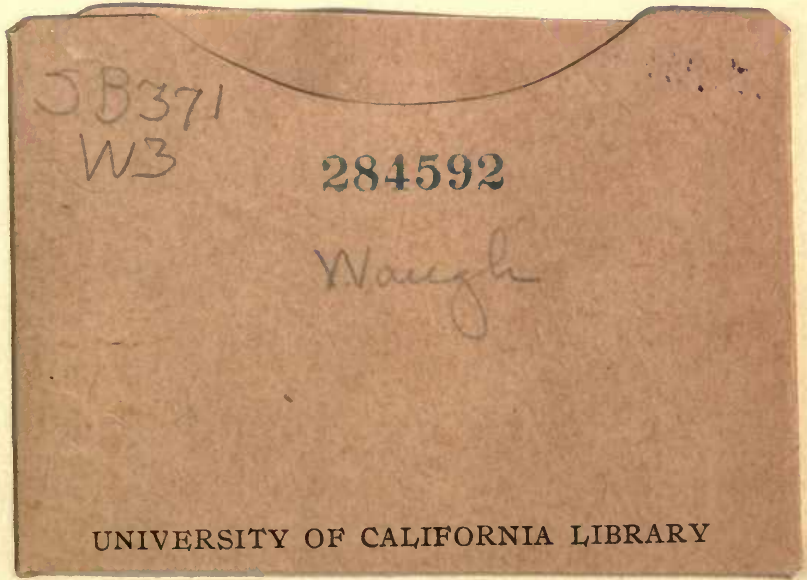

a Us 
